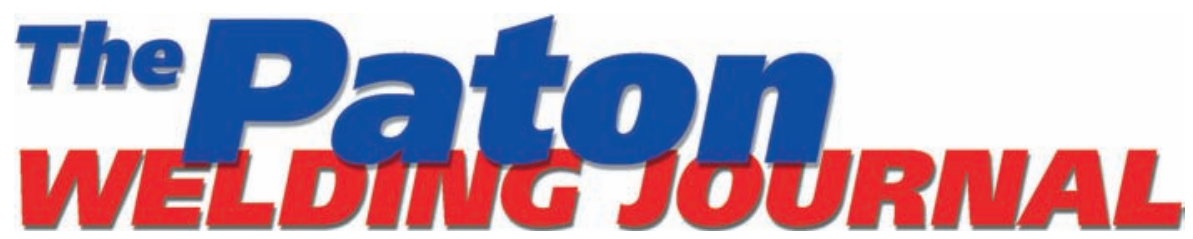

October 2017 No. 10

Published since 2000

\section{EDITORIAL BOARD \\ Editor-in-Chief B.E. Paton}

Scientists of PWI, Kiev S.I. Kuchuk-Yatsenko (vice-chief ed.), V.N. Lipodaev (vice-chief ed.)

Yu.S. Borisov, G.M. Grigorenko A.T. Zelnichenko, V.V. Knysh,

I.V. Krivtsun, Yu.N. Lankin, L.M. Lobanov, V.D. Poznyakov, I.A. Ryabtsev, K.A. Yushchenko

Scientists of Ukrainian Universities V.V. Dmitrik, NTU «KhPI», Kharkov V.V. Kvasnitsky, NTUU «KPI», Kiev V.D. Kuznetsov, NTUU «KPI», Kiev

\section{Foreign Scientists}

N.P. Alyoshin

N.E. Bauman MSTU, Moscow, Russia Guan Qiao

Beijing Aeronautical Institute, China A.S. Zubchenko

DB «Gidropress», Podolsk, Russia M. Zinigrad

Ariel University, Israel V.I. Lysak

Volgograd STU, Russia

Ya. Pilarczyk

Welding Institute, Gliwice, Poland U. Reisgen

Welding and Joining Institute, Aachen, Germany G.A. Turichin

St. Petersburg SPU, Russia

Founders

E.O. Paton Electric Welding Institute, NASU International Association «Welding» Publisher

International Association «Welding» Translators

A.A. Fomin, O.S. Kurochko, I.N. Kutianova Editor

N.G. Khomenko

Electron galley

D.I. Sereda, T.Yu. Snegiryova Address

E.O. Paton Electric Welding Institute, International Association «Welding» 11 Kazimir Malevich Str. (former Bozhenko Str.), 03680, Kiev, Ukraine

Tel.: (38044) 20060 16, 2008277

Fax: (38044) 2008277,2008145

E-mail: journal@paton.kiev.ua

www.patonpublishinghouse.com

State Registration Certificate

KV 4790 of 09.01.2001

ISSN 0957-798X

doi.org/10.15407/tpwj2017.08.01

Subscriptions

$\$ 348,12$ issues per year

air postage and packaging included.

Back issues available. All rights reserved.

This publication and each of the articles contained herein are protected by copyright.

Permission to reproduce material contained in this journal must be obtained in writing from the Publisher.

\section{CONTENTS}

\section{SCIENTIFIC AND TECHNICAL}

Grigorenko G.M., Poznyakov V.D., Zuber T.A. and Kostin V.A.

Peculiarities of formation of structure in welded joints of microalloyed

structural steel S460M

Degtyarev V.A. Efficiency of different methods of strengthening

treatment of welded joints

Kolisnichenko O.V., Tyurin Yu.N. and Tovbin R. Efficiency of process

of coating spraying using multichamber detonation unit

Kolesnik R.V., Yurzhenko M.V., Korab N.G., Shadrin A.A. and Litvinenko Yu.V. Modeling thermomechanical processes in welding high-tech plastics with embedded element

\section{INDUSTRIAL}

Gruzevich A.V. Efficiency of application of substructure strengthened

tubes on heating surfaces of supercritical boiler blocks

Elagin V.P. Influence of welding wire composition on weld quality in welded joints of dissimilar steels in gas-shielded mechanized welding

Lukyanenko A.O., Labur T.M., Poklyatsky A.G., Kuleshov V.A. and Darko R. Babich. Sanitary-hygienic characteristic of the process of nonconsumable electrode argon-arc welding of 1201 and 1460 aluminium alloys

\section{BRIEF INFORMATION}

Korobov Yu.S., Shumyakov V.I., Filippov M.A., Pimenova O.V., Balin A.N. and Vishnevsky A.A. Flux-cored wires for wearand heat-resistant surfacing and spraying

\section{NEWS}

International Conference on Beam Technologies 49 


\title{
PECULIARITIES OF FORMATION OF STRUCTURE IN WELDED JOINTS OF MICROALLOYED STRUCTURAL STEEL S460M
}

\author{
G.M. GRIGORENKO, V.D. POZNYAKOV, T.A. ZUBER and V.A. KOSTIN \\ E.O. Paton Electric Welding Institute of the NAS of Ukraine \\ 11 Kazimir Malevich Str., 03150, Kiev, Ukraine. E-mail: office@paton.kiev.ua
}

\begin{abstract}
Structural steels of C440 strength class and higher have found a wide application in high-rise construction, bridge construction and freight rail transport. Application of steel roll stock with yield limit of $440 \mathrm{MPa}$ allows reducing specific amount of metal per structure by $39 \%$ in comparison with steel of St3sp (killed) (C275) grade and by $26 \%$ in comparison with 09G2S (C345) steel grade. Present work examines the peculiarities of formation of structure in the welded joints of structural steel S460M. A CCT diagram of austenite decay in steel S460M was plotted. Effect of cooling rate of HAZ metal sample simulator on structure and strength properties was determined. It is shown that heat treatment of welded joints of steel S460M (thermal cycling, i.e. heating to $1200{ }^{\circ} \mathrm{C}$ with $25{ }^{\circ} \mathrm{C} / \mathrm{s}$ rate plus annealing at $950{ }^{\circ} \mathrm{C}$ during $1 \mathrm{~h}$ plus air cooling) provides formation in HAZ metal of a favorable complex of ferrite-bainite structures due to decrease of banded structures, reduction of portion of Widmanstatten ferrite and pearlite. 8 Ref. 2 Tables, 7 Figures.
\end{abstract}

Keyw ord s: high-strength steel, welding thermal cycle, microstructure, acicular ferrite, cooling rate, CCT diagram of austenite decay

Today the key Ukrainian commercial production industries have faced with the urgent problem of increase of resource and energy saving, reduction of specific amount of metal in wide designation structures and rise of their reliability $[1,2]$. Such a complex of requirements can be received by means of application of new high-strength steels having yield strength of $440 \mathrm{MPa}$ and higher.

Structural steels of C440 strength class and higher have found application in high-rise construction, bridge construction and freight rail transport. Replacement of ordinary structural steels of C245, C345 grades by steels of C440 strength class allows almost 1.5 times decrease of specific amount of metal of building structures due to decrease of wall thickness under similar indices of compression strength. Application of rolled metal of steel with $440 \mathrm{MPa}$ yield limit allows reducing specific amount of metal per structure by $39 \%$ in comparison with steel of St3sp (killed) grade (C275) and by $26 \%$ in comparison with steel of 09G2S (C345) grade [3].

Analysis of new modern structural steels showed that new S460M grade structural microalloyed steel of C440 strength class is characterized by good perspectives in scope of practical application. This steel is produced using a technology of thermomechanical controlled rolling with further heat treatment according to DSTU EN 10025-4:2007 at Mariupol Metal- lurgical Plant named after Illich (Illich Iron \& Steel Works) (Ukraine).

This steel based on data of EN 10025-4 [4] standard has the following mechanical properties, namely yield limit $\sigma_{y}>460 \mathrm{MPa}$, ultimate strength $\sigma_{\mathrm{t}}=540$ $720 \mathrm{MPa}$, relative elongation $\delta_{5}>18 \%$, impact toughness $K C V_{-40}>27 \mathrm{~J} / \mathrm{cm}^{2}$. High mechanical properties of steel S460M are provided due to application of mechanism of dispersion strengthening using niobium and vanadium carbonitrides. Application of the technology of thermomechanical controlled rolling guarantees formation of a fine grain structure in steel with low value of carbon equivalent $(0.45-0.48)$ that provides its good weldability, forming in cold state, stability to brittle fracture at operation temperatures up to $-50{ }^{\circ} \mathrm{C}$ and high values of impact toughness.

It is known fact $[5,6]$ that the most problem area of welded joint from point of view of brittle fracture resistance is metal of heat-affected zone (HAZ), in which structure and, therefore, mechanical properties of metal undergo significant changes in effect of welding thermal-deformation cycle (WTC). It is related with grain growth in heating as well as formation in cooling of intermediate and quenching structures, promoting decrease of metal resistance to brittle fracture.

In this connection, the aim of present work lied in study of kinetics of austenite transformation, peculiarities of formation of HAZ metal structure and 
determination of its effect on mechanical properties in mechanized welding of S460M steel.

Investigation procedure. Structural steel S460M of $16 \mathrm{~mm}$ thickness with the following composition, wt.\%: 0,15 C; 0,23 Si; 1,3 Mn; 0,09 Cr; 0,019 Ni; 0,01 V; 0,05 Nb; 0,025 Al; 0,007 N; 0,013 S; 0,017 $\mathrm{P}$ was taken for investigations. Mechanical properties of investigated steel S460M in as-delivered condition are $\sigma_{\mathrm{y}}=480 \mathrm{MPa} ; \sigma_{\mathrm{t}}=600 \mathrm{MPa} ; \delta_{5}=27 \% ; \psi=58 \%$.

A nature of structural transformations in metal of the investigated welds was studied by the method for simulation WTC using Gleeble 3800 complex equipped with high-speed dilatometer [7]. The investigations were carried out employing cylinder samples of $6.0 \mathrm{~mm}$ diameter and $80 \mathrm{~mm}$ length produced of sheet products of $20 \mathrm{~mm}$ thickness. In accordance with the procedure developed at the E.O. Paton Electric Welding Institute and using set computer program the samples were heated in a vacuum chamber to $1250{ }^{\circ} \mathrm{C}$ temperature and then cooled at cooling rates corresponding to different welding thermal cycles. The cooling curves were set by Newton-Richmann's dependence and corresponded to cooling rates in $5-126{ }^{\circ} \mathrm{C} / \mathrm{s}$ range at $500-600{ }^{\circ} \mathrm{C}$ temperature region (Table 1). At that, it was sufficiently accurate reproduction of real cooling parameters (heat and time) of metal of the welded joints. Used range of cooling rates conformed virtually to all types of welding (automatic submerged arc welding, gas-shielded mechanized welding, manual arc welding with coated electrodes), which are applied in manufacture of metal structures.

The samples for metallographic investigations were made on standard procedure using diamond pastes of different dispersion on high-speed disks. Microstructures of the samples were revealed by chemical etching in $4 \%$ alcoholic solution of nitric acid.

Metallographic exanimations were carried out employing light microscope Neophot-32 at different
Table 1. Modes of welding simulation for S460M steel samples on Gleeble 3800

\begin{tabular}{|c|c|c|c|c|}
\hline $\begin{array}{c}\text { Sample } \\
\text { number }\end{array}$ & $\begin{array}{c}\text { Cooling rate, } \\
{ }^{\circ} \mathrm{C} / \mathrm{s}\end{array}$ & $\begin{array}{c}\text { Holding time, } \\
t, \mathrm{~s}\end{array}$ & Structure type & $\begin{array}{c}\text { Microhardness } \\
\text { HV1, MPa }\end{array}$ \\
\hline 1 & 5 & 10 & $\mathrm{~F}$ & 2300 \\
\hline 2 & 10 & 10 & $\mathrm{~F}$ & 2640 \\
\hline 3 & $30^{*}$ & 30 & $\mathrm{~B}$ & 3450 \\
\hline 4 & 30 & 10 & $\mathrm{~B}$ & 3600 \\
\hline 5 & 35 & 10 & $\mathrm{~B}+\mathrm{M}$ & 3650 \\
\hline 6 & 60 & 10 & $\mathrm{M}+\mathrm{B}$ & 4010 \\
\hline 7 & 126 & 10 & $\mathrm{M}+\mathrm{B}$ & 4260 \\
\hline
\end{tabular}

Note. F - ferrite, B — bainite, $\mathrm{M}$ - martensite; heating temperature $T_{\max }=1250^{\circ} \mathrm{C}$.

magnifications $(\times 200, \times 500)$. A non-metallic impurity level was determined by means of visual comparison with scale references (GOST 1778-70). A banding level was determined by visual comparison with standard scales of GOST 5640-68. Microhardness of separate structural constituents was measured on hardness gage M-400 of LECO Company at $100 \mathrm{~g}$ (HV0.1) loading and that of integral hardness (HV1) at $1 \mathrm{~kg}$ loading. A digital image was registered by Olympus digital camera $(40 \times 40)$.

Content of non-metallic inclusions in the initial state meets level 2 of «Spotted nitrides» Table. Single dispersed oxides $\mathrm{SiO}_{2}$ and sulfides were detected in steel S460M in the initial state. Impurity level with spotted oxides and sulfides does not exceed the $1^{\text {st }} l e v-$ el of «Spotted oxides» and «Sulfides» Table.

Obtained results and discussion. The changes of HAZ metal structure (Figure 1) were studied after simulation of typical welding modes and plotting an austenite decay CCT-diagram.

The initial metal structure of steel S460M consists of mixture of ferrite (80-85\%) and pearlite (20-15\%) constituents. An expressed rolling texture (Figure 2, $a$ ) is formed in the metal as a result of thermal-mechanical controlled rolling. The banding level of the

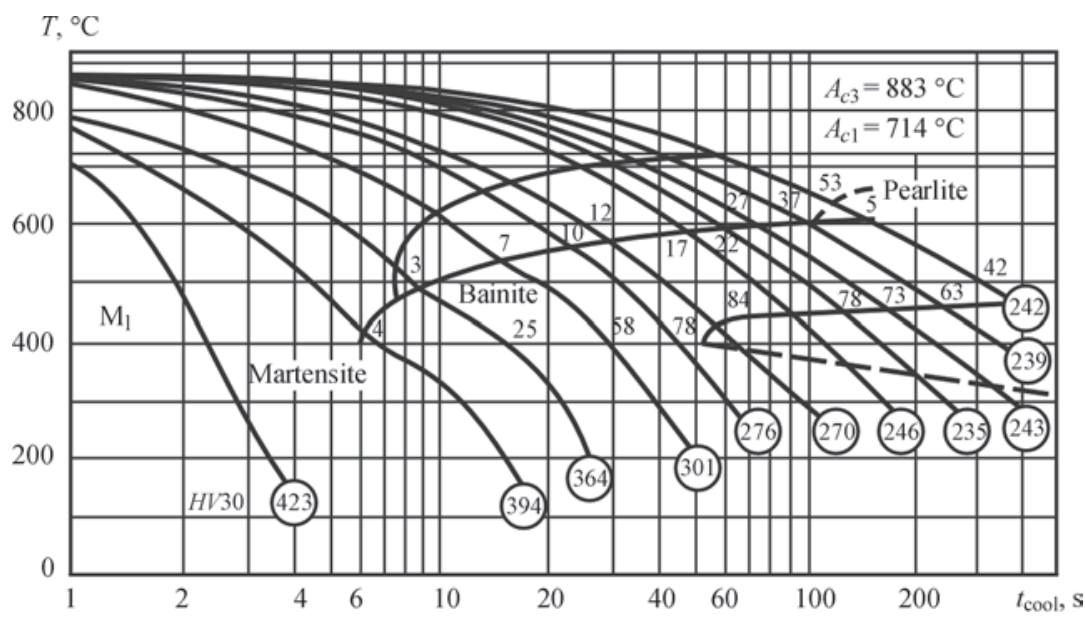

Figure 1. CCT diagram of austenite decay of steel S460M (numbers in circles — Vickers's hardness; numbers on diagrams — phase portion) 

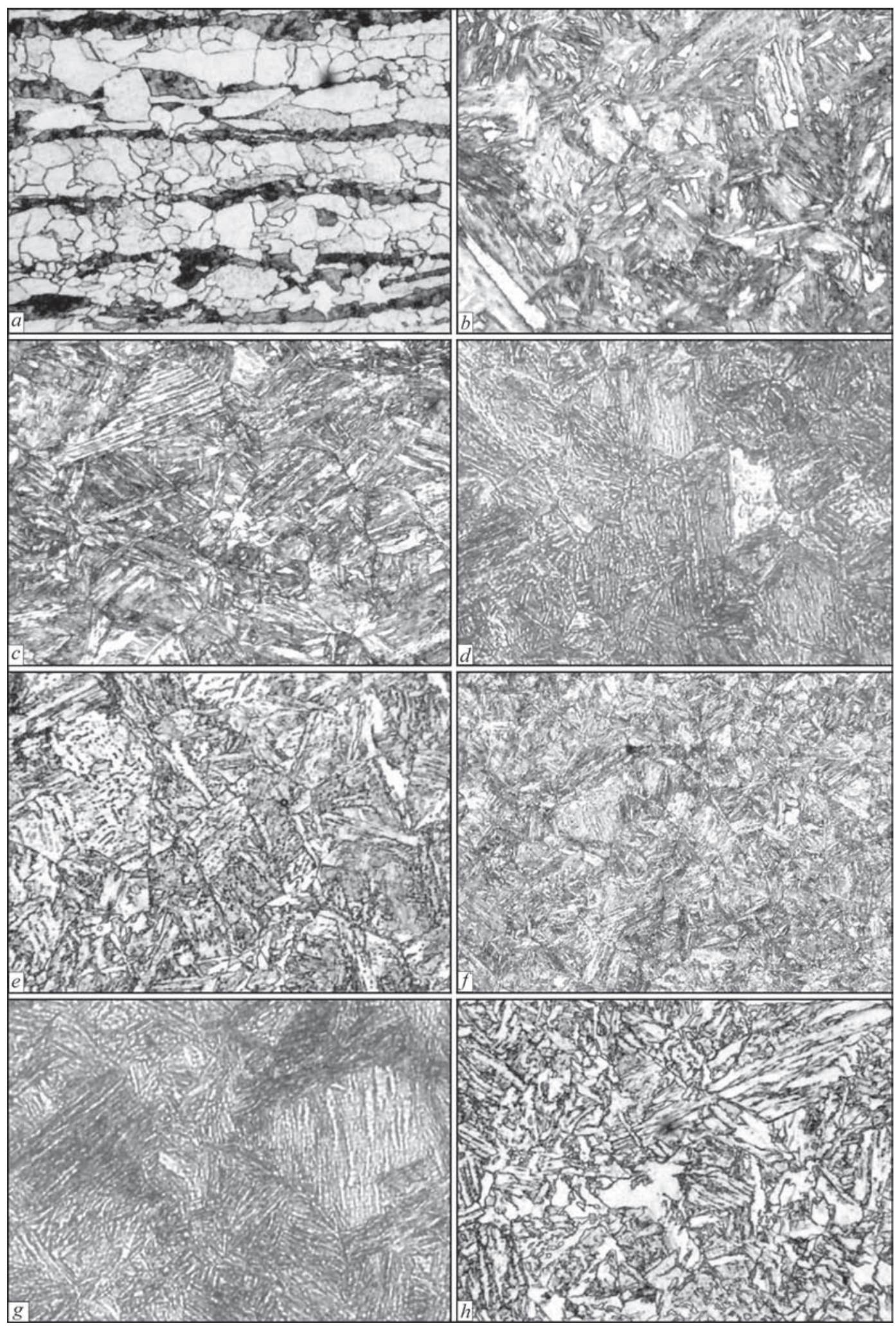

Figure 2. Microstructure $(\times 500)$ of base metal and sample simulators of HAZ metal of steel S460M at different cooling rates $w_{6 / 5}: a-$ base metal; $b-5 ; c-10 ; d-30(10 \mathrm{~s}) ; e-30$ (30 s); $f-35 ; g-60 ; h-126^{\circ} \mathrm{C} / \mathrm{s}$

structure corresponds to level 5 of series B on scale No.3 «Banding of ferrite-pearlite structure $(\times 100)$ ». Microhardness (HV0.1) of ferrite makes 1930-1990, that of pearlite 2300-2360 MPa.

A structure of sample simulator of steel S460M HAZ metal cooled at $w_{6 / 5}=5{ }^{\circ} \mathrm{C} / \mathrm{s}$ rate consists of different morphological forms of ferrite, i.e. acicu- lar ferrite, polygonal ferrite, ferrite with ordered and disordered secondary phase, free ferrite and pearlite (Figure 2, b). Increase of cooling rate of steel S460M sample simulators to $w_{6 / 5}=10{ }^{\circ} \mathrm{C} / \mathrm{s}$ results in formation of mainly acicular ferrite (Figure 2, c). Further increase of cooling rate of the sample simulators to $w_{6 / 5}=30^{\circ} \mathrm{C} / \mathrm{s}$ results in formation in HAZ metal of 


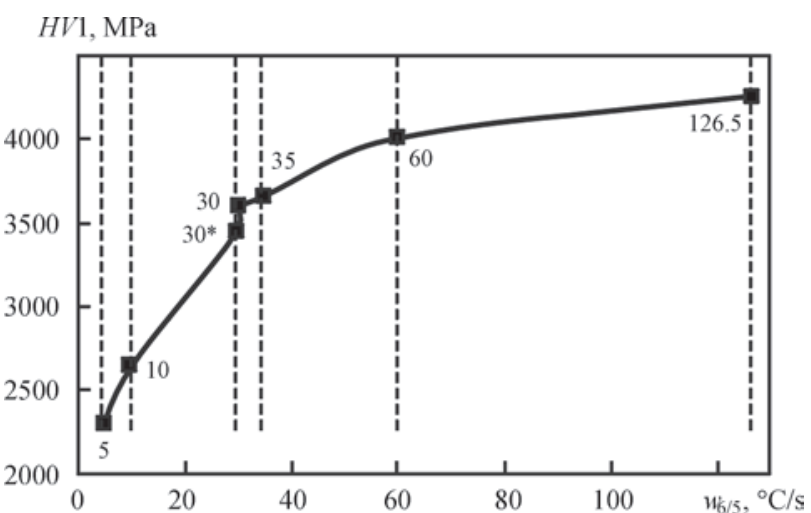

Figure 3. Effect of cooling rate on integral hardness of sample simulators of S460M steel HAZ metal

bainite packages of different orientation with registration of insignificant amount of (smooth light) areas of residual austenite (Figure 2, $d$ ). Microstructure of the sample simulator of HAZ metal of steel S460M, cooled at the same rate $w_{6 / 5}=30{ }^{\circ} \mathrm{C} / \mathrm{s}$, but with increased time of holding to $30 \mathrm{~s}$ (in comparison with $10 \mathrm{~s}$ ) at the maximum heating temperature, consists of the dispersed bainite needles in form of rosettes and areas of residual austenite (Figure 2,e).

Further increase of cooling rate of steel S460M to $w_{6 / 5}=35{ }^{\circ} \mathrm{C} / \mathrm{s}$ (normalizing mode, free cooling on air) (Figure 2, $f$ ) results in formation of bainite of different morphology (upper and/or lower), residual austenite and minor amount (up to 3-5\%) of martensite. Microhardness HV0.1 of structural constituents is $3300-3360$ for upper bainite and $3630-37500 \mathrm{MPa}$ for lower bainite. Martensite acicular type structure is typical for S460M sample cooled with $w_{6 / 5}=60{ }^{\circ} \mathrm{C} / \mathrm{s}$ rate (Figure 2, g). Martensite areas of two types differed on carbon content are formed. Microhardness (HV0.1) of areas of dark etching martensite makes 3600-3760 MPa and that for bright etching martensite is somewhat above up to 3860-4260 MPa. Microstructure of sample simulator of S460M steel HAZ metal cooled with the highest rate $w_{6 / 5}=126^{\circ} \mathrm{C} / \mathrm{s}$ (Figure 2, i) consists of the weak etching close-packed packages of martensite with 4100-4630 MPa microhardness.

Analysis of a structural state of S460M steel HAZ metal of sample simulators showed that increase of cooling rate from 1 to $35-40{ }^{\circ} \mathrm{C} / \mathrm{s}$ provokes change of structure from ferrite-pearlite to ferrite-bainite with primary formation of acicular ferrite, which, as it is known [8], provides optimum combination of strength, ductility and impact toughness to welded joints of microalloyed steels. Further rise of cooling rate for more than $40{ }^{\circ} \mathrm{C} / \mathrm{s}$ is accompanied by growth of martensite constituent that increases the risk of cold crack formation in S460M steel HAZ metal.

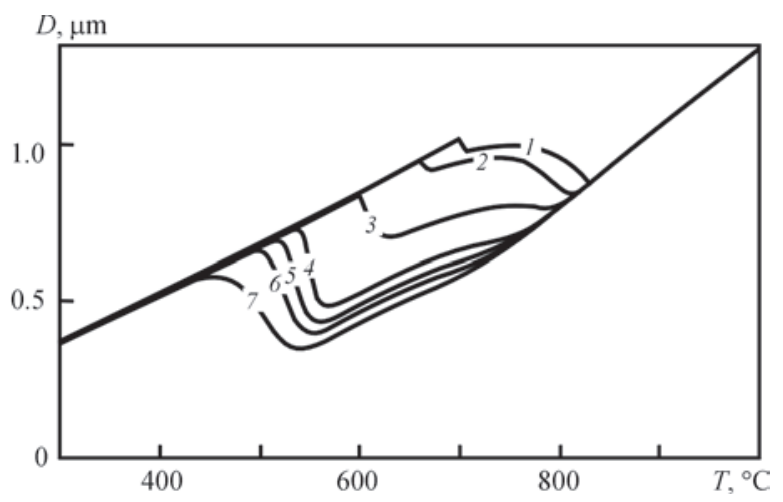

Figure 4. Dilatometric curves of $5460 \mathrm{M}$ steel cooling: $1-0.01$; $2-0.1 ; 3-1 ; 4-10 ; 5-20 ; 6-30 ; 7-50{ }^{\circ} \mathrm{C} / \mathrm{s}(D$ is the measurement of sample dimensions (metal volume) in heating as a result of dilatometric investigations, $\mu \mathrm{m}$ )

A type of phase transformations, which is realized in process of continuous cooling and structural changes taking place in HAZ metal volume results in the fact that properties of HAZ metal significantly depend on its cooling rates.

A quantitative assessment of the structure-phase content of S460M steel HAZ metal was realized based on a complex analysis of the microstructure, testing of a set of hardness samples and analysis of dilatometric curves.

Effect of cooling rate of sample simulators of S460M steel HAZ metal on integral Widmanstatten hardness $H V 1$ is presented on Figure 3 and that for nature of change of dilatometric curves is on Figure 4 and portion of structural constituents is on Figure 5.

Analysis of the dilatometric curves of cooling of steel S460M sample simulators allowed determining temperature of start and end of phases' formation, i.e. ferrite, bainite and martensite.

Analysis of the experimental diagrams showed that the temperature of start of ferrite transformation for given steel make $720^{\circ} \mathrm{C}$ and that for bainite is $580^{\circ} \mathrm{C}$. Temperature $A_{c 3}$ makes $855{ }^{\circ} \mathrm{C}$ and $A_{c 1}$ temperature is $723{ }^{\circ} \mathrm{C}$. Typical temperatures of martensite transformation make $400{ }^{\circ} \mathrm{C}$ for the beginning, $342{ }^{\circ} \mathrm{C}$ is temperature of formation of $50 \%$ of martensite and

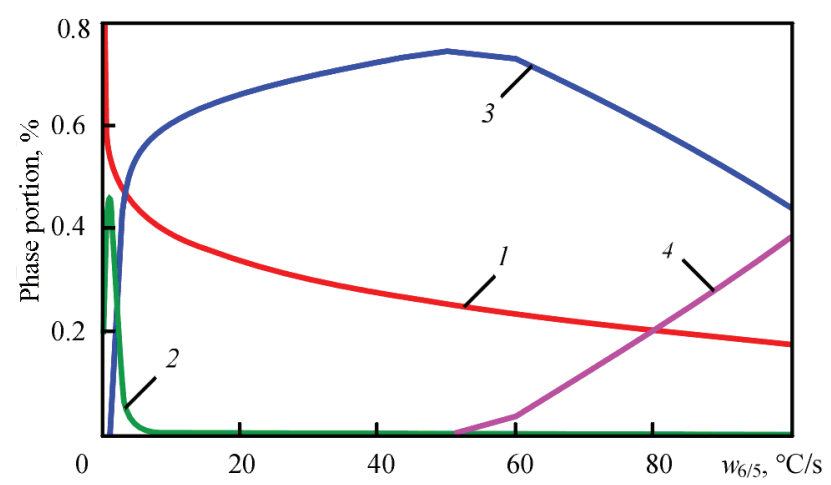

Figure 5. Effect of cooling rate of S460M steel HAZ metal on portion of structural constituents: 1 - ferrite; 2 - pearlite; 3 bainite; 4 - martensite 
Table 2. Mode of deposition of «bead probes» of steel S460M

\begin{tabular}{|c|c|c|c|c|c|}
\hline Number & $I_{\mathrm{w}}, \mathrm{A}$ & $U_{\mathrm{a}}, \mathrm{V}$ & $v_{\mathrm{w}}, \mathrm{m} / \mathrm{h}$ & $Q_{\mathrm{w}}, \mathrm{kJ} / \mathrm{cm}$ & $w_{8 / 5},{ }^{\circ} \mathrm{C} / \mathrm{s}$ \\
\hline 1 & $540-550$ & 30 & 13.2 & 40.4 & 3 \\
\hline 2 & $540-550$ & 30 & 24.0 & 22.1 & 10 \\
\hline 3 & $540-550$ & 30 & 35.5 & 14.8 & 20 \\
\hline 4 & $500-510$ & 21 & 37.8 & 9.0 & 50 \\
\hline
\end{tabular}

$272{ }^{\circ} \mathrm{C}$ is temperature of formation of $90 \%$ of martensite. A critical cooling rate, at which completely martensite structure is formed in welding of $\mathrm{S} 460 \mathrm{M}$ steel, makes $300^{\circ} \mathrm{C} / \mathrm{s}$.

As it was mentioned above, the changes of structure in HAZ metal of welded joints take place under effect of welding thermal cycles. However, investigations carried on the reference samples can not provide full presentation of structure formation in different areas of HAZ metal under effect of WTC due to their small size. Therefore, further investigations were carried out on the samples, size of which allows reconstruct conditions of thermal as well as deformation processes taking place in the welded joints during their heating/cooling.

The investigations were performed using «bead probes» method following GOST 13585-68. Effect of welding heat input on formation of a structure of welded joints of thermal-mechanical strengthened steel S460M was researched. The beads were deposited on modes providing variation of cooling rate in area of HAZ metal overheating in $3-5{ }^{\circ} \mathrm{C} / \mathrm{s}$ interval. Bead deposition was done by Sv-10NMA wire of
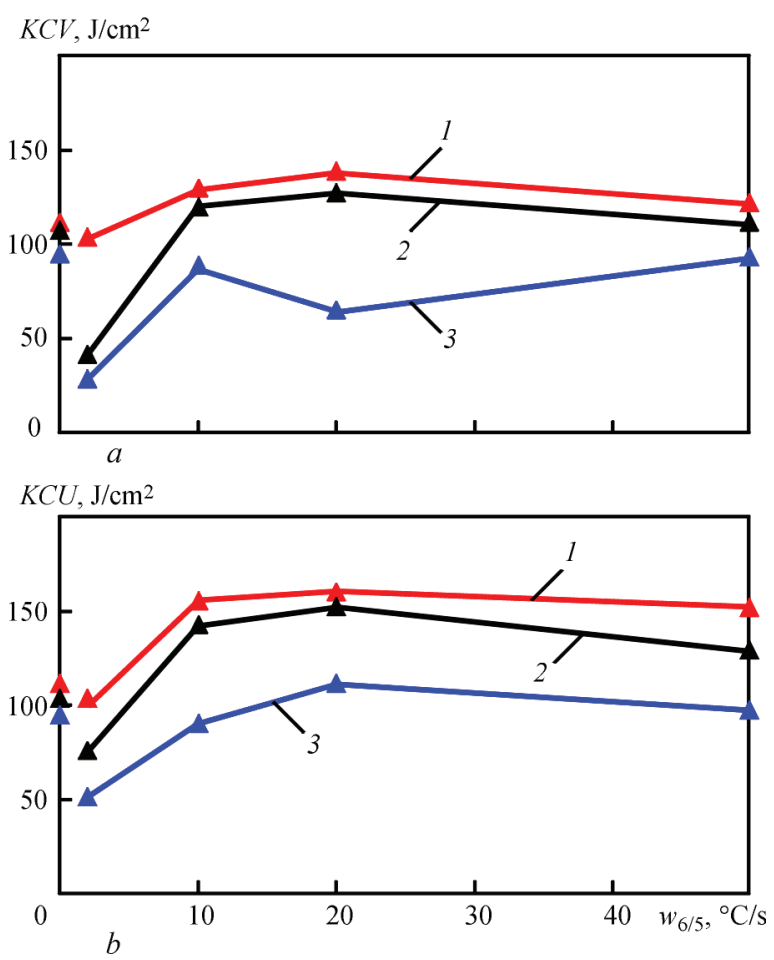

Figure 6. Impact toughness $K C V(a)$ and $K C U(b)$ of HAZ metal of S460M welded joints at different testing temperatures: $1-20$; $2--20 ; 3--40{ }^{\circ} \mathrm{C}$
$4 \mathrm{~mm}$ diameter under AN 60 flux with reverse polarity $\mathrm{DC}$ at $20^{\circ} \mathrm{C}$ temperature without preheating.

Parameters of the welding modes and corresponding to them cooling rates of «bead probes» HAZ metal are given in Table 2 .

Figure 6 shows the dependencies of effect of a welding heat input on impact toughness of HAZ metal of S460M steel welded joints. It is determined that effect of the welding heat input on impact toughness of HAZ metal of S460M steel welded joints is ambiguous.

The lowest indices of impact toughness at V- and U-notch tests, which are 2 times lower than the indices of base metal, are observed in testing at -20 and $-40{ }^{\circ} \mathrm{C}$ temperatures in the case when welding was carried out with $40 \mathrm{~kJ} / \mathrm{cm}$ heat input, that corresponded to $3{ }^{\circ} \mathrm{C} / \mathrm{s}$ cooling rate of HAZ metal.

At increase of cooling rate to $10-30{ }^{\circ} \mathrm{C} / \mathrm{s}$ range $\left(9 \leq Q_{\mathrm{w}} \leq 22 \mathrm{~kJ} / \mathrm{cm}\right)$ the indices of impact toughness are at the level of base metal properties in as-delivered condition and even exceed them at all testing temperatures. Decrease of impact toughness indices at cooling rates below $10{ }^{\circ} \mathrm{C} / \mathrm{s}$ is, apparently, related with formation in HAZ metal of the low-ductility structures, i.e. ferrite with ordered secondary phase and pearlite (Figure 2, b). Reduction of the impact toughness indices at cooling rates above $30{ }^{\circ} \mathrm{C} / \mathrm{s}$, to the larger extent, is related with growth of part of martensite constituent in HAZ metal of steel S460M.

The lowest indices of impact toughness of HAZ metal on the sharp notch samples at $-40{ }^{\circ} \mathrm{C}$ testing temperature were observed in the case of cooling at less than $20^{\circ} \mathrm{C} / \mathrm{s}$ rate (i.e. heat input above $Q_{\mathrm{w}}=$ $=14.8 \mathrm{~kJ} / \mathrm{cm}$ ). At the same time in this situation the indices of impact toughness of HAZ metal of steel S460M exceed the standard values of $K C V_{-40} \geq 34 \mathrm{~J} / \mathrm{cm}^{2}$ and make $K C V_{-40}=62-68 \mathrm{~J} / \mathrm{cm}^{2}$.

Due to the fact that steel $\mathrm{S} 460 \mathrm{M}$ is microalloyed with vanadium and niobium and after controlled rolling is subjected to special heat treatment mode, it was necessary to analyze the effect of different modes of heat treatment on structure and properties of steel S460M welded joints.

Several modes of heat treatment were proposed. Their simulation was done on Gleeble 3800 unit. The initial sample for comparison was sample simulator of steel S460M, produced with $25^{\circ} \mathrm{C} / \mathrm{s}$ cooling rate (sample No.5). Sample No.6 was heat treated on the following mode, namely annealing at $950{ }^{\circ} \mathrm{C}$ temperature during $1 \mathrm{~h}$ and then cooling down on air. Sample No.7 was subjected to thermal cycling at $1200{ }^{\circ} \mathrm{C}$ temperature with $25{ }^{\circ} \mathrm{C} / \mathrm{s}$ rate + annealing at $950{ }^{\circ} \mathrm{C}$ temperature during $1 \mathrm{~h}$, then cooling on air. 


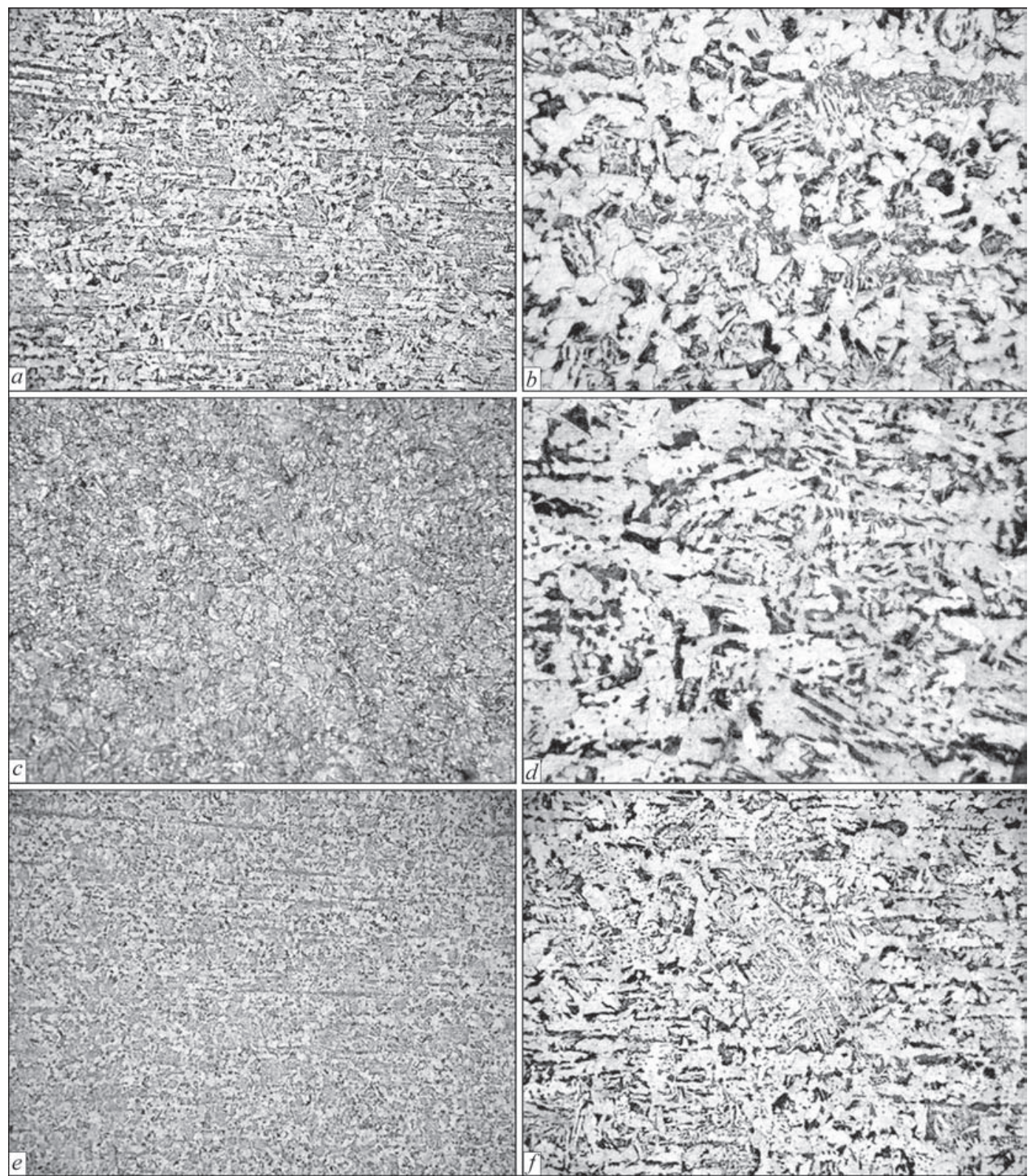

Figure 7. Microstructure of sample simulators of steel S460M after heat-treatment: $a, b$ — initial; $c, d$ — at $950{ }^{\circ} \mathrm{C}$ during 1 h, cooling on air; $e, f$ - thermal cycling: heating to $1200{ }^{\circ} \mathrm{C}$ with $25^{\circ} \mathrm{C} / \mathrm{s}$ rate + tempering at $950{ }^{\circ} \mathrm{C}$ during $1 \mathrm{~h}$ and cooling on air $(a, c, d-\times 100$; $b, d, f-\times 500)$

Figure 7 presents carried metallographic examinations of the initial and heat-treated samples of structural steel S460M.

Microstructure of sample No.6 (annealing at $950{ }^{\circ} \mathrm{C}$ during $1 \mathrm{~h}$ and cooling on air) is given in Figure $7, c, d$, and presented by ferrite-pearlite structure of band type. The level of structure banding corresponds to No.2b, determined in accordance with standard scale No.3 «Banding of ferrite-pearlite structure». The structure of sample No.6 includes areas of Widmanstatten ferrite and pearlite (Figure 7, c, d). Vickers' hardness of sample No.6 makes HV0.1$1700 \mathrm{MPa}$. Grain size corresponds to level No.4 on GOST 5639-82.

The microstructure of sample No.7, received on thermal cycling mode at $1200{ }^{\circ} \mathrm{C}$ temperature with

$25^{\circ} \mathrm{C} / \mathrm{s}$ rate + annealing at $950^{\circ} \mathrm{C}$ during $1 \mathrm{~h}$ and cooling on air, is ferrite-bainite with the areas of acicular ferrite and Widmanstatten ferrite. Size of ferrite grains is significantly smaller in comparison with grain size of sample No.6. Grain level corresponds to Nos. 6-7 on GOST 5639-82 (Figure 7, $e, f$ ).

Sample No.7 base metal has larger hardness in comparison with base metal of sample No.6 by approximately 300-500 MPa. Lower structure banding is observed in sample No.7 than in sample No.6, namely banding level is No.1 comparing with No.2b for sample No.6. It is determined that heat treatment of the sample simulators in the welded joints of steel S460M (thermal cycling at $1200{ }^{\circ} \mathrm{C}$ with $25{ }^{\circ} \mathrm{C} / \mathrm{s}$ rate + annealing at $950^{\circ} \mathrm{C}$ in course of $1 \mathrm{~h}+$ cooling on air) provides formation of a favorable complex of 
ferrite-bainite structures in HAZ metal due to formation of acicular ferrite, decrease of portion of Widmanstatten ferrite and pearlite, decrease of structure banding.

\section{Conclusions}

1. A set of ferrite-bainite structures is formed in HAZ metal of structural steel S460M during welding. It provides high characteristics of strength, ductility and impact toughness.

2. The indices of impact toughness of HAZ metal $K C U_{-20}, K C U_{-40}$ and $K C V_{-20}, K C V_{-40}$ are two times lower than the indices of base metal in welding of steel S460M with cooling rate $3{ }^{\circ} \mathrm{C} / \mathrm{s}$ (heat input $40 \mathrm{~kJ} / \mathrm{cm}$ ). The indices of impact toughness at all testing temperatures at increase of cooling rate to $10-30{ }^{\circ} \mathrm{C} / \mathrm{s}(9.0 \leq$ $\leq Q_{\mathrm{w}} \leq 22.1 \mathrm{~kJ} / \mathrm{cm}$ ) are on the level of initial metal and even exceed them due to formation of lower bainite structure.

3. There is a decrease of the indices of impact toughness in the sharp notch samples to $62-68 \mathrm{~J} / \mathrm{cm}^{2}$ values at cooling rate above $30{ }^{\circ} \mathrm{C} / \mathrm{s}\left(Q_{\mathrm{w}}<90 \mathrm{~kJ} / \mathrm{cm}\right)$ due to formation of mainly martensite structure in HAZ metal.

4. Heat treatment of welded joints of steel S460M on thermal cycling mode (heating to $T=1200{ }^{\circ} \mathrm{C}$ with $w_{5 / 6}=25^{\circ} \mathrm{C} / \mathrm{s}+$ annealing at $T=950{ }^{\circ} \mathrm{C}$ during $1 \mathrm{~h}$ and cooling on air) provides increase of mechanical prop- erties of the welded joints due to reduction of structure banding, decrease of portion of Widmanstatten ferrite and pearlite.

1. Odessky, P.D., Molodtsov, A.F., Morozov, Yu.D. (2011) New efficient low-alloy steels for building metal structures. Montazhnye i Spetsialnye Raboty v Stroitelstve, 5, 20-25 [in Russian].

2. Bolshakov, V.I., Laukhin, D.V., Beketov, A.V. (2008) Use of low-carbon high-strength steels in metal structures of the carcass superstructure of five-storey residential buildings. In: Building. Material sciences. Mechanical engineering. Series: Innovative technologies for the life cycles of civil, industrial and transport facilities, Vol. 47, 103-108 [in Russian].

3. Hot-rolled structural steel S460M /ML DSTU EN 100254:2007. Thermomechanical treated fine-grain welded steel. www.metinvestholding.com [in Russian].

4. BS EN 10025:4:2004: Hot-rolled products of structural steels. Pt 4: Technical delivery conditions for thermomechanical rolled weldable fine- grain structural steels [in Russian].

5. Poznyakov, V.D., Zhdanov, S.L., Zavdoveev, A.V. et al. (2016) Weldability of high-strength microalloyed steel S460M. The Paton Welding J., 12, 21-28 [in Russian].

6. Guenter, H.P., Hildebrand, J., Rasche, C. et al. (2012) Welded connections of high-strength steels for the building industry. Welding in the World, 5-6, 86-106.

7. Grigorenko, G.M., Kostin, V.A., Orlovsky, V.Yu. (2008) Current capabilities of simulation of austenite transformations in low-alloyed steel welds. The Paton Welding J., 3, 22-24 [in Russian].

8. Kostin, V.A., Grigorenko, G.M., Zhukov, V.V. (2013) Features of the structure formation in the welding of high-strength steels with carbonitride hardening. Visnyk NUK im. Adm. Makarova, 1, 34-41 [in Russian]. 


\title{
EFFICIENCY OF DIFFERENT METHODS OF STRENGTHENING TREATMENT OF WELDED JOINTS
}

\author{
V.A. DEGTYAREV \\ G.S. Pisarenko Institute for Problems of Strength of the NAS of Ukraine \\ 2 Timiryazevskaya Str., 01014, Kiev-14, Ukraine, Ukraine. E-mail: ips@ipp.kiev.ua
}

\begin{abstract}
The efficiency of selection of non-damaging modes of vibration treatment of welded elements of low-carbon steel metal structures with the purpose of reducing residual stresses in them without danger of fatigue fracture at the stage of technological treatment is shown. The comparative fatigue investigations showed an increase in the service life of vibrotreated welded joints and an increase in their fatigue limit at the increase of test base. A method for determination of fatigue limits for butt welded joints of low-carbon steel after different modes of high-frequency mechanical peening, using experimental data of groove depth measurement, was proposed. The efficiency of increasing their fatigue limit is shown depending on the speed of high-frequency mechanical peening and the amplitude of oscillations of the working tool. The results of experimental investigations of increasing fatigue resistance of welded joints of low-alloy and low-carbon steels under harmonic and repeated impact loading at the temperature of $-60{ }^{\circ} \mathrm{C}$ after high-frequency mechanical peening, argon-arc, explosive, and mechanical treatments were analyzed and a comparative analysis of their efficiency was presented. 23 Ref., 4 Tables, 10 Figures.
\end{abstract}

Ke y w ord s: welded joint, fatigue resistance, fatigue limit, residual stresses, depth of groove, speed of peening

Until now a large experience in using different technological methods of increasing the fatigue resistance of welded joints has already been gained [1-3]. The application of this or that method is connected with the peculiarity of production, the availability of technological equipment, operating conditions and so on. However, many of them require their optimization and conducting of additional investigations. This fully concerns vibration treatment (VT) [4] and high-frequency mechanical peening (HMP) [5] of welded elements of metal structures.

The analysis of works, devoted to the vibration treatment showed that it is used to reduce tensile residual stresses (RS), which can decrease the service life of the product [1], or change its shape [6]. Its advantage is in the fact that when subjecting the entire structure to cyclic loading as a whole, RS decreases in the elements, having different rigidity, in one technological cycle. However, the disadvantage of VT is that the value of variable stresses in the structures, created by mechanical vibrators, is selected experimentally $[7,8]$.

High-frequency mechanical peening of different types of welded joints provides a considerable increase in their fatigue resistance and service life [9], including the conditions of low climatic temperatures due to strengthening of a narrow zone at the transition of weld to base metal. At present, a notable progress has been achieved in the search for a reliable criterion, reflecting its efficiency. Instead of speed of the working tool displacement along the weld $[10,11]$, the procedure was proposed for evaluating the increase in fatigue limits by groove depth [12], formed after HMP, and the parameters of HMP speed were proposed depending on the amplitude of the working tool oscillations. However, up to the present time, the effect of different treatment modes on fatigue resistance of welded joints remains not investigated.

The aim of this work was the optimization of different types of strengthening treatment of welded joints, experimental evaluation of their effect on fatigue resistance of welded specimens and elements of metal structures.

Objects of investigation, testing equipment. The investigations of effect of types of strengthening treatments were carried out both in laboratory conditions on welded specimens of low-alloy and low-carbon steels with butt and T-joints, as well as in the industrial conditions on welded girders of box-type section (further girders) of sheet steel of $20 \mathrm{~mm}$ thickness, modeling the structure of a locomotive diesel underframe. The used grades of rolled steel, basic dimensions of specimens and their mechanical properties are given in Table 1.

The specimens were cut out either of welded workpieces with the dimensions in plane of 400x660 $\mathrm{mm}$, where butt joints were made by manual electric arc welding (steel 14Kh2GMR) or by semi-automatic welding in carbon dioxide (steel 12GN2MFAYu, St.3sp (killed), and T-joints were made by automatic submerged arc welding (steel 15KhSND and 09G2S), or individually with a stiffener welded-on 
Table 1. Basic dimensions of welded specimens and mechanical properties of steels at room temperature

\begin{tabular}{|c|c|c|c|c|c|c|c|c|}
\hline \multirow{2}{*}{ Steel grade, type of joint } & \multicolumn{6}{|c|}{ Dimensions, $\mathrm{mm}$} & \multirow{2}{*}{$\sigma_{y^{\prime}}, \mathrm{MPa}$} & \multirow{2}{*}{$\sigma_{t}, \mathrm{MPa}$} \\
\hline & $h$ & $b$ & $L$ & $e$ & $k$ & $H$ & & \\
\hline 14Kh2GMR, butt & 16 & 80 & 400 & 12 & - & - & 702 & 800 \\
\hline 12GN2MFAYu, butt & 24 & 40 & 400 & - & - & - & 620 & 710 \\
\hline 15KhSND, T-joint & 14 & 80 & 400 & 12 & 14 & 40 & 435 & 600 \\
\hline 09G2S, T-joint & 20 & 40 & 400 & - & 20 & 36 & 340 & 520 \\
\hline Steel 20, with longitudinal stiffener & 20 & 100 & 400 & - & 12 & 40 & 290 & 440 \\
\hline Steel 20, girder & 190 & 170 & 2100 & - & - & - & 290 & 440 \\
\hline St.3sp, butt & 14 & 40 & 400 & - & - & - & 300 & 470 \\
\hline
\end{tabular}

Note. $h, b, L$ - thickness, width, length of specimen; $e$ - width of surfacing; $k, N$ - thickness and height of welded-on stiffener.

using semiautomatic welding along the long side of the specimen in carbon dioxide (steel 20). In order to obtain the fatigue limits of welded structures by the results of testing specimens, the latter must have high residual stresses, which were created by surfacing a longitudinal bead on the specimen back side, or by its half-thickness immersion into water. The residual stresses in girders of steel 20 were induced by applying longitudinal surfacing on the edges, and stress concentrators - by welding-on special cover plates in the tensile RS field. The value and sign of RS in the direction coinciding with the direction of the load applying were determined by the magnetic-noise method based on the Barkhausen effect [13]. Considering that in the near-weld zone the material undergoes structural changes as a result of welding, a series of calibration curves was preliminarily plotted to improve the accuracy of evaluating the value and distribution of RS. Each curve was determined at that distance from surfacing, at which determination of RS took place.

The fatigue tests of specimens were carried out during bending under the conditions of a preset coefficient of asymmetry of the stress cycle $\mathrm{R}$ at the harmonic loading in the mode of a given deformation amplitude and repeated impact loading in the mode of a preset impact energy at the temperature of $-60^{\circ} \mathrm{C}$ [14]. The amplitude of stresses was measured applying strain gauge method. At low-temperature tests, the specimens were cooled by a regulated supply of liquid nitrogen through the holes specially made in them. As the criterion of fracture of specimens, the formation of limited crack length on the surface, equal to $10 \mathrm{~mm}$, which corresponds to its subcritical depth of about $2.5 \mathrm{~mm}$ [3], or their brittle fracture at a shorter crack length, was accepted.

The vibration treatment of girders was carried out both by means of electromechanical vibrator IV 107 by creating variable stresses at the resonance or near-resonance frequencies, as well as by pulsator TsDM-200Pu in the mode of forced oscillations, which allow testing at any asymmetry of the cycle. The amplitude of stresses was measured applying strain gauge method. During tests, three-point and cantilever loading schemes were used.

The fusion line of weld with the base metal was subjected to high-frequency mechanical peening by means of ultrasonic magnetostriction transducer [15] at a frequency of oscillations of $24.5 \mathrm{kHz}$, excited by the generator UZG-10M of the $1.2 \mathrm{~kW}$ power consumption. Then the ultrasonic piezoceramic tool USP-300 [16] was used with oscillation frequency of $22.0 \mathrm{KHz}$. The deforming mechanism of both instruments represented a special head with built-in four steel rods of $2.8-3 \mathrm{~mm}$ diameter. After HMP a groove of $3.5 \mathrm{~mm}$ width is formed with a depth $h$, depending on the speed $V$ of the working tool displacement along the weld (peening speed), which was determined as the ratio of length of weld treated to treatment time. At each speed, at least two specimens were treated and the value of groove depth was determined as the arithmetic mean.

Results of investigations and their discussion. Analysis of vibration treatment efficiency. The optimization of vibrotreatment procedure, which consists in selecting the non-damaging loading modes to reduce RS, was tested on the example of testing welded girders of steel 20 (see Table 1 ). To determine the complex diagram of limiting stresses of the cycle (DLSC), necessary for this purpose, the specimens of steel 20 with the stiffener welded-on along the long side of an edge were used. The welding-on of stiffener applying semiautomatic method in the carbon dioxide environment at the immersion of specimen into the water to half of its thickness allowed creating high tensile RS stresses, equal to 0.76 of yield strength of the material $\sigma_{y^{y}}$ at the boundary of the weld to the base metal. The carried out fatigue tests in the conditions of harmonic loading at the values $R$, equal to 0 and 0.7 (line 1), and the cylindrical specimens for cyclic creep at $R=0.7$ and 0.85 (line 2) allowed determining the area (shaded) of safe loading from the point of view of fatigue fracture (Figure 1). From the top and bottom it is limited by the lines of fatigue limits 1 and the limits of cyclic creep $\sigma_{\text {crrR }}[17] 2$, respectively. The Figure shows a part of the diagram. The values of $\sigma_{\text {ccrR }}$ were determined at 
$\varepsilon_{\mathrm{pl}}=0.2 \%$ under the conditions of tension, since, taking into account the cross-section dimensions of the vibrotreated girders, the stress gradient is equal to zero. The selection of stresses from external load on the condition that the maximum stresses (taking into account the residual stresses) are lower than the line 1 , will provide the absence of fatigue damages, and above the line 2 it will provide the process of effective reducing of RS. Before the beginning of tests on the width of girders, the diagrams of the initial RS were determined. As an example, Figure 2 shows one of them. The asymmetry of the left and right parts of the diagram is explained by the order of application of deposits. The higher RS indicate that on this area the deposits of girders were produced the last. Later, analyzing the kinetics of RS, the value of initial maximum residual tensile stress $\sigma_{\text {res }}^{\mathrm{i}}$ was used. In Figure 1 two variants for reducing RS are shown. In the first batch of girders at the value $\sigma_{\text {res }}^{\mathrm{i}}=245 \mathrm{MPa}(p . A)$, its reduction was carried out under the conditions of a symmetrical stress cycle. This type of loading is provided by vibrator. The duration of VT at the near-resonant frequency, equal to $95 \mathrm{~Hz}$, was approximately 20 min, which corresponded to $10^{5}$ cycles of loading. The end of the process was judged by change in the current consumed by the vibrator. At the maximum admissible amplitude of stresses $\sigma_{a}=40 \mathrm{MPa}$, the decrease in RS occurred down to $(0.6-0.62) \sigma_{\mathrm{y}}\left(p . A_{1}\right)$. It should also be noted that when the value of the initial RS is equal to $120 \mathrm{MPa}$ and amounts to 0.41 $\sigma_{\mathrm{y}}$, VT does not lead to its change (curve 2 in Figure 2). Taking into account the opinion accepted in the literature [3] that RS, equal to $0.5 \sigma_{y}$, do not already influence the fatigue limit, then the necessity of their further reduction is obvious. However, for this it is necessary to increase the amplitude of stresses (section $A B$ ) to such an extent that along with their reduction, a fatigue fracture of the construction can occur. Therefore, to effectively reduce them (especially if RS are already negligible in the initial state), the application of an asymmetric vibrational load is necessary. For this purpose, the second batch of girders was tested in the pulsator TsDM-200pu (version 2 ) at an asymmetric cycle of harmonic loading. At the value of $\sigma_{\text {res }}^{\mathrm{i}}=200 \mathrm{MPa}(p . C)$, the parameters of the external load were calculated (the values are shown in Figure). In contrast to the symmetrical cycle, in this case it is possible to achieve a much higher maximum stress ( $p . K)$, keeping the condition of safe loading. The RS, determined in several girders, decreased to about $\sigma_{\text {res }}^{\mathrm{c}}=145-155 \mathrm{MPa}\left(p . C_{1}\right)$, which corresponds to $(0.5-0.52) \sigma_{y}$. Thus, asymmetric loading allows a significant expansion of the capabilities of VT by increasing stresses from the external load, leaving them

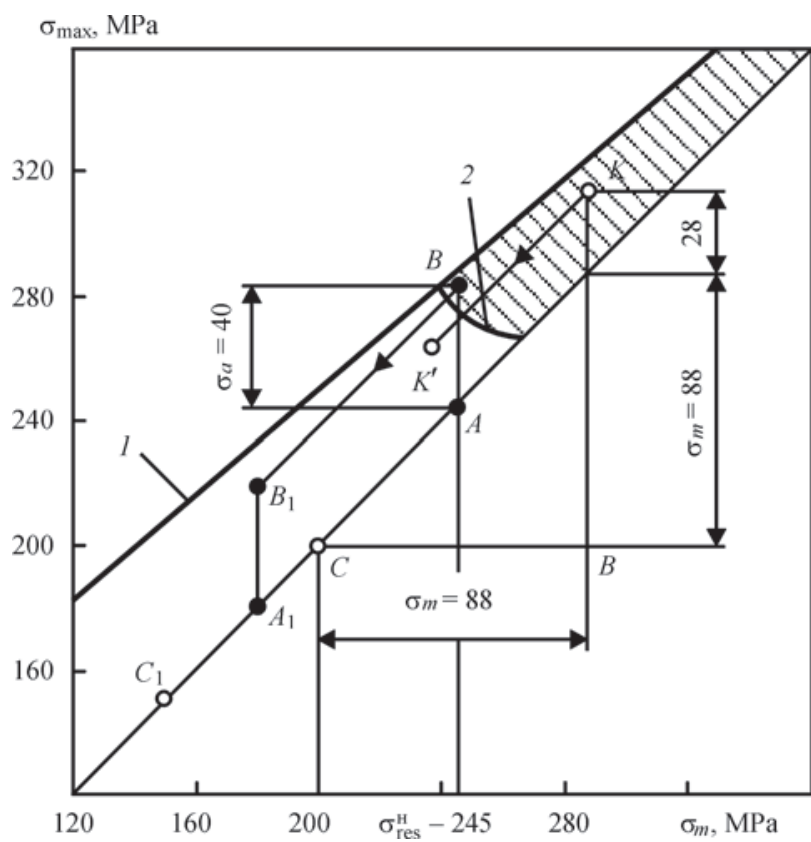

Figure 1. Decrease of RS in welded girders of box section of steel 20 (1 - line of limiting stresses; 2 - line of limits of cyclic creep of material under tension)

in a safe region. It is seen that the vibrator treatment reduced the initial RS on average by $20 \%$, and applying pulsator — by $32 \%$, which amounted to 0.61 and 0.51 of the yield strength, respectively. As a comparison, the RS values in the girders after heat treatment, corresponded on average to $0.35 \sigma_{\mathrm{y}}$.

To evaluate the effect of low RS, comparative fatigue tests of specimens were carried out. Preliminarily, the initial RS were reduced in them by non-damaging loading modes to the level equal to $0.5 \sigma_{\mathrm{y}}$. The analysis of the obtained results of investigation at harmonic zero loading under the conditions of room temperature (Figure 3) indicates an increase in the fatigue life of specimens after VT throughout the whole range of stresses application (curve 2). For comparison, the Figure shows also the fatigue curve of specimens with high residual stresses in the initial state (curve 1). It

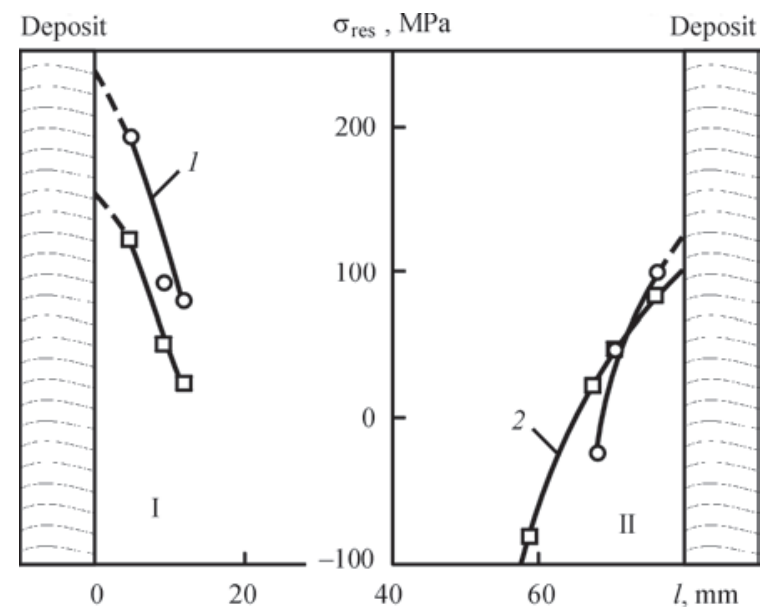

Figure 2. Distribution of RS across the width of the girder with longitudinal deposits in initial state (1) and after VT (2) 


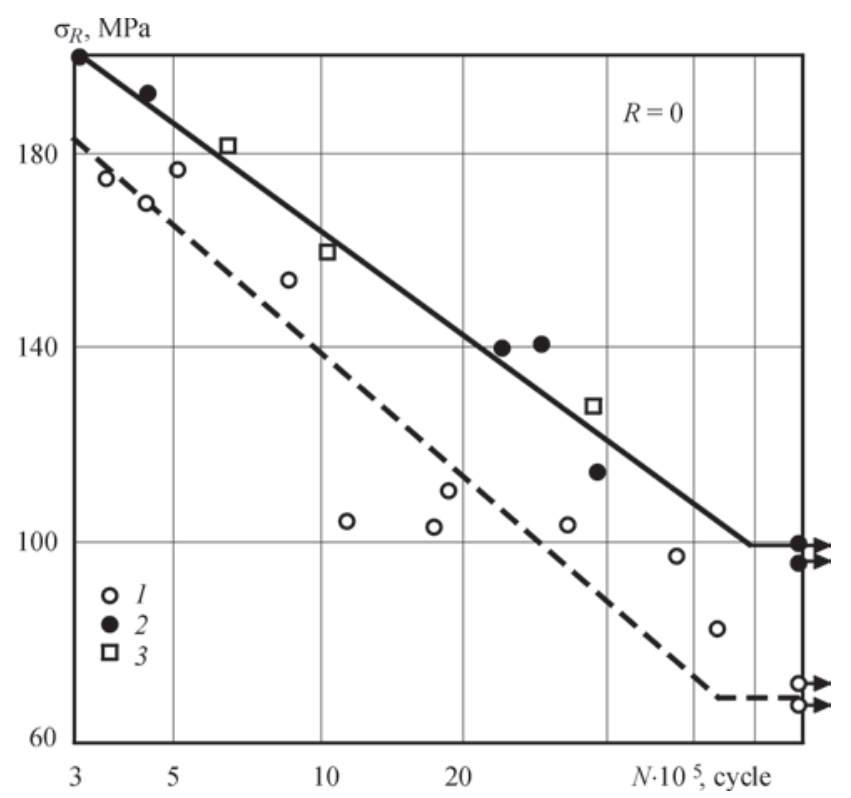

Figure 3. Fatigue curves of steel 20 welded specimens with welded-on stiffener in the initial state (1), after VT (2) and heat-treatment (3)

is seen that with lowering of the load, the effect of residual stresses is manifested to a greater extent, as a result of which the fatigue life of vibrotreated specimens increases with increase in the testing base as compared to the initial state, and the fatigue limit increases. For example, on the basis of $2 \cdot 10^{6}$ and $5 \cdot 10^{6}$ cycles of loading, it increased by 27 and $40 \%$, respectively.

In order to evaluate the fatigue life of specimens at even lower values of RS, the specimens subjected to tempering at $600-620^{\circ} \mathrm{C}$ were tested. The maximum $\mathrm{RS}$ in them was about $0.35 \sigma_{\mathrm{y}}$. It is seen that the points lie on the fatigue curve of the vibrotreated specimens

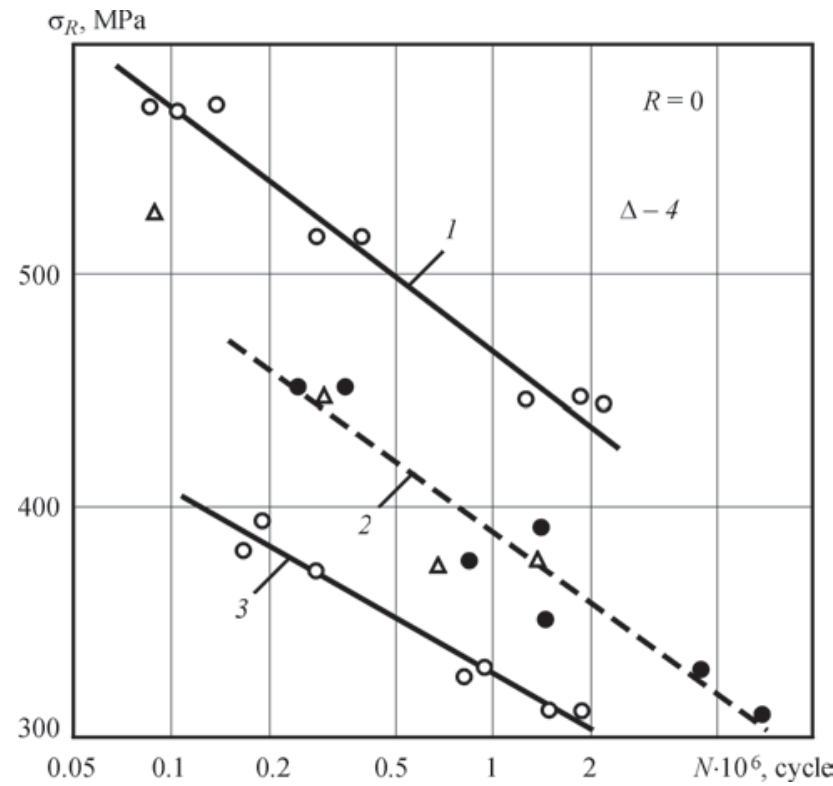

Figure 4. Fatigue curves of steel 09G2S T-joints in the initial state (2, 3), after HMP $(1,4)$; under the conditions of harmonic loading at the room temperature (2) and impact loading at $-60{ }^{\circ} \mathrm{C}(1,3,4)$ not badly. The similar results were obtained in the comparative fatigue tests of the joining girders of 120-ton railway tank [18]. Based on the results of specimen tests, a similar increase in fatigue resistance and an increase in the fatigue life of steel structures after VT in the real conditions of their service can be assumed.

Therefore, the carried out tests showed that to increase the fatigue life and fatigue resistance of non-critical structures of low-carbon steel, it is not necessary to apply an expensive procedure of heat treatment in all the cases for maximum reduction of RS in them.

However, the experience in operation of many metal structures demonstrates their fatigue fracture in a narrow weld-to-base metal transition zone. This task is successfully solved by a high-frequency mechanical peening.

Analysis of efficiency of high-frequency mechanical peening. The earlier investigations [12] allowed suggesting the optimal treatment mode, in which the groove depth is provided after a peening of weld zone of at least $0.14 \mathrm{~mm}$. On the basis of the obtained dependences, it follows that to such depth of the groove the speed of the working tool movement along the weld $V=0.065 \mathrm{~m} / \mathrm{min}$ at the amplitude of oscillations of the waveguide end $a=19 \mu \mathrm{m}$ and $0.092 \mathrm{~m} / \mathrm{min}$ at $26 \mu \mathrm{m}$ corresponds. This is well illustrated by the results of comparative fatigue tests of T-joints of low-alloyed steel 09G2S (Figure 4) and butt joints of low-carbon steel St.3sp (Figure 5) under the conditions of harmonic loading at a room temperature and impact loading at $-60{ }^{\circ} \mathrm{C}$. After cutting the welded workpiece on specimens, the latter (see Table 1) were subjected to HMP. The analysis of the data (Figure 4) indicates that in the initial state the fatigue resistance under the conditions of repeated impact loading at $-60{ }^{\circ} \mathrm{C}$ (curve 3) is lower than the harmonic loading and room temperature (curve 2). The fatigue limits, determined on the basis of $2 \cdot 10^{6}$ load cycles, were 307 and $360 \mathrm{MPa}$, respectively. The strengthening of specimens at the speed of peening to higher than the recommended one showed that their resistance to fatigue under the conditions of repeated impact loading is somewhat increased, but it did not exceed the fatigue resistance in the initial state under harmonic loading. The points lie on the fatigue curve 2. HMP, performed in strict accordance with the speed recommended in the work, provided a significant increase in the fatigue resistance under the conditions of impact loading throughout the whole investigated range of fatigue life (curve 1). The fatigue limit increased by $21 \%$ as compared to the data of tests of specimens in the initial state under the conditions of harmonic 
loading. The analysis of results of tests of steel St.3sp welded joints (Figure 5), treated at a peening speed equal to $0.065 \mathrm{~m} / \mathrm{min}$, showed that the fatigue limit was $375 \mathrm{MPa}$ (curve 1), which is by $87 \%$ higher than that obtained during tests of specimens in the initial state (curve 2). During deviation from the recommendations regarding the speed of peening and violation of HMP technology, there were metal overlays on the weld - «ripples», which were the powerful sources of stress concentration. In this case, the fatigue crack developed from these ripples. The similar results were obtained in the work [19]. As a result, the fatigue life of such specimens increased on average by 2.5 times in comparison with the initial state, and the increase in the fatigue limit was only $11 \%$ (curve 3 ).

It is known that as a result of HMP, deformation strengthening of material occurs at some depth from the surface of the groove. Obviously, to different modes of treatment not only the different depth of plastically deformed layer will be corresponded, but also the different depth of a groove $h$. The influence of different treatment modes on fatigue resistance was determined on the example of tests of steel St.3sp welded butt joints (see Table 1). After cutting of welded workpiece into specimens, the latter were subjected to HMP at the amplitude of oscillations of working tool $a=19 \mu \mathrm{m}$ and to the given speed of its displacement $\mathrm{V}$, equal to $0.232,0.116$ and $0.06 \mathrm{~m} / \mathrm{min}$, respectively. After strengthening, a groove with width of $2.8-3.5 \mathrm{~mm}$ and a depth of $0.041,0.062$, and $0.143 \mathrm{~mm}$, respectively, was formed depending on the speed of treatment. The analysis of influence of groove depth on the strengthening effect, expressed in increasing fatigue limit of welded joint, was made on the basis of Figure 6 , in which the experimentally determined fatigue limits of welded butt joints in the initial state $\left(\sigma_{R}^{\mathrm{i}}=\right.$ $200 \mathrm{MPa}$ ) and at the speed of HMP equal to $0.065 \mathrm{~m} /$ $\min \left(\sigma_{R}=375 \mathrm{MPa}\right)$, at $a==19 \mu \mathrm{m}$ (see Figure 5), as well as the corresponding values of the groove depth are noted. The calculated dependence of the fatigue limit of welded joints on the current groove depth $h_{i}$ in this case has the following form

$$
\sigma_{R}^{i}=\sigma_{R}^{\mathrm{i}}+K h_{i}=\sigma_{R}^{\mathrm{i}}+\frac{\sigma_{R}-\sigma_{R}^{\mathrm{i}}}{h} h_{i},
$$

where $K=\frac{\sigma_{R}-\sigma_{R}^{\mathrm{i}}}{h}$ is the correlation coefficient; $h_{i}$ is the current value of the groove depth obtained after different speed of HMP.

From the known values of fatigue limits of welded joints and the experimentally established $h=$ $=0.143 \mathrm{~mm}$, we found that $K=1.224 \cdot 10^{3} \mathrm{MPa} / \mathrm{mm}$. Through calculations the proposed expression allows evaluating the fatigue limit of welded joint (darkened points) at any depth of the groove without carrying

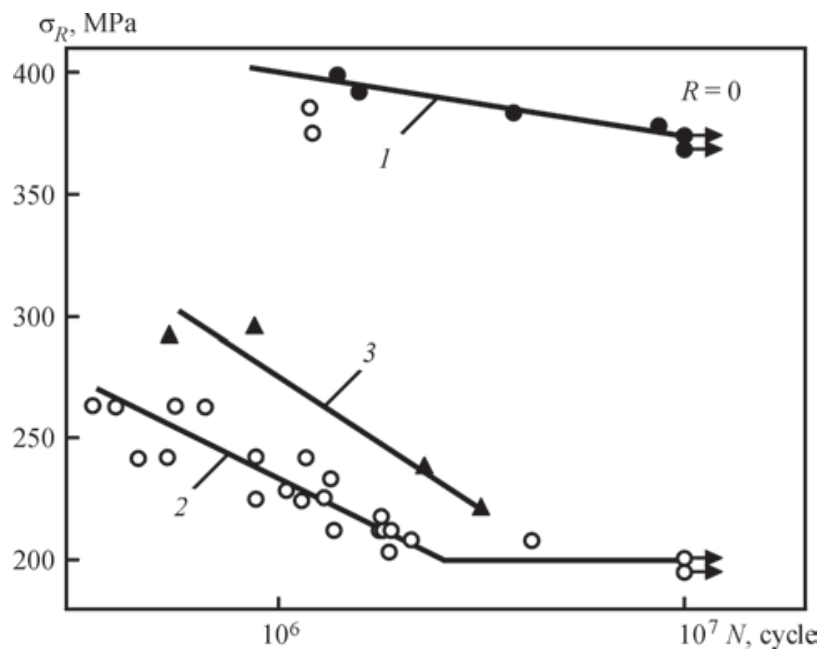

Figure 5. Fatigue curves of butt joints of steel St.3sp: 1 - according to the recommended speed of peening; 2 - in initial state; 3 - with deviation from the recommended HMP technology

out labor- and time-consuming tests. The calculated values $\sigma_{R}^{\mathrm{i}}$ are given in Table 2. The assumption about the proportional increase in the fatigue limit of a strengthened welded joint with increase in $h_{i}$ requires further experimental confirmation. However, in favor of its proportional increase both the test data of strengthened specimens from literature [20] and the available information on the proportional dependence between the groove depth and the fatigue life of welded joints [12] evidence. It should be noted that the groove depth represents an integral characteristic which indirectly reflects the depth of the plastically deformed layer and the corresponding compression RS. The depth of the groove obtained in the work [12] for this thickness of welded joint is considered as an optimal, since its further increase may not be accompanied by strengthening and the probability of peeling of the strengthened surface is increased that negatively effects the fatigue resistance of specimens. As to the stress concentration coefficient, then the earlier investigations showed [21], that the share of its influence in totality of all factors is only $14 \%$.

It is known that the groove depth largely depends on the amplitude of the working tool oscillations. As practice showed, most often welded elements of metal structures are treated at $a$, varying in the range from 19

Table 2. Dependence of fatigue limits of butt joints on groove depth and the corresponding speed of HMP at different amplitude of working tool oscillations

\begin{tabular}{|c|c|c|c|c|}
\hline \multirow{2}{*}{$\begin{array}{c}\text { Depth of } \\
\text { groove } h_{\mathrm{i}},\end{array}$} & \multicolumn{2}{|c|}{ Limit of fatigue $\sigma_{R}^{\mathrm{i}}$, MPa } & \multicolumn{2}{c|}{$\begin{array}{c}\text { Speed of HMP (m/min) at } \\
\text { the amplitude of oscillations }\end{array}$} \\
\cline { 2 - 5 } $\mathrm{mm}$ & Calculation & Experiment & $a=19 \mu \mathrm{m}$ & $a=26 \mu \mathrm{m}$ \\
\hline 0.041 & 251 & - & 0.4 & 0.4 \\
0.062 & 278 & - & 0.11 & 0.24 \\
0.1 & 325 & - & 0.075 & 0.125 \\
0.143 & 379 & 375 & 0.06 & 0.092 \\
\hline
\end{tabular}




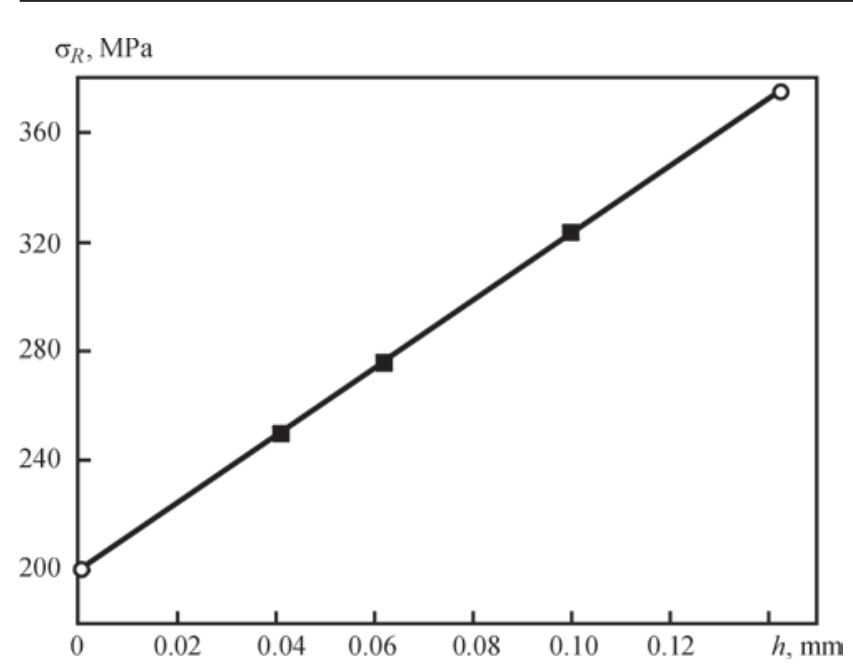

Figure 6. Calculated (dark points) and experimental (light points) dependence of fatigue limit of strengthened butt welded joints on the groove depth

to $26 \mu \mathrm{m}$. In this connection, using previously obtained dependences of groove depth on the speed of HMP at the amplitudes of 19 and $26 \mu \mathrm{m}$ [12], Figure 7 shows the summary diagram on which the dependences between the groove depth and the fatigue limit of welded joints (Table 2) are presented on one side and between the groove depth and speed of peening for different amplitude of oscillations of working tool on the other, respectively. The analysis of the results presented in such a form allows determining not only the change in the groove depth at a given peening speed depending on the amplitude of oscillations of working tool, but also the fatigue limit of welded joint. It follows from the diagram that as the speed of treatment increases, the groove depth decreases, and the effect of amplitude of oscillations of working tool on the strength characteristics becomes less effective, since the curves 1 and 2 are practically converged. At $V=0.4 \mathrm{~m} / \mathrm{min} h$ practically does not depend on $a$, which in its turn determines the same values of
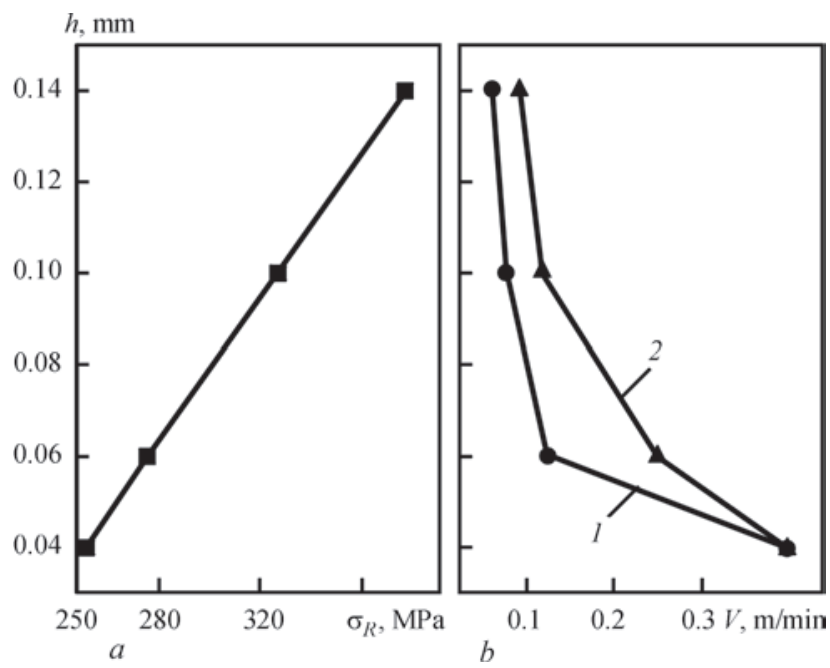

Figure 7. Dependence between the groove depth and fatigue limit of strengthened welded joints (a), and also the speed of HMP at the amplitude of working tool oscillations of 19 (1) and $26 \mu \mathrm{m}$ (2) (b)

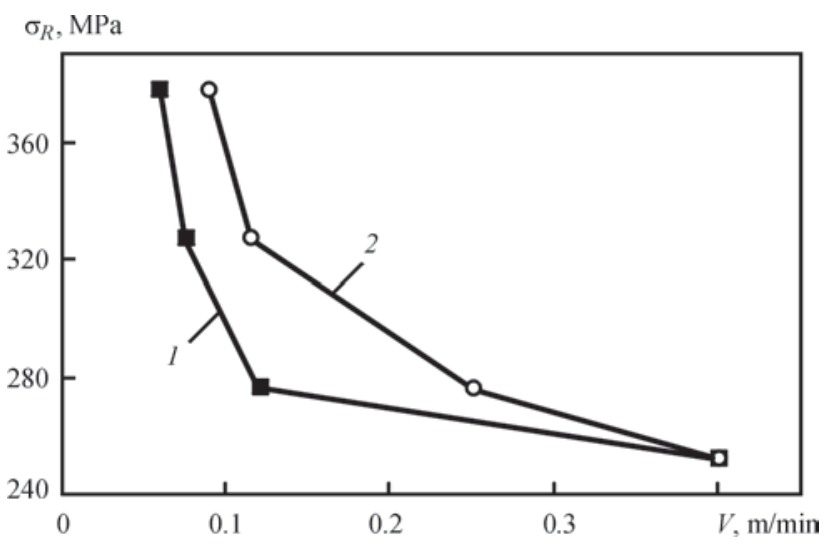

Figure 8. Dependence of fatigue limits of welded joints on the speed of HMP at the amplitude of working tool oscillations of 19 (1) and 26 (2) $\mu \mathrm{m}$

fatigue limits of welded specimens. The obtained effect can have a practical importance in using this strengthening technology.

Often, during repair and restoration works in hardto-reach places of structural elements it is not always possible to determine the groove depth reliably, but it is easier to fix the speed of peening. In this connection, Figure 8 shows the dependences of fatigue limits of welded joints on the speed of peening, determined at the amplitude of oscillations of working tool of 19 and $26 \mu \mathrm{m}$, respectively. It is seen that with increase in $V$, not only their decrease occurs, but also a decrease in difference between them. In addition, at $V=$ $=0.4 \mathrm{~m} / \mathrm{min}$, the values $\sigma_{R}$ are the same independently of $a$, but $25 \%$ higher than the fatigue limit of welded joint in the initial state.

The relative increase in $\sigma_{R}$ of welded joints, determined after a different speed of HMP in the range of varying $a$ from 19 to $26 \mu \mathrm{m}$, illustrates well the dependences shown in Figure 9. Their calculated values at the current amplitude of oscillations of working tool $a_{i}$ can be determined from the equation

$$
\frac{\sigma_{R i}}{\sigma_{R}^{\mathrm{i}}}=\frac{\sigma_{R 1}}{\sigma_{R}^{\mathrm{i}}}+\frac{\sigma_{R 2}-\sigma_{R 1}}{\sigma_{R}^{\mathrm{i}}\left(a_{2}-a_{1}\right)}\left(a_{i}-a_{1}\right),
$$

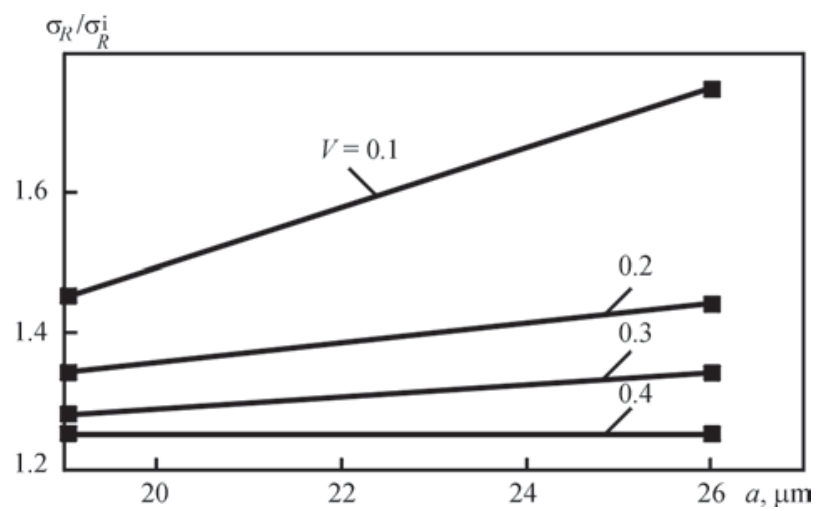

Figure 9. Relative increase in fatigue limits of welded joints, determined after different speeds of HMP in the range of varying amplitude of working tool oscillations of 19-26 $\mu \mathrm{m}$ 
where $\sigma_{R 1}$ and $\sigma_{R 2}$ are the fatigue limits of welded joints determined after different speed of HMP at the amplitude of oscillations of working tool $a_{1}=19 \mu \mathrm{m}$ and $a_{2}=26 \mu \mathrm{m}$, respectively (Table 3 ); $\beta=\left(\sigma_{R_{2}}-\sigma_{R_{1}}\right)$ $\left(\sigma_{R}^{\mathrm{i}}\left(a_{2}-a_{1}\right)\right)$ is a coefficient with specific value for each speed of peening; $\sigma_{R}^{\mathrm{i}}=200 \mathrm{MPa}$ is the fatigue limit of welded joint in the initial state.

From the analysis of results, given in Figure, it follows that both at decrease in the speed of peening and at increase in the amplitude of oscillations of working tool, a more intensive increase in the fatigue limits occurs. The presented data provide a more specific approach to selection of optimal modes of high-frequency mechanical peening at a different combination of its speed and amplitude of oscillations of working tool.

Analysis of results of using mechanical, argon-arc, explosive treatments. The weld zones in specimens of low-alloy steels were subjected to strengthening.

The mechanical treatment (MT) of butt joint of steel 14Kh2GMR produced by manual electric arc welding consisted in removing the weld reinforcement flush with the base metal.

In the argon-arc treatment (AAT) of the butt joint of steel 12GN2MFAYu, which was performed by semiautomatic welding in a carbon dioxide, the zones of weld transition to the base metal were melted by a non-consumable tungsten electrode of $4 \mathrm{~mm}$ diameter in argon. The T-joint of steel 15KhSND, made by automatic submerged arc welding, was subjected to explosive treatment (ExT). For this, the cylindrical charges of explosive material of grade DSha-12 were used, laid along the weld on plasticine backings.
Table 3. Calculated values of fatigue limits for butt welded joints, determined after different speed of HMP at different amplitude of working tool oscillations

\begin{tabular}{|c|c|c|c|}
\hline \multirow{2}{*}{$\begin{array}{c}\text { Speed of HMP, } \\
\mathrm{m} / \mathrm{min}\end{array}$} & \multicolumn{2}{|c|}{ Fatigue limit $\sigma_{\mathrm{R}}, \mathrm{MPa}$} & \multirow{2}{*}{$\beta \cdot 10^{-2}, \mu \mathrm{m}^{-1}$} \\
\cline { 2 - 3 } & $a_{1}=19 \mu \mathrm{m}$ & $a_{2}=26 \mu \mathrm{m}$ & \\
\hline 0.1 & 290 & 350 & 4.29 \\
\hline 0.2 & 269 & 290 & 1.79 \\
\hline 0.3 & 255 & 265 & 0.714 \\
\hline 0.4 & 250 & 250 & 0 \\
\hline
\end{tabular}

The efficiency of methods of strengthening the above-mentioned types of welded joints under different conditions of cyclic loading is shown in Figure 10. In order not to cumber the figures, some fatigue curves are given without experimental points. There, the fatigue curves of specimens in the initial state are also given. The tests of specimens with RS were carried out at $R=0$, and without RS at $R=0.5$. This selection was made on the grounds that, as was shown by the earlier investigations [22], at $R=0.5$ the fatigue limits of welded specimens with high RS and without them have the same values. This allows determining the DLSC of welded joint with high RS according to the results of testing specimens without RS. Analysis of the obtained results showed that fatigue resistance of specimens in the initial state under impact loading is lower than in the case of harmonic loading (curves $1,2)$. All the treatments increase the fatigue resistance of welded joints both at harmonic as well as at impact loadings in the whole investigated range of fatigue life within the limits of 1.1-1.6 times. From Figure it is also seen that fatigue resistance of treated joints in the conditions of impact loading and $-60^{\circ} \mathrm{C}$ slightly exceeds their fatigue resistance in the initial state at
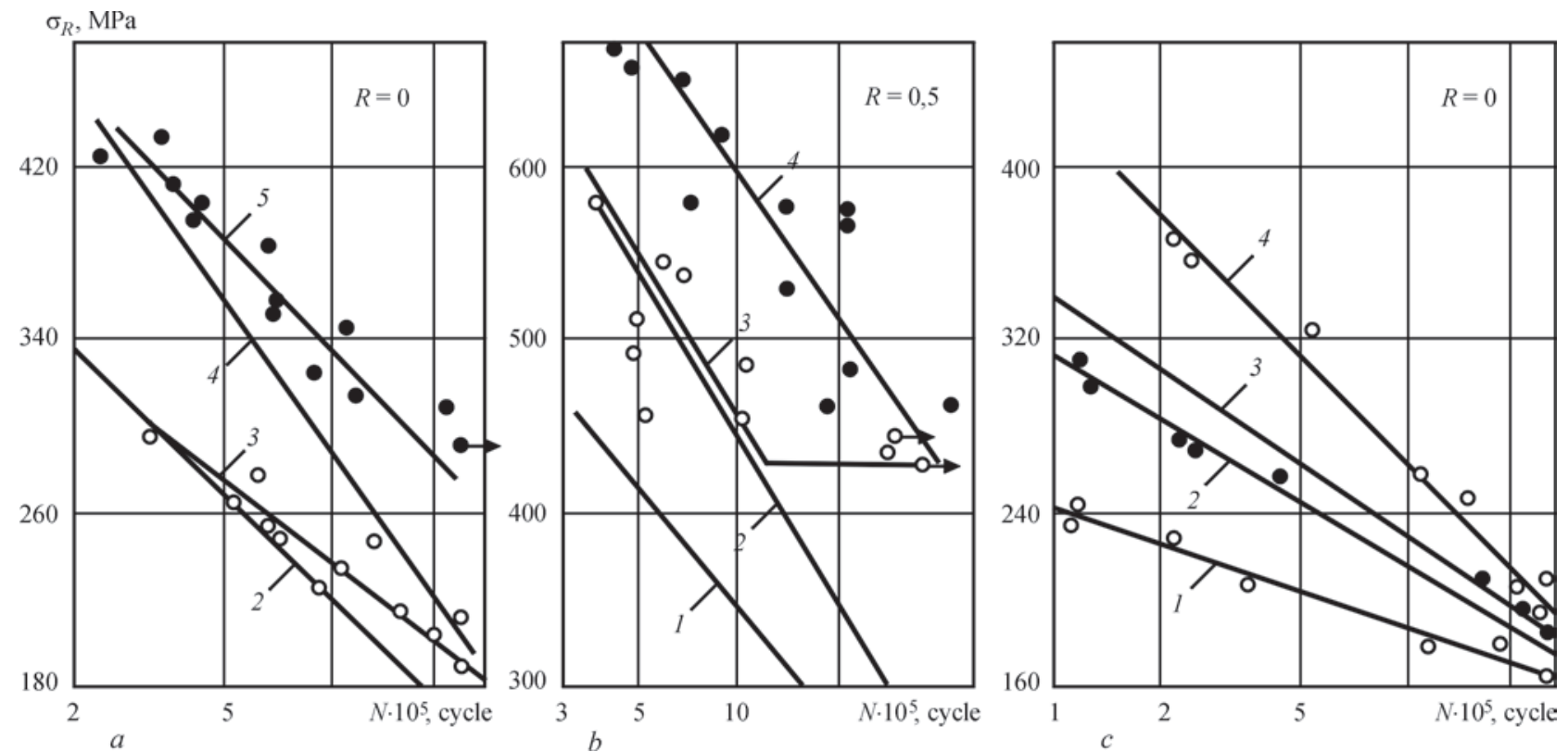

Figure 10. Fatigue curves of butt joints of steels 14Kh2GMR $(a)$ after mechanical, 12GN2MFAYu $(b)$ after argon-arc treatments, respectively, T-joint $15 \mathrm{KhSND}(\mathrm{c})$ after explosive treatment: 1,3 - impact loading at $-60{ }^{\circ} \mathrm{C}$ in the initial state and after treatment, respectively; 2, 4 — harmonic loading at room temperature in the initial state and after treatment, respectively; 5 - at $-60{ }^{\circ} \mathrm{C}$ 
Table 4. Comparative evaluation of effect of type of strengthening treatment on fatigue resistance of welded joints on $10^{6}$ base of loading cycles

\begin{tabular}{|c|c|c|c|c|c|c|c|}
\hline Grade of steel, type of joint & Type of weld treatment & Character of loading & $T,{ }^{\circ} \mathrm{C}$ & $\begin{array}{c}\sigma_{R}, \sigma_{R O}, \\
\mathrm{MPa}\end{array}$ & $K_{V 1}$ & $K_{V 2}$ & $K_{V 3}$ \\
\hline 14Kh2GMR, butt & $\begin{array}{c}\text { MT } \\
\text { MT } \\
\text { Without treatment } \\
\end{array}$ & $\begin{array}{c}\text { Impact } \\
\text { Harmonic } \\
\text { Harmonic } \\
\end{array}$ & $\begin{array}{c}-60 \\
20 \\
20 \\
\end{array}$ & $\begin{array}{l}245 \\
295 \\
225 \\
\end{array}$ & 1.32 & - & 1.08 \\
\hline 12GN2MFAYu, butt & $\begin{array}{c}\text { AAT } \\
\text { AAT } \\
\text { Without treatment } \\
\text { Without treatment }\end{array}$ & $\begin{array}{l}\text { Impact } \\
\text { Harmonic } \\
\text { Harmonic } \\
\text { Impact }\end{array}$ & $\begin{array}{c}-60 \\
20 \\
20 \\
-60\end{array}$ & $\begin{array}{l}451 \\
605 \\
443 \\
335\end{array}$ & 1.37 & 1.35 & 1.02 \\
\hline 15KhSND, T-joint & $\begin{array}{c}\text { ExT } \\
\text { ExT } \\
\text { Without treatment } \\
\text { Without treatment }\end{array}$ & $\begin{array}{c}\text { Impact } \\
\text { Harmonic } \\
\text { Harmonic } \\
\text { Impact } \\
\end{array}$ & $\begin{array}{c}-60 \\
20 \\
20 \\
-60 \\
\end{array}$ & $\begin{array}{l}235 \\
269 \\
220 \\
187\end{array}$ & 1.22 & 1.26 & 1.07 \\
\hline 09G2S, T-joint & $\begin{array}{c}\text { HMP } \\
\text { Without treatment } \\
\text { Without treatment }\end{array}$ & $\begin{array}{c}\text { Impact } \\
\text { Harmonic } \\
\text { Impact } \\
\end{array}$ & $\begin{array}{c}-60 \\
20 \\
-60 \\
\end{array}$ & $\begin{array}{l}468 \\
398 \\
330 \\
\end{array}$ & - & 1.38 & 1.18 \\
\hline Steel St.3sp, butt & $\begin{array}{c}\text { HMP } \\
\text { Without treatment }\end{array}$ & $\begin{array}{l}\text { Harmonic } \\
\text { Harmonic }\end{array}$ & $\begin{array}{l}20 \\
20 \\
\end{array}$ & $\begin{array}{l}402 \\
235\end{array}$ & 1.71 & - & - \\
\hline Steel 20 with welded-on stiffener & $\begin{array}{c}\text { VT } \\
\text { Without treatment }\end{array}$ & $\begin{array}{l}\text { Harmonic } \\
\text { Harmonic }\end{array}$ & $\begin{array}{l}20 \\
20 \\
\end{array}$ & $\begin{array}{l}166 \\
140 \\
\end{array}$ & 1.19 & - & - \\
\hline
\end{tabular}

harmonic loading and room temperature (curves 2, $3)$. This means that the positive effect of strengthening is leveled by negative effect of impact and low temperature, which has a considerable importance for metal structures operated in the conditions of the Extreme North. The explanation of the obtained result is the fact that under the conditions of impact loading and low temperature, the pores existing in welds become dangerous sources of stress concentration, from which the fatigue cracks are developing. This was established during investigations of welded joints of steel 14Kh2GMR with the removed weld reinforcement [23].

To compare the efficiency of methods for strengthening welded specimens, taking into account the different conditions of fatigue test and to give them a quantitative evaluation, a number of coefficients was introduced. The effect of treatment on fatique resistance of welded joints under the conditions of harmonic loading and room temperature was evaluated by the coefficient $K_{V 1}$, and the effect the impact loading and low temperature by $K_{V 2}$

$$
\begin{gathered}
K_{V 1}=\frac{\sigma_{R O}}{\sigma_{R}}, \\
K_{V 2}=\frac{\sigma_{R O}^{\prime}}{\sigma_{R}^{\prime}},
\end{gathered}
$$

where $\sigma_{R}, \sigma_{R}^{\prime}$ and $\sigma_{R O}, \sigma_{R O}^{\prime}$ are the limits of limited fatigue of welded joint in the initial state and after additional treatment respectively, whose values at the same fatigue life were determined from the equations of fatigue curves.
The joint effect of treatment, impact loading and low temperature on fatigue resistance of investigated welded joints was evaluated as

$$
K_{V 3}=\frac{\sigma_{R O}^{\prime}}{\sigma_{R}} \text {. }
$$

The results of calculations of the coefficients for all types of treatments are presented in Table 4.

It follows from Table that the most effective method of strengthening from the considered ones is HMP, which increases the fatigue resistance of strengthened specimens by $71 \%$, under the conditions of harmonic loading and room temperature, determined on the base of $10^{6}$ load cycles, and under the conditions of repeated impact and a low temperature it increases the fatigue resistance of the same joint by $18 \%$, tested in the initial state at the harmonic loading and room temperature. Observing the right treatment technology, this gives grounds to recommend it for strengthening of structures, which operate also in the conditions of cold climate. Regarding VT, the following can be noted. Despite the fact that this method is not distinguished by efficiency of increasing fatigue resistance, however it has an indisputable advantage, which consists in the capability of treating the structural elements with different rigidity in one technological cycle. The analysis of table data showed also that the effect of strengthening almost does not depend on test conditions. This means that fatigue resistance of treated joints under the comparable test conditions is increased approximately in the same way. It can also be noted that the efficiency of the considered treatments according to the coefficient $K_{V 3}$ is several times lower than simply under the comparable test conditions, 
i.e. under the conditions of harmonic loading at room temperature or impact loading at $-60{ }^{\circ} \mathrm{C}$. As to the efficiency of strengthening, which is evaluated under the conditions of harmonic loading on the base of $10^{6}$ cycles, the treatments can be arranged in the following sequence: HMP -71 , AAT -37 , MT -32 , ExT - 22, VT - $19 \%$.

Therefore, on the basis of carried out investigations, it can be concluded that all the considered methods of strengthening treatments increase the fatigue resistance of welded joints, but their efficiency is different and to a great extent depends on the combination of type of cyclic loading and ambient temperature.

\section{Conclusions}

1. The procedure for optimizing the selection of vibration treatment modes of welded elements of metal structures of low-carbon steels, which provide an effective reduction of tensile residual stresses without the risk of arising fatigue damages, was tested experimentally.

2. The procedure for determination of fatigue limits of strengthened butt welded joints was suggested applying the technology of high-frequency mechanical peening in the depth of the groove.

3. The efficiency of increasing the fatigue limit of welded joint was determined depending on the high-frequency mechanical peening speed and the amplitude of the working tool oscillations.

4. It was established that the high-frequency mechanical peening is the most effective method of strengthening the investigated welded joints, evaluated according to the criterion of increasing fatigue resistance in different conditions of cyclic loading and ambient temperature. Further the treatments according to their results can be arranged in the following sequence: argon-arc treatment, mechanical dressing of weld reinforcement, explosive treatment, vibration treatment.

1. Asnis. A.E., Ivashchenko, G.A. (1978) Increase in strength of welded structures. Kiev, Naukova Dumka [in Russian].

2. Kudryavtsev, I.V., Naumchenkov, N.E. (1976) Fatigue of welded structures. Moscow, Mashinostroenie [in Russian].

3. Trufyakov, V.I. (1973) Fatigue of welded joints. Kiev, Naukova Dumka [in Russian].

4. Dreger, D.R. (1978) Good vibes reduce stresses in metal parts. Machine Design, 50(13), 100-103.

5. Ting, W., Dongpo, W., Lixing, H., Yufend, Z. (2008) Discussion on fatigue design of welded joints enhanced by ultrasonic peening treatment (UPT). International J. of Fatigue, 3, 1-7.
6. Shpeer, F.Z., Panov, V.I. (1983) Vibration treatment of largesized welded structures to decrease the strains and crack formation susceptibility. Svarochn. Proizvodstvo, 5, 13-15.

7. Thompson, L. (1969) A method of removing stresses in components by vibration and a setup for this purpose. UK Pat. 1259556 [in Russian].

8. Zimnitsky, Yu.A., Khvalynsky, V.N. (2004) Experimental verification of influence of low-frequency vibration treatment on service reliability of hull structures. Sudostroenie, 1, 50-52 [in Russian].

9. Xiaohui, Z., Dongpo, W., Lixing, H. (2011) Analysis of the S-N curves of welded joints enhanced by ultrasonic peening treatment. Materials \& Design, 32, 88-96.

10. Mikheev, P.P., Nedoseka, A.Ya., Parkhomenko, I.V. et al. (1984) Efficiency of application of ultrasonic peening treatment for improvement of fatigue resistance of welded joints. Avtomatich. Svarka, 3, 4-7 [in Russian].

11. Lobanov, L.M., Kirian, V.I., Knysh, V.V. et al. (2006) Improvement of fatigue resistance of welded joints in metal structures by high-frequency mechanical peening (Review). The Paton Welding J., 9, 2-8 [in Russian].

12. Degtyarev, V.A. (2011) Evaluation of effect of high-frequency mechanical peening modes of welded joints on their fatigue resistance. Problemy Prochnosti, 2, 61-70 [in Russian].

13. Grishakov, S.V., Kovalev, A.M. (1988) Application of Barkhausen effect for evaluation of stresses and damages in ferromagnetic materials. Kiev, IPS [in Russian].

14. Degtyarev, V.A. (1982) Units of DSO type for fatigue tests under impact reloading with different cycle asymmetry. Problemy Prochnosti, 10, 110-113 [in Russian].

15. Statnikov, E.Sh., Shevtsov, E.M., Kulikov, V.F. (1977) Ultrasonic peening instrument for strengthening of welds and reducing the residual stresses. In: New physical methods of intensification of technological processes. Moscow, Metallurgiya, 27-29 [in Russian].

16. Prokopenko, G.I., Kleiman Ya.I., Kozlov, O.V. et al. Device for ultrasonic peening treatment of metals. Ukraine Pat. 47536, Publ. 15.07.2002 [in Ukrainian].

17. Degtyarev, V.A. (1991) Influence of coefficient of cycle stress asymmetry on fatigue and cyclic creep of low-alloyed steels. Rep. 2. Problemy Prochnosti, 2, 27-31 [in Russian].

18. Visilovsky, N.G., Pozhidaev, N.G., Demin, V.M. (1992) Problems of application of vibration treatment instead of heat treatment. Tyazholoe Mashinostroenie, 8, 20-22 [in Russian].

19. Marguis, G. (2010) Failure modes and fatigue strength of improved HSS welds. Engineering Fracture Mechanics, 77, 2051-2062.

20. Serensen, S.V., Kogaev, V.P., Shnejderovich, R.M. (1975) Load-carrying capacity and strength calculations of machine parts. Moscow, Mashinostroenie [in Russian].

21. Kirian, V.I., Knysh, V.V. (2008) High-frequency mechanical peening of welded joints of metal structures. Svarochn. Proizvodstvo, 11, 36-41 [in Russian].

22. Shulginov, B.S., Degtyarev, V.A., Matveev, V.V. (1984) On ultimate cycle stresses of welded joints with high residual stresses. Problemy Prochnosti, 3, 58-61 [in Russian].

23. Shulginov, B.S., Matveev, V.V., Degtyarev, V.A. (1985) About influence of microdefects in welds on fatigue resistance of metal structures of mining and transport technics. In: Proc. of $2^{\text {nd }}$ Republ. Conf. on Improvement of Reliability and Service Life of Machines and Constructions. Kiev, Naukova Dumka, 167-168. 


\title{
EFFICIENCY OF PROCESS OF COATING SPRAYING USING MULTICHAMBER DETONATION UNIT
}

\author{
O.V. KOLISNICHENKO ${ }^{1}$, Yu.N. TYURIN ${ }^{1}$ and R. TOVBIN ${ }^{2}$ \\ ${ }^{1}$ E.O. Paton Electric Welding Institute of the NAS of Ukraine \\ 11 Kazimir Malevich Str., 03150, Kiev, Ukraine. E-mail: office@paton.kiev.ua \\ ${ }^{2}$ Sputtek Inc. \\ 1 Goodmark Place, Unit 4, Toronto, Ontario, Canada M9W 6M1
}

\begin{abstract}
A multichamber detonation unit is designed for coating deposition using powder materials. Heating and acceleration of powders is carried out by detonation combustion products of gas mixture of propane, oxygen and air with $20 \mathrm{~Hz}$ frequency and more. A difference of multichamber detonation unit is a presence of additional combustion chamber, which rises gas-dynamic parameters of the detonation products and efficiency of spraying process. Effect of unit design peculiarities on gas-dynamic parameters of detonation products was determined. Velocity of detonation products reaches $1520 \mathrm{~m} / \mathrm{s}$, detonation wave pressure makes approximately 3.5 MPa. Velocity of the sprayed particles using this unit reaches $1200 \mathrm{~m} / \mathrm{s}$. The unit is equipped with a valveless system for gas and powder feeding. This provides reliable operation at high frequency of detonation initiation (up to $50 \mathrm{~Hz}$ ). A spraying deposition efficiency at that reaches 82 and $67 \%$ for cermet powders and oxide ceramics, respectively. Coatings received at that are characterized with small porosity (<1\%) and high adhesion to substrate. 13 Ref., 1 Table, 6 Figures.
\end{abstract}

Keywords : multichamber detonation unit, velocity and pressure of detonation products, spraying deposition efficiency, velocity and extention of powder jet

A coating spraying method based on application of processes of detonation combustion of gas mixtures, remains the dynamically developing technological direction from the moment of first patent granting in 1955 [1]. Mastering of this technology was started in Kiev in the 1960s under the leadership of Prof. G.V. Samsonov and at the beginning of the 1980 s there were already around tens of modifications of detonation guns for spraying. A vast practical material has been collected from that time. Investigation of physical processes of detonation spraying allowed optimizing the technology and design of the unit and increase coating quality. However, mass application of the detonation technology in the industry was limited by low efficiency, problems of powder dosing and feeding in a pulse jet of the combustion products, relatively low spraying deposition efficiency (SDE) and low safety of detonation units in whole. The perspective direction is development of a valveless detonation unit operating at increased frequencies. For the first time the valveless high-frequency detonation unit (frequency of more than $80 \mathrm{~Hz}$ ) was created and produced in 1976 [2]. The methods of detonation deposition of coatings and units with continuous feed of the combustible mixture components, gas-dynamic mixture and application of propane, methane and other carbureted hydrogen gases [3] as a combustible gas (c) O.V. KOLISNICHENKO, Yu.N. TYURIN and R. TOVBIN, 2017 were developed in the 1976-1980s. A high-frequency pulse detonation gun HFPD [4] can be referred to one of the variants of such class of the units.

Coating material in thermal spraying is formed as a result of interaction of flow of dispersed particles (powder) with treated part material. The key parameters, determining physical-chemical peculiarities of materials' interaction and the possibility of formation of quality coatings, are velocity and temperature of the particles at the moment of collision with a substrate. These parameters determine a nature of contact, namely dynamics of spread of material of the dispersed particle, level of substrate deformation etc. Currently, further development of the high-velocity thermal methods of coating formation is directed on increase of powder kinetic energy at decrease of its temperature. High velocity of the particles at their lower temperature allows carrying out plastic deformation and structuring of the powder material. This provides the possibility of formation of the nanosubmicrocrystalline, dense coating materials, without oxidation and with high parameters of adhesion and cohesion.

The detonation units with nonstationary combustion processes [5] are reasonable to use for getting a high-velocity gas-powder jet. Application of the nonstationary modes of detonation combustion allows significant increase of quality characteristics of the deposited coatings as well as reducing their weight and dimensions of the unit. A mode of overcompressed detonation can be 
realized, for example, in the convergent channels [6] or at electric discharge of a capacitive storage behind a detonation wave front [7]. Now an important factor is also a level of technology automation. A computerized detonation complex CCDS Dragon [8] can be an example of technological process control. Regardless the achieved success, there are still problems with increase of efficiency of interaction of combustion products' jet and powder particles as well as automation of dosing and rise of dosing accuracy. An important problem is also increase of velocity and pressure of the combustion products and, respectively, a powder jet velocity. It is also necessary to provide complete automation of unit operation and high indices of its reliability and reparability.

An automated multichamber detonation unit (MCDU) [9] was developed for solving these problems. This unit realizes a mode of detonation combustion of the gas mixture in specially profiled chambers. Accumulation of combustion energy from two chambers in a cylindrical barrel provides formation of a high-velocity jet of combustion products, which accelerates and heats sprayed powder. The aim of carried work was investigation of pressure behind the detonation wave front, velocity of detonation products and powder sprayed particles outflow using this unit. A special valveless assembly for dosing and feeding of the powder doses to the barrel was developed to get the high parameters of spraying deposition efficiency (SDE). The dosing assembly includes powder feeder, providing mixing and transporting of gas-powder mixture along pipeline, and gas-dynamic dozing unit. Feeding into these devices provide accurate feeding MCDU barrel portions (doses) of the powder, synchronized with detonation generation frequency (20-50 Hz).

Equipment and investigation procedure. Materials, design peculiarities and principles of MCDU operation. Investigations, optimizing technological modes and design were carried out on a laboratory experimental prototype of MCDU (Figure 1). Consumption of the combustible mixture components varied in the following ranges, namely $0.6-1.6 \mathrm{~m}^{3} / \mathrm{h}$ for propane and 3.0-9.0 $\mathrm{m}^{3} / \mathrm{h}$ for oxygen. The unit has three chambers: 1 - prechamber for initiation of detonation process; 2 - main cylindrical chamber, where development of detonation combustion mode takes place; 3 - annular chamber with slot output into the cylindrical barrel 4. Annular chamber 3 is used for compression of the combustion products and development of an additional jet, which «support» in the cylindrical barrel 4 the detonation products of main

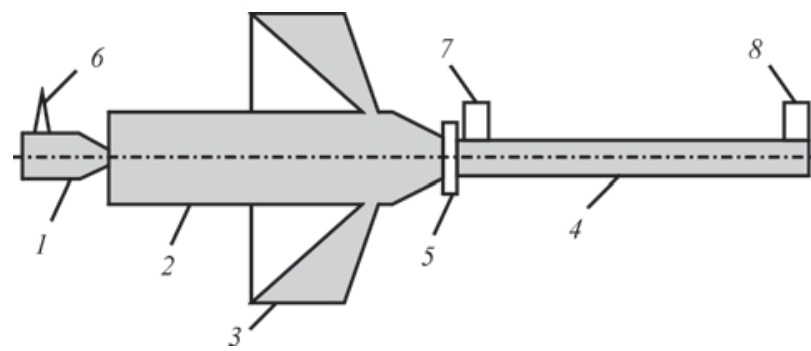

Figure 1. Scheme of multichamber detonation unit (see designations in the text)

chamber 2. A dose of powder is fed into the barrel for acceleration and heating. The barrel can have internal diameter $16-20 \mathrm{~mm}$ and length $300-520 \mathrm{~mm}$ and is selected depending on properties of sprayed powder material. Constriction of working volume of the cylinder chamber of $24 \mathrm{~mm}$ diameter to barrel diameter $16 \mathrm{~mm}$ provides overcompression of the detonation combustion mode. Further contraction of the combustion products takes place due to annular chamber. Gas-dynamic process of detonation initiation in the annular chamber provides collapse of the combustion products along the barrel axis that dramatically increases their velocity, pressure and density.

A dose of powder material is fed ahead a front of the high-velocity combustion products. This dose is fed through annular slot of special gas-dynamic feeder assembly 5. The size of slot in radial direction is selected experimentally and being the fact of optimizing for specific powder. SDE, determined by weight method, was used as an optimizing parameter. Initiation of the combustion detonation mode for gas mixture was made by car ignition plug 6. Powder of H.C. Starck: AMPERIT $^{\circledR} 740.0-\mathrm{Al}_{2} \mathrm{O}_{3}$ (5.6-22.5 $\mu$ m dispersion) and AMPERIT ${ }^{\circledR} 554.074$ - WC-Co-Cr(86-10-4 \%) 15-45 $\mu \mathrm{m}$ dispersion were used in the experiments

Mode of spraying of $\mathrm{Al}_{2} \mathrm{O}_{3}$ and WC-Co-Cr using MCDU

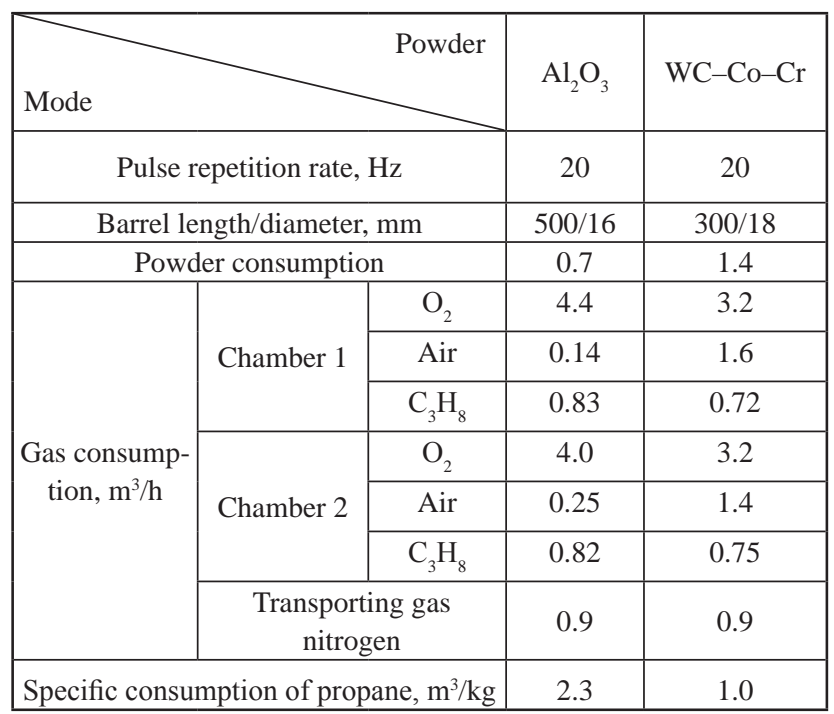


on optimizing the design, measurement of velocity of gas-powder jet and coating spraying. Spaying modes are indicated in the Table.

Procedures for investigation of pressure, velocity of detonation products and powder particles. Measurement of pressure in the detonation products and velocity of detonation wave were carried out using piezoelectric pressure probes LKh-611, which are calibrated on shock tube with known parameters. The first probe 7 (see Figure 1) was fixed at approximately $60 \mathrm{~mm}$ distance form outlet of the annular chamber directly at barrel inlet. The second probe 8 was fixed at the outlet from the barrel. The barrel of $500 \mathrm{~mm}$ length and $16 \mathrm{~mm}$ diameter was used in the experiments. The distance between the probes' axes is $525 \mathrm{~mm}$. The experiments were carried out using combustible mixture of propane and oxygen in stochiometric proportion. A signal from the probes through a signal converter ADC L-card783 was recorded using Powergraph 3.0 program.

Powder velocity was determined using a device visualizing luminance of heated gas-powder jet. Two fast germanium photodiodes FD287 (time of rise of pulse front $10 \mathrm{~ns}$ ) with operating spectral range $\lambda=$ $=0.5-1.7 \mu \mathrm{m}$ were used as a photodetector. The signal from the probes after amplification came into ADC L-Card783 and was recorded using Powergraph

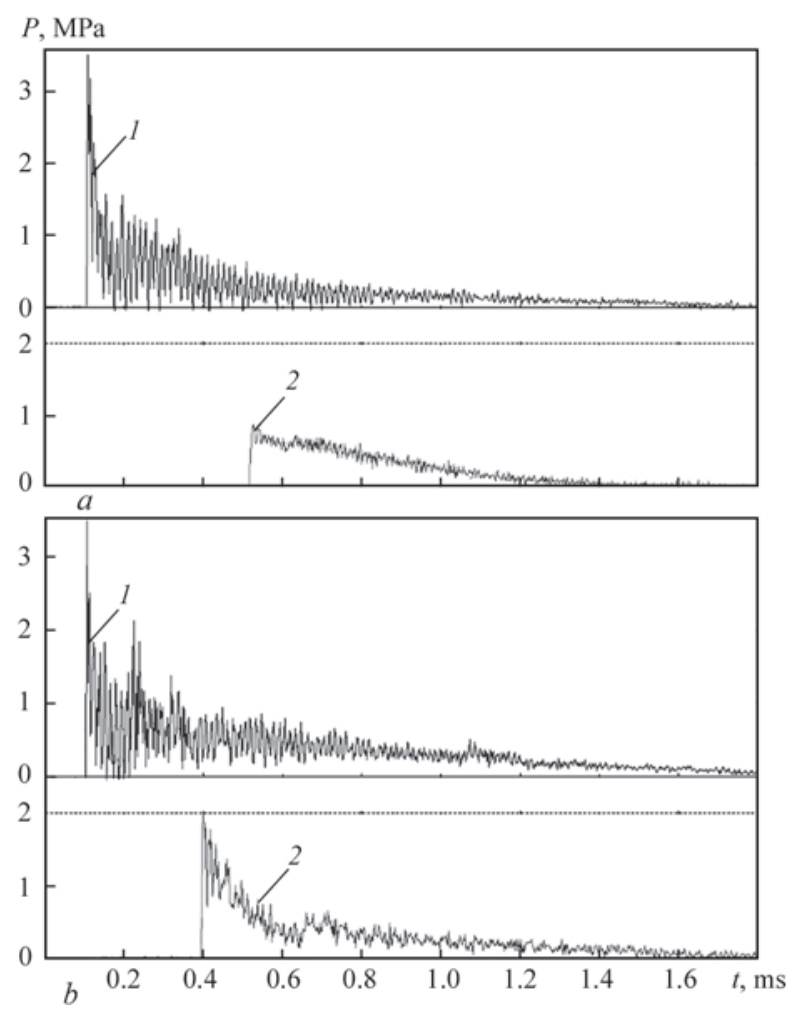

Figure 2. Change of pressure $P$ in time: $a-$ using one chamber; $b$ - with second chamber connected $(1-$ at the barrel inlet; 2 at the outlet)
3.0 program. An amplifier and receiving photodiodes were removed from the detonation unit and the signal from gas-powder jet were supplied to photodetector by means of fiber-optic cables. The axes of the latter were located normal to the gas-powder jet axis. The distance from nozzle section to the axis of measurement system was varied in $40-100 \mathrm{~mm}$ range. It is well known fact that density of a radiation flow from the heated gas is much lower than from the powder particles, that allows neglecting radiation of combustion products and register radiation only from the heated powder.

Metallographic examinations. Optical microscope Olympus GX51 and electron scanning microscope Quanta 200 3D equipped with spectrometer of X-ray radiation of PEGASUS system from EDAX Company were used for metallographic examinations and phase analysis of coating microsections. Coating porosity was determined by means of analysis of the microsections, performed by image-processing system. It consists of optical inverted microscope OLYMPUS GX51 and software for image quantitavite analysis. Hardness measurement was carried out using an automated system for microhardness analysis DM-8 by Vickers method at indenter loading $300 \mathrm{~g}$. Adhesion of coating from WC-Co-Cr powder was determined on a glue procedure according to ASTM C633 standard.

Results of investigations and discussion. Pressure and velocity parameters of detonation products. Determination of velocity of a stationary detonation wave in the unit was carried out at its complete filling with combustible mixture. The combustible mixture was not fed in the annular chamber (see Figure 1).

The experiments showed that time of passing of the detonation wave between the probes makes on average $0.25 \mathrm{~ms}$ and velocity is $2100 \pm 100 \mathrm{~m} / \mathrm{s}$. The value of stationary detonation velocity, corresponding to Chapman-Jouguet conditions, reaches $2450 \mathrm{~m} / \mathrm{s}$ [10] for oxygen-propane mixture of stochiometric relationship. Received velocity is low due to energy losses during movement in the barrel of $16 \mathrm{~mm}$ diameter. Besides, there is a possibility of air admixture in process of chamber filling between the pulses and deviation from stochiometry.

The situation is completely changed, if the detonation unit is filled with the combustible gas mixture to the level of location of the first probe. Such filling of internal volume of the unit with combustible mixture components is used during spraying. At that, the detonation process is finished at the inlet to the barrel, transfer of a detonation wave into shock one takes 


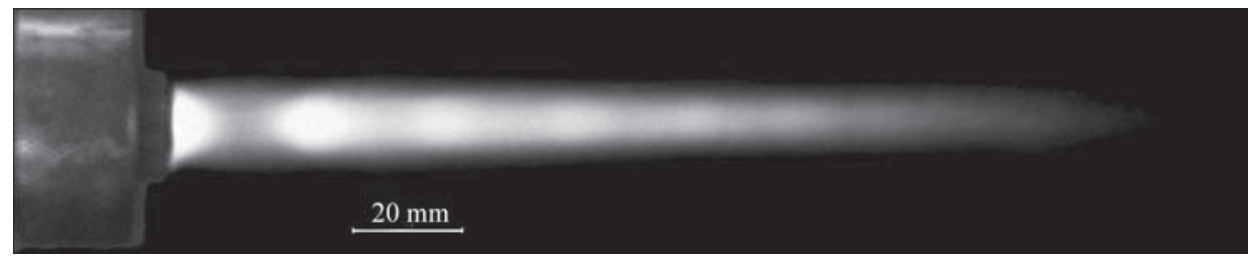

Figure 3. Appearance of supersonic pulse jet coming from detonation unit nozzle

place and the latter is developed inside the cylinder barrel. Intensive attenuation of the shock wave takes place due to passing along the barrel when using one chamber (Figure 2,a). There is decrease of pressure, velocity and extension of combustion products' zone.

Simultaneous application of the second (annular) chamber allows significantly changing physical parameters behind the shock wave (Figure 2, b). The second chamber creates an additional jet, which proceeds by detonation products after the first detonation wave and feed them with energy. The first probe registers formation of the shock wave second front. An amplitude of shock wave at the second probe makes 2.0 MPa, that two times exceeds the indices in using one chamber. Extension of the combustion products flow, having increased pressure at nozzle outlet, is also higher and makes $1.2 \mathrm{~ms}$. An average velocity of shock wave between the probes at that makes $1750 \mathrm{~m} / \mathrm{s}$, whereas using one chamber it is $1300 \mathrm{~m} / \mathrm{s}$. In order to evaluate the gas velocity behind straight line front of the shock wave, expression [11] is used

$$
V=\frac{2}{k+1} D\left(1-\frac{c_{1}^{2}}{D^{2}}\right),
$$

where $k=1.3$ is the adiabat; $D$ is the shock wave velocity; $c_{1}$ is the sound velocity in still environment.

Then estimation of average velocity of the combustion products in the barrel makes 1130 and $1520 \mathrm{~m} / \mathrm{s}$ using one and two chambers, respectively.

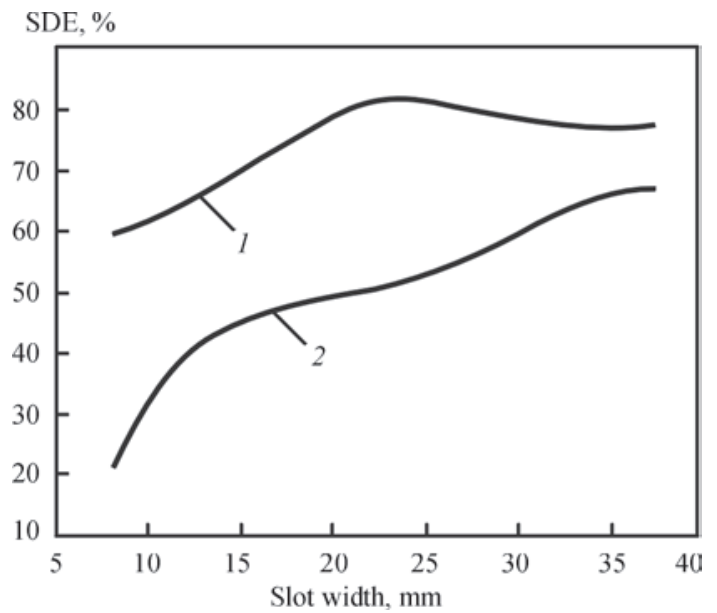

Figure 4. Change of SDE depending on width of assembly slot for powder feed: $1-\mathrm{WC}-\mathrm{Co}-\mathrm{Cr} ; 2-\mathrm{Al}_{2} \mathrm{O}_{3}$
Direct estimation of outflow velocity of the combustion products at barrel outlet is also possible by length of periodic structure wave of a supersonic jet in still environment [12]

$$
L=2.613 r \sqrt{M-1} \text {, }
$$

where $r$ is the radius of detonation unit nozzle; $M=$ $=V / a_{0}$ is the Mach number; $L$ is the length of periodic structure wave (distance to shock wave); $a_{0}$ is the local sonic speed in combustion products.

Figure 3 shows an image of supersonic pulse jet at MCDU operation in two chambers with $16 \mathrm{~mm}$ diameter barrel. The structure of gas jet is typical for supersonic outflow in underexpanded mode and agrees with explosion nature of detonation unit operation, at which pressure in the chamber significantly exceeds environment pressure.

Based on experiment data $\left(a_{0} \approx 1000 \mathrm{~m} / \mathrm{s}, r=\right.$ $=8 \mathrm{~mm}, L \approx 27 \mathrm{~mm}$ ), the outflow velocity $V \approx 1600 \mathrm{~m} / \mathrm{s}$ is received. This result is correlated with estimation of outflow velocities of the combustion products, given above on the results of experimental investigation of pressure in combustion products and shock wave for $16 \mathrm{~mm}$ diameter and $500 \mathrm{~mm}$ length barrel.

Carried investigations prove that velocity of the combustion products is significantly increased at the second chamber connection. At that more extended flow of the combustion products is formed in the barrel, having two pressure maxima and higher velocity.
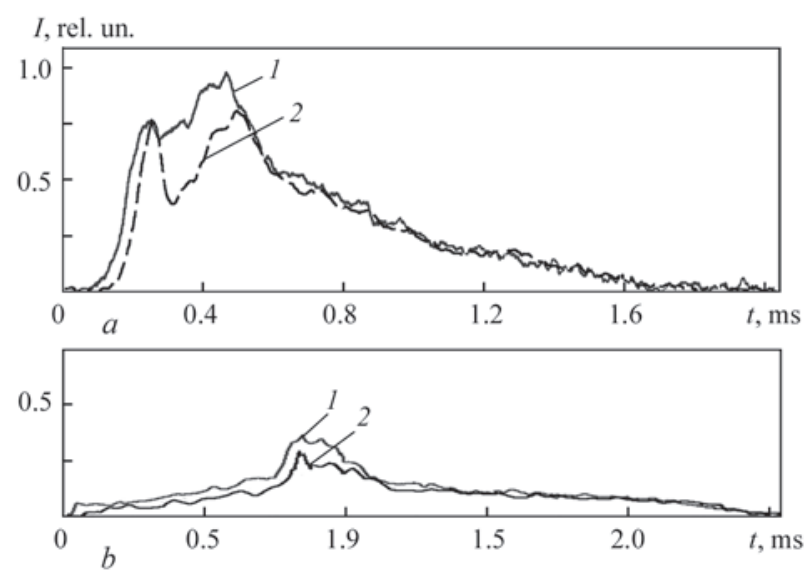

Figure 5. Radiation of gas-powder jet of $\mathrm{Al}_{2} \mathrm{O}_{3}(a)$ and WC-Co$\mathrm{Cr}(b)$ registered using germanium photodiodes FD287: 1 - at $30 \mathrm{~mm}$ distance from nozzle section; 2 - at $60 \mathrm{~mm}$ distance 


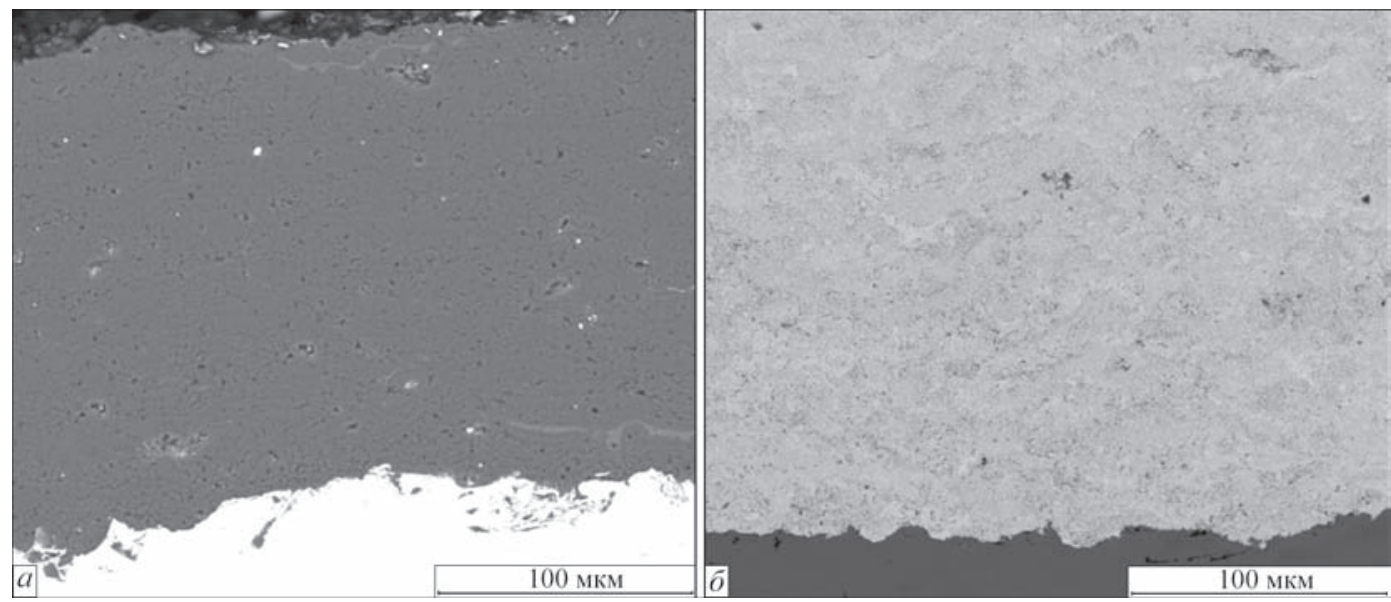

Figure 6. Microsection of cross section of specimen with coating of powders: $a-\mathrm{Al}_{2} \mathrm{O}_{3}$, dispersion $5.6-22.5 \mu \mathrm{m}$; $b-\mathrm{WC}-\mathrm{Co}-\mathrm{Cr}$ 86-10-4 \%, dispersion 15-45 $\mu \mathrm{m}$

Such a flow is more effective in powder particle acceleration.

Optimizing a powder feeder for MCDU. Taking into account that MCDU works at increased frequencies (20 Hz and more), application of the pulse valve systems for powder feeding, containing moving mechanical parts, is not reasonable from point of view of reliability.

Specially developed assembly for powder feed used in MCDU has a cavity, to which powder is fed from a distantly remote feeder. In the process of spraying the powder comes in the barrel of unit through annular slot during wave discharge. A moment of powder injection in the barrel for the following pulse is determined by slot length in radial direction (slot width). A size spectrum of assemblies for powder feed was manufactured in 5 pcs. amount to get maximum SDE. Figure 4 shows an effect of slot width in SDE for $\mathrm{Al}_{2} \mathrm{O}_{3}$ and $\mathrm{WC}-\mathrm{Co}-\mathrm{Cr}$. Aluminum oxide has significantly lower density than cermet and, respectively, lower inertia. In order to obtain the maximum SDE in $\mathrm{Al}_{2} \mathrm{O}_{3}(67 \%)$ spraying the slot width shall make $37 \mathrm{~mm}$. That for WC-Co-Cr is $23 \mathrm{~mm}$. At that SDE will reach $82 \%$.

Velocity parameters of powder in coating deposition. Visualization of integral radiation of a heated gas-powder jet allows evaluating its dynamics and extension. The velocity of powder jet was determined taking into account time shift of signals from the first and second photoprobes. Figure 5 shows a variation of radiation time from the gas-powder jet at deposition of coatings of $\mathrm{Al}_{2} \mathrm{O}_{3}$ and $\mathrm{WC}-\mathrm{Co}-\mathrm{Cr}$. The spraying modes are given in the Table. Obtained results were averaged by 20 measurements.

The investigations showed that duration of outflow of the gas-powder jet, containing $\mathrm{Al}_{2} \mathrm{O}_{3}$, makes approximately $1.4 \mathrm{~ms}$. The velocity of jet front at a distance of spraying surface location (up to $60 \mathrm{~mm}$ from nozzle section) equals $1000 \pm 200 \mathrm{~m} / \mathrm{s}$. Such parameters provide spraying of quality coating on solid substrate. For example, Figure 6, $a$ shows coating cross-section of given powder, deposited on a sample of low-carbon steel. The investigations showed that the coating has $<1 \%$ porosity. The maximum hardness $H V 0.3-1320 \pm 25$ was received in coating upper layers. Hardness gradually decreases by approximately $30 \%$ and in the layers, adjacent to the boundary, has the values of HV0.3-900 \pm 25 . Composition of coating material is the following corundum $\left(\alpha-\mathrm{Al}_{2} \mathrm{O}_{3}\right)$ to $47 \%$; other phases - softer modifications of oxide $\left(\gamma\right.$ and $\theta-\mathrm{Al}_{2} \mathrm{O}_{3}$ ).

In cerment coating deposition, for example, WCCo-Cr, the temperature of combustion products was reduced by dilution of the combustible mixture with air (see Table). It is necessary for prevention of the processes of thermal decomposition of higher carbides [13], resulting in decrease of service properties of the coatings. Reduction of powder temperature effects radiation intensity trapped by photodiodes (Figure $5, b$ ). Increased content of air in the combustible mixture results in decrease of the detonation product velocity and, respectively, powder outflow velocity. Investigations showed that the average velocity of WC-Co-Cr powder reduces to $550 \pm 100 \mathrm{~m} / \mathrm{s}$ (Figure $5, b)$, that is sufficient for producing coating material with low porosity $<0.7 \%$ (see Figure 6, $b$ ) and high adhesion (> $80 \mathrm{MPa}$ ) to substrate.

\section{Conclusions}

1. High-frequency (more than $20 \mathrm{~Hz}$ ) valveless multichamber detonation unit was developed. It allows generating pulse jets of the combustion products, 
having two pressure maxima (3.5 and 2.0 MPa) due to energy cumulation from cylinder and annular combustion chambers.

2. Application of double-chamber design provided increase of velocity of the detonation combustion products by $35-40 \%$, that, respectively, rises velocities of powder material. For example, velocity for $\mathrm{Al}_{2} \mathrm{O}_{3}$ powder of 5.6-22.5 $\mu \mathrm{m}$ dispersion made $1200 \mathrm{~m} / \mathrm{s}$.

3. A gas-dynamic powder dosing assembly was created. It provides accurate feeding of powder portion before detonation initiation that increased SDE to $82 \%$ for cerment and $67 \%$ for aluminum oxide.

4. High efficiency of spraying process using MCDU is proved by the example of investigation of two types of coating materials - cermet WC-Co-Cr and ceramics $\mathrm{Al}_{2} \mathrm{O}_{3}$. The coatings are dense (porosity less than $1 \%$ ), having high adhesion to the base (more than $80 \mathrm{MPa}$ ). Formation of $1 \mathrm{~kg}$ of material of cermet and ceramics coating required 1.0 and $2.3 \mathrm{~m}^{3}$ of propane, respectively, that is 2 times less than in known detonation units.

1. Poorman, R.M., Sargent, H.B., Lamprey, H. (1955) Method and apparatus utilizing detonation waves for spraying and other purposes. US Pat. 2714563.

2. Tyurin, Yu.N., Ralf, S.E., Shulzhenko, V.A. et al. (1976) Device for detonation deposition of coatings. USSR author's cert. 669539 [in Russian].
3. Tyurin, Yu.N., Garbuzov, A.P. (1983) Methods of detonation deposition of coatings. USSR author's cert. 1045491 [in Russian].

4. Endo, T., Obayashi, R., Tajiri, T. et al. (2016) Thermal spray using a high-frequency pulse detonation combustor operated in the liquid-purge mode. J. Therm. Spray Technol., 25(3), 494-508.

5. Gavrilenko, T.P., Nikolaev, Yu.A., Ulyanitsky, V.Yu. (2010) Application of overcompressed detonation of coating deposition. Fizika Goreniya i Vzryva, 46(3), 125-133 [in Russian].

6. Prokhorov, E.S. (2011) Approximate calculation of overcompressed gas detonation in converging channels. Vestnik $N G U$, Ser.: Fizika, 6(2), 5-9 [in Russian].

7. Tyurin, Y.N., Pogrebnjak, A.D. (1999) Advances in the development of detonation technologies and equipment for coating deposition. Surf. and Coat. Technol., 111(2-3), 269-275.

8. Shtertser, A., Muders, C., Veselov, S. et al. (2012) Computer controlled detonation spraying of WC/Co coatings containing $\mathrm{MoS}_{2}$ solid lubricant. Ibid., 206(23), 4763-4770.

9. Tyurin, Yu.M., Kolisnichenko, O.V. (2008) Method of detonation spraying of coatings and device for its realization. Pat. 83831, Ukraine [in Russian].

10. Khitrin, L.N. (1957) Fizika Goreniya i Vzryva. Moscow, MSU [in Russian].

11. Baum, F.A., Stanyukovich, K.P., Shekhter, B.I. (1959) Physics of explosion. Moscow, Fizmatgiz [in Russian].

12. Baj Shi-i (1960) Theory of jets. Moscow, Gos. Izd-vo Fiz.Mat. Lit-ry [in Russian].

13. Markashova, L.I., Tyurin, Yu.N., Kolisnichenko, O.V. et al. (2014) Structure-phase condition of wear-resistant composite coatings of $\mathrm{Cr}_{3} \mathrm{C}_{2}-\mathrm{NiCr}$ system, deposited using multi-chamber detonation installation. In: Proc. of $7^{\text {th }}$ Int. Conf. on Mathematical Modelling and Information Technologies in Welding and Related Processes (15-19 September 2014, Odessa, Ukraine), 37-42 [in Russian]. 


\title{
MODELING THERMOMECHANICAL PROCESSES IN WELDING HIGH-TECH PLASTICS WITH EMBEDDED ELEMENT*
}

\author{
R.V. KOLESNIK, M.V. YURZHENKO, N.G. KORAB, A.A. SHADRIN and Yu.V. LITVINENKO \\ E.O. Paton Electric Welding Institute of the NAS of Ukraine \\ 11 Kazimir Malevich Str., 03150, Kiev, Ukraine. E-mail: office@paton.kiev.ua
}

\begin{abstract}
Heat-resistant polymers are ever wider applied in aerospace, automotive and other industries. For the process of thermopastics welding it is important to study temperature distribution inside the overlap welded joint. In this work thermal and deformation processes in welding with embedded element of sheet samples from high-tech heat-resistant polymer ZEDEX ZX-410 based on polyetherimide, were modeled. Melting temperature and polymer material destruction temperature were the criteria for optimization of process parameters. Good correlation is shown for modeling results and experimental data obtained both from thermal studies of the process of welded joints formation, and mechanical testing of the formed welded joints. 9 Ref., 12 Figures.
\end{abstract}

Ke y w o rds : welding with embedded element, high-tech polymers, modeling, testing

With advance of engineering and technology new polymers with improved service properties are being developed in the world, which oust metals and other traditional materials in many spheres. High-tech heat-resistant polymers of polyarylene class - polyetherimide (PEI), polyetherketone (PEEK), polyphenylsulphide (PPS) and others have been actively used over the recent years. These polymers are thermoplastics, so that various welding processes are used for joining them. Application of high-tech heat-resis-

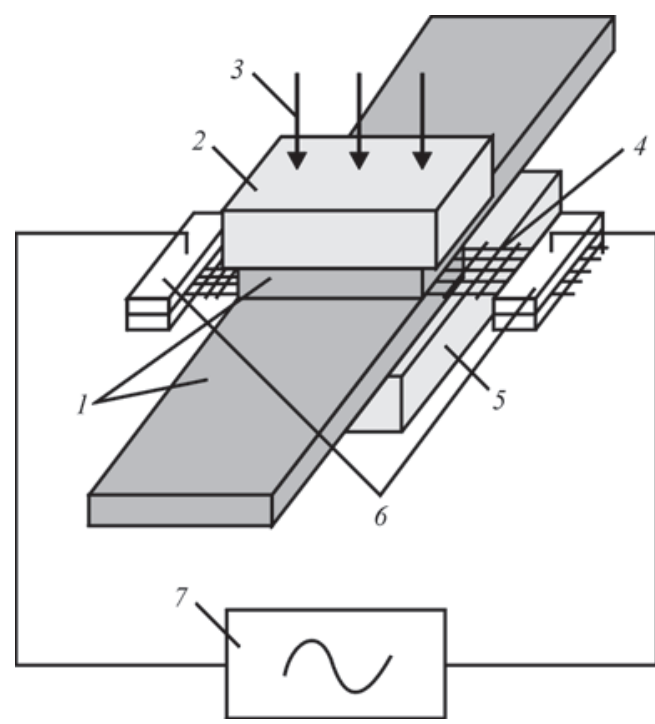

Figure 1. Schematic of the process of welding with embedded element: 1 - samples; 2 — clamp; 3 - working pressure; 4 - embedded element; 5 — base; 6 - electric contacts; 7 - power source tant polymers is the most intensively developing in aerospace and automotive industries, as well as in mechanical engineering, where it is often necessary to make extended welds of a complex geometry and in difficult-of-access places. Such joints are usually welded using an embedded heating element.

Typical schematic of the process of welding with embedded element is given in Figure 1. The embedded element is made from metal wire, mesh or strip and when applied it becomes the source of thermal energy, and after welding it remains inside the welded joint. Heating of the embedded element is most often performed due to heat evolution at passing of electric current through it, supplied from a special power source. Working pressure is applied to the joint outer surface to ensure sound weld formation.

Polymer material melting and joint formation in welding with embedded element occur in a closed space between the surfaces of the parts being welded. The possibility of monitoring the heating and cooling of the butt is limited, welding process parameters are usually set and regulated by indirect indices (embedded element heating rate, amount of formed flash, etc.). The main problem in welding with embedded element is ensuring an optimum amount of heat, which evolves in the welding zone. In welding extended welds of a complex shape, there is high probability of appearance of unheated zones and formation of lacks-of-penetration in some sections of the

${ }^{*}$ K.O. Zvorykin, NTUU «I. Sikorsky KPI» took part in performance of the work. 
joint, and as well as appearance of overheated zones with destructured polymer material in other sections. Therefore, preliminary mathematical modeling of thermomechanical processes in welding with embedded element to determine the admissible parameters of embedded elements in heating parts of different geometry is urgent.

Beginning of application of welding with embedded elements for joining parts from high-tech polymers was accompanied by appearance of the first mathematical models of the process of embedded element heating [1]. These are two-dimensional models developed for assessment of temperature distribution during welding over the surface of strip embedded elements made from metal or PEEK-based carbon fibre composite.

Furtheron, 3D thermal models of the process of welding with embedded element were developed, which already allowed for thermal conductivity of polymer material, heat losses and latent heat. Difficulties of modeling the contact surfaces between the embedded element and the parts being welded were noted, which were described on the basis of physical concept of thermal conductivity of the gap. Known are three-dimensional models of thermal processes in welding with embedded element of PEEK- and PEIbased polymer composite materials with preliminary preparation of the embedded element by covering it with film from the main polymer material [2].

Similar work was performed for cases of welding PEEK- and PEI-based multilayer glass-fibre composites using metal mesh [3, 4]. Models of dynamic distribution of temperature over the embedded element surface were used for determination of admissible and critical parameters of the welding process. The criteria for parameter optimization were physical characteristics of matrix polymer, namely temperature of melting and destruction, and modeling adequacy was compared with experimental data. Mathematical modeling results were used to determine the regions («windows») of optimum values of the main parameters of thermistor welding (specific power and heating duration) for embedded elements from metal mesh of different typesizes [5].

Ukraine is one of the few countries in the world with its own aerospace industry. However, investigations on welding of high-tech polymer materials using embedded element have not been performed here up to now. In this study, domestic experimental work and modeling of the process of welding with embedded element of PEI-based heat-resistant polymer material ZX-410 of ZEDEX trade mark were conducted for the first time. Unlike foreign studies $[1,3]$, in this work the influence of thermal energy released by the embedded element during welding on the extent of residual plastic deformation was additionally deter- mined and potential zones of the start of welded joint fracture were predicted, when modeling the process of thermistor welding. In the experimental part of the work, the main thermophysical parameters of the used polymer material and their behaviour, depending on temperature, were studied. The obtained data were further used as a basis for model development. To assess the adequacy of modeling the thermal processes, a series of experiments was performed on welding overlap joints with synchronous measurement of temperature in several points directly inside the welded joint and recording the thermal fields by filming in infrared spectrum.

Experimental. Materials. Sheet polymer material ZX-410 based on high-tech heat-resistant PEI was used in the work. The main thermomechanical characteristics of this material at the temperature of $20{ }^{\circ} \mathrm{C}$ claimed by the manufacturer, are as follows: density $\rho-1.33 \mathrm{~kg} / \mathrm{dm}^{3}$; fracture strength $\sigma_{\mathrm{t}}-$ $101 \mathrm{MPa}$; relative elongation at fracture $\delta-25 \%$; Young's modulus $E-3368 \mathrm{MPa}$; maximum working temperature $T_{\text {max }}-180{ }^{\circ} \mathrm{C}$; vitrification temperature $T_{\mathrm{gl}}-210^{\circ} \mathrm{C}$; melting temperature $T_{\mathrm{m}}-320^{\circ} \mathrm{C}$; coefficient of thermal expansion $\alpha-4.0 \cdot 10^{-5} 1 / \mathrm{K}$ (at up to $0{ }^{\circ} \mathrm{C}$ temperature) and $5.8 \cdot 10^{-5} 1 / \mathrm{K}$ (at $0-50$ ${ }^{\circ} \mathrm{C}$ temperature); coefficient of thermal conductivity $\lambda-0.25 \mathrm{~W} /(\mathrm{m} \cdot \mathrm{K})$; coefficient of heat capacity $c_{p}-$ $1.85 \mathrm{~kJ} /(\mathrm{kg} / \mathrm{K})$

At modeling thermal processes it is important to take into account the considerable dependence of the coefficient of thermal conductivity $\lambda$ and coefficient of heat capacity $c_{\mathrm{p}}$ of polymer material on temperature values. Temperature dependencies of thermophysical coefficients of ZX-410 material were determined experimentally.

Coefficient of thermal conductivity $\lambda$ at different temperatures was determined using an all-purpose dynamic calorimeter IT-400, in which measurements are performed with monotonic linear temperature rise. In order to take measurements, samples were made from the studied material in the form of discs of $15 \mathrm{~mm}$ diameter and $1.2 \mathrm{~mm}$ height, which were conditioned for a $24 \mathrm{~h}$ day at the temperature of $22{ }^{\circ} \mathrm{C}$ directly before taking the measurements. Because of the technical limitations of the instrument, $\lambda$ coefficient was measured in the temperature range of $22-250{ }^{\circ} \mathrm{C}$ every $5^{\circ} \mathrm{C}$.

Derived temperature dependence of $\lambda$ is given in Figure 2. One can see that an initial abrupt lowering of the coefficient of thermal conductivity with temperature rise, and subsequent stabilization of its values are observed. When the temperature of $100{ }^{\circ} \mathrm{C}$ has been reached, monotonic growth of $\lambda$ coefficient begins right up to the temperature of material vitrification (approximately $217^{\circ} \mathrm{C}$ [6]), where extremum 


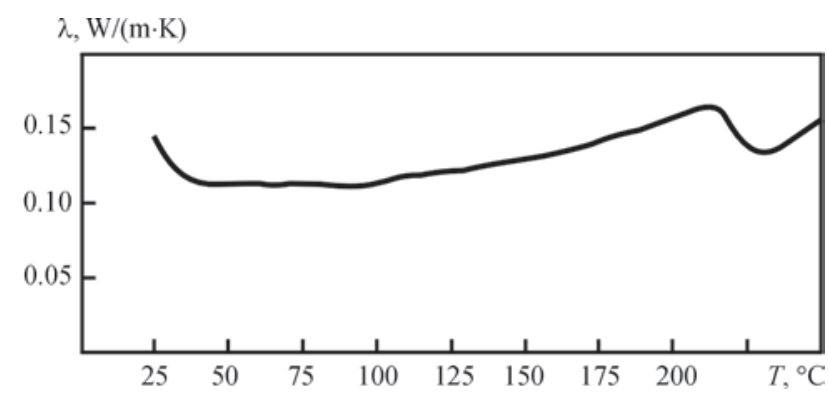

Figure 2. Dependence of the coefficient of thermal conductivity $\lambda$ of polymer material ZX-410 on temperature

of the graph, lowering and subsequent increase of $\lambda$ values are observed.

Temperature dependence of the coefficient of thermal conductivity $c_{\mathrm{p}}$ of ZX-410 material was studied by the method of differential scanning calorimetry (DSC) [7] in DSC Q2000 instrument of TA Instruments Company (USA) in inert atmosphere of higher purity gaseous nitrogen. Measurements were conducted in the temperature range of $40-450{ }^{\circ} \mathrm{C}$ at a constant heating rate of $20^{\circ} \mathrm{C} / \mathrm{min}$. Before taking measurements, samples of $10 \mathrm{mg}$ weight were conditioned for a $24 \mathrm{~h}$ day at the temperature of $22{ }^{\circ} \mathrm{C}$ and weighed in electronic scales ANG50C with the accuracy of $0.0001 \mathrm{~g}$.

Derived temperature dependence of the coefficient of heat capacity is given in Figure 3. Two peaks appear on the curve at $T=220$ and $326{ }^{\circ} \mathrm{C}$. The peak at $T=220^{\circ} \mathrm{C}$ is attributed to such a thermal process as devitrification of PEI amorphous phase, and at $T=$ $=326^{\circ} \mathrm{C}$ it is attributed to melting of its crystalline phase. Measured value of vetrification temperature practically coincides with the value derived at determination of the coefficient of thermal conductivity (Figure 2). At devitrification, a local maximum of the coefficient of heat capacity forms, which in this case is associated with enthalpy restoration [8], when the polymer density rises, and its free volume is reduced [9]. The process of the crystalline phase melting with energy $\Delta H=96 \mathrm{~J} / \mathrm{g}$ is of a two-stage nature. The premelting process in the temperature range

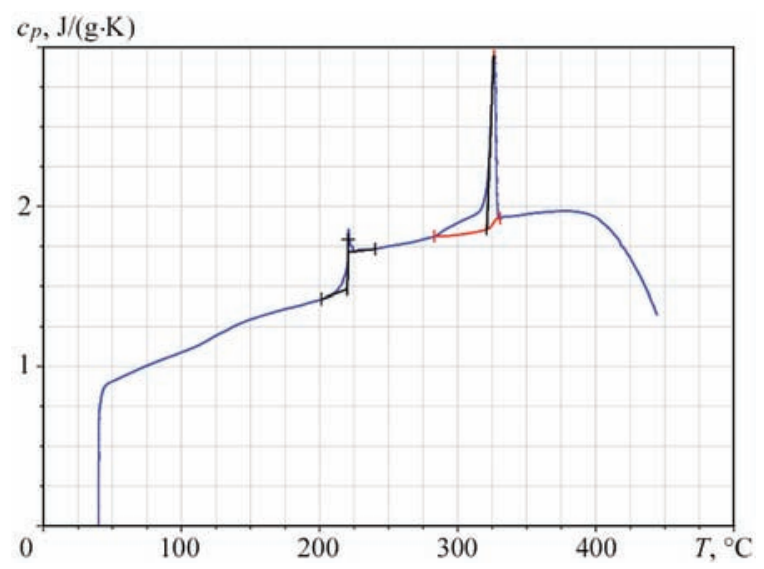

Figure 3. Dependence of the coefficient of heat capacity $c_{\mathrm{p}}$ of polymer material ZX-410 on temperature of $280-320^{\circ} \mathrm{C}$ is indicative of presence of a certain interphase connection and crystallites of a complex structure in the polymer.

Experimental setup for welding with embedded element. Experimental set up was assembled in keeping with the schematic given in Figure 1 . Sheet samples of ZX-410 polymer material of $25 \times 100 \mathrm{~mm}$ size of thickness from $8 \mathrm{~mm}$ were welded with an overlap. The embedded element used was metal woven mesh from high-alloyed 12Kh18N9T steel, manufactured in keeping with the requirements of GOST 3826 and having the following parameters: wire diameter of $0.25 \mathrm{~mm}$, pass-through cell size of $0.8 \mathrm{~mm}$, material specific resistance of $0.7-0.8 \mathrm{Ohm} \cdot \mathrm{mm}^{2} / \mathrm{m}$. Embedded element dimensions were $25 \times 60 \mathrm{~mm}$, those of the welded joint were $25 \times 25 \mathrm{~mm}$. Power was supplied from a source of alternating current of $50 \mathrm{~Hz}$ mains frequency with adjustable ranges of voltage of $1-50 \mathrm{~V}$ and current of 5-45 A. Working pressure in welding was $0.2 \mathrm{MPa}$.

Temperature measurement. Temperature measurement during welding with embedded element was performed in three characteristic points inside the welded joint (Figure 4). Point 1 is designed for measurement of embedded element temperature and it is located in immediate vicinity of its longitudinal wire. Point 2 is located in the mesh cell center, and point 3 is in the polymer above the embedded element.

TKhK thermocouples (type $L, 0.5 \mathrm{~mm}$ diameter) were used for temperature measurement. Fixation and recording of signals of three thermocouples were performed using OVEN UKT-38 multichannel instrument connected to a computer. Temperature field of visible surfaces of the welded joint was also recorded using DT-918 infrared imager.

Mechanical testing. In the world practice, ASTM D1002-10 standard developed for adhesive joints is usually used for mechanical testing of overlap joints of sheet polymer materials, in view of the absence of a special standard. In keeping with it, lap shear strength (LSS) is determined for welded joints. A similar GOST 14759 was also developed for determination of adhesive joint strength.

In this work, mechanical tensile testing of overlap welds was conducted in keeping with the require-

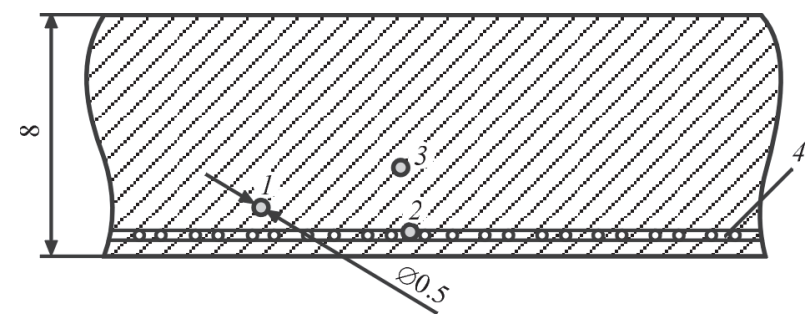

Figure 4. Temperature measurement points during welding with embedded element (1-3) — longitudinal wires of embedded element mesh 
ments of the above standards in rupture machine FP-10 (Germany) with the speed of mobile clamp movement of $25 \mathrm{~mm} / \mathrm{min}$. Both complete welded joints and samples cut out of them in the form of longitudinal strips were tested.

Mathematical model. Different kinds of software, such as COMSOL Multiphysics, ANSYS and Abaqus FEA can be used for modeling thermomechanical problems of heat distribution, development of strains and stresses. Abaqus FEA was used in this work. Abaqus software package was initially oriented to solution of the most complex and important problems, allowing for all kinds of non-linearity, as well as performance of multidisciplinary static and dynamic analysis within one algorithm. Such a concept positively distinguishes Abaqus from other programs of this level (ANSYS software package uses third-party program LS-DYNA for analysis of strongly nonlinear and fast processes). It allows using Abaqus to solve multipurpose tasks within a common approach, combining the advantages of explicit and implicit FEA procedures and their combination.

When plotting the model, the embedded heating element from woven metal mesh was simplifiedly modeled as a homogeneous and isotropic metal strip. Embedded element heating, when electric current was passed through it, was modeled as volume heat evolution, equivalent to applied electric power. The criterion for parameters optimization was melting temperature and destruction temperature of ZX-410 polymer material. A two-dimensional model of the joint was used, which is given in Figure 5. Dimensions of welded samples were equal to $8 \times 25 \times 50 \mathrm{~mm}$, with working pressure of $0.2 \mathrm{MPa}$. In keeping with experimental data, heating time was equal to $100 \mathrm{~s}$.

Calculations were performed using Abacus/Standard submodule - one of the two main solvers of Abaqus software package, using the implicit formulation of finite element method, which is described below.

The following conditions were taken as boundary ones: a limitation was applied to the base of sample 2 (Figure 5), which prevented its displacement in the direction of $X$ and $Y$ axes, as well as rotation around $Z$ axis; surface heat flow was applied to sample edges, which characterized heat removal into the ambient medium (coefficient of thermal conductivity of air).

Results and their discussion. Process of welding with embedded element proceeded in the stationary mode, without molten metal displacement. Heat transfer from the heating embedded element occurs mainly due to thermal conductivity of polymer material. Therefore, in the used two-dimensional model solution of the stationary equation of heat conductiv-

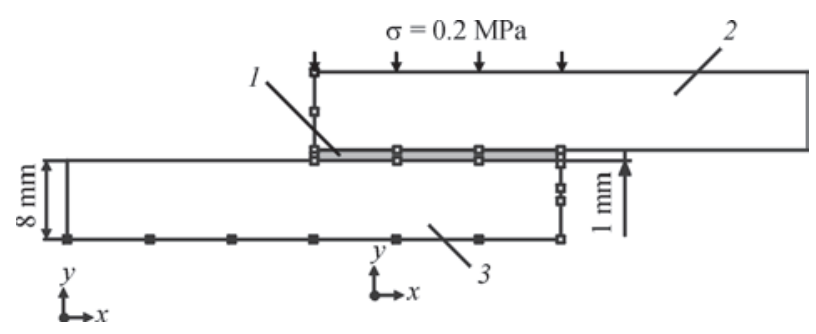

Figure 5. Schematic of a two-dimensional model of overlap joint in welding with embedded element: 1 - embedded element; 2 sample $1 ; 3$ - sample 2

ity was performed by finite element method. Here, experimentally derived temperature dependencies of thermophysical coefficients of the studied material were used (Figures 2, 3).

Heat distribution from the heating element into the polymer matrix follows the Fourier thermal conductivity law:

$$
q=-k A \frac{\partial T}{\partial x},
$$

where $q$ is the heat flow; $A$ is the area over which the heat flow is distributed; $k$ is the material thermal conductivity; $\partial T / \partial x$ is the temperature gradient in the heat flow direction.

Determinant equation of equilibrium for finite element model has the following form:

$$
P^{N}-I^{N}=M^{N M} \ddot{u}^{M},
$$

where $P^{N}$ is the vector of external force; $I^{N}$ is the vector of internal force; $M^{N M} \ddot{u} M$ is the vector of the force of inertia of the material.

Internal forces are determined by equations given below:

$$
I^{N}=\int_{V} \beta^{N} / \sigma V,
$$

where $V$ is the model volume; $\sigma(x)$ are the stresses in point $x ; \beta^{N}(x)$ is the extent of deformation - displacement, which is determined in interpolation assumptions in element $\dot{\varepsilon}=\beta^{N} \dot{u}^{n}$.

Dynamic equilibrium suggests that the forces of d'Alembert are considerable:

$$
M_{N M} \ddot{u}^{M} \text {, }
$$

where $M^{N M}$ is the mass matrix; $\ddot{u}^{M}$ is the vector of acceleration.

Static equilibrium means that the forces of d'Alembert change slowly, are constant in time, and $M^{N M} \ddot{u}^{M} \approx 0$.

Abaqus/Standard uses the Newton method for static equilibrium solution. It is assumed that this is a supposed solution at iteration $i, u_{(i)}^{N}$, so that the Taylor series will have the following form:

$$
P^{N}-I^{N}+\left(\frac{\partial P^{N}}{\partial u^{M}}-\frac{\partial I^{N}}{\partial u^{M}}\right) c^{M}+\ldots=0,
$$

which can be written as

$$
P^{N}-I^{N}=K^{N M} C^{M},
$$




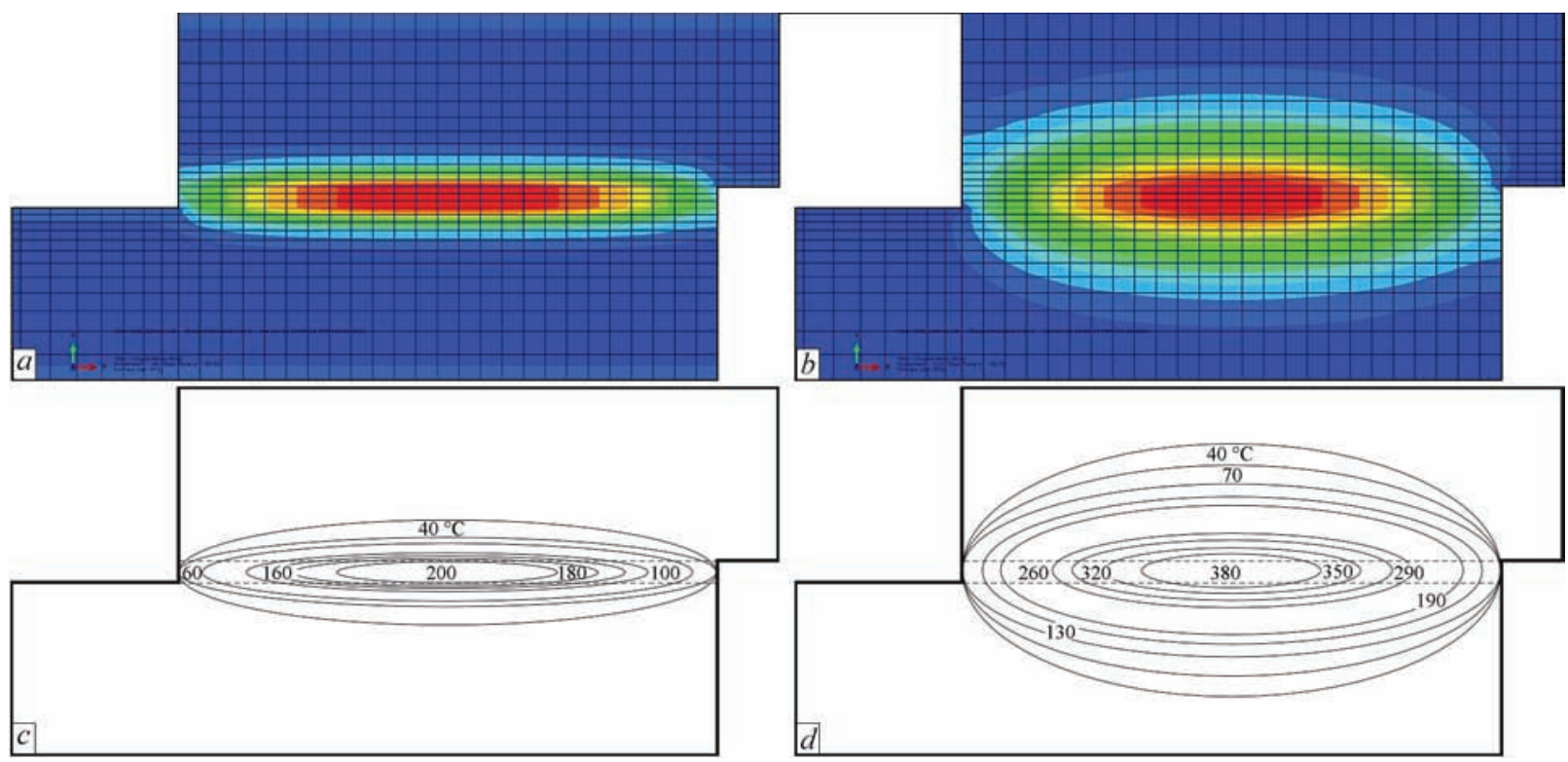

Figure 6. Temperature field at the initial $(a)$ and final $(b)$ moments of time of the welding process and their isotherms $(c, d)$, respectively where $K^{N M}=\frac{\partial I^{N}}{\partial u^{M}}-\frac{\partial P^{N}}{\partial u^{M}}$ is the system rigidity, or Jacobian matrix; $c^{M}$ is the correction to the solution of degrees of freedom $N$.

Increment $\Delta u$ is corrected according to equation

$$
\Delta u_{(i+1)}^{N}=\Delta u_{(i)}^{N}+c_{(i)}^{N} \text {, }
$$

Iterations are repeated at each increment until convergence has been reached, which means that:

- contact conditions are satisfied in each point;

- equilibrium has been reached in each point;

- equilibrium of moments has been reached in each point.

Exact implementation of the Newton method includes non-symmetrical Jacobian matrix, as it is shown in the presented matrix of connected equations:

$$
\left(\begin{array}{cc}
K_{u u} & K_{u \theta} \\
K_{u \theta} & K_{\theta \theta}
\end{array}\right)\left\{\begin{array}{c}
\Delta u \\
\Delta \theta
\end{array}\right\}=\left\{\begin{array}{c}
R_{u} \\
R_{\theta}
\end{array}\right\},
$$

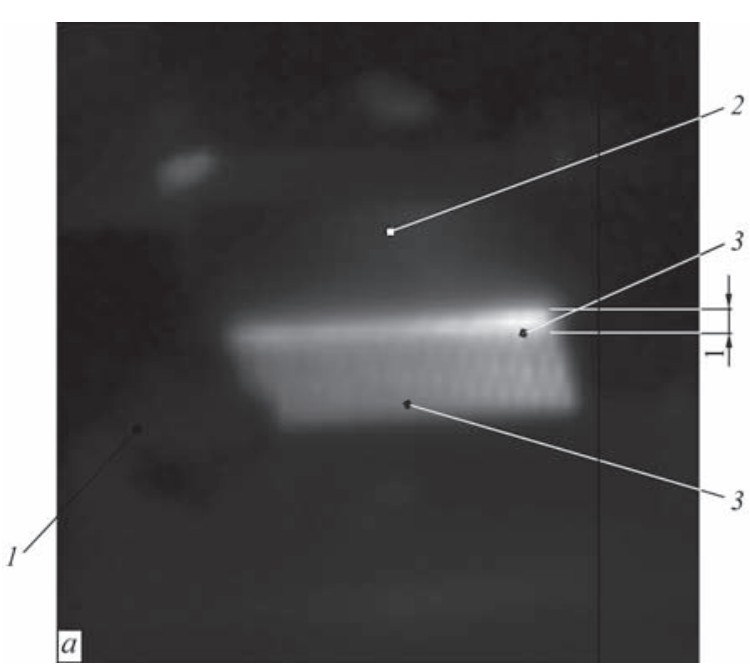

where $\Delta u, \Delta \theta$ are the corrections for incremental movement and temperature; $K_{i j}$ are the submatrices of bound Jacobian matrix; $R_{u}$ and $R_{\theta}$ are the mechanical and thermal nullity vector, respectively.

Main equation of heat transfer in the matrix form can be written as

$$
[C]\{\dot{T}\}+[K]\{T\}=\{Q\},
$$

where $[C]$ is the matrix of specific heat; $\{\dot{T}\}$ is the time derivative of temperature; $[K]$ is the matrix of effective thermal conductivity; $\{T\}$ is the vector of nodal temperatures; $\{Q\}$ is the vector of effective heat flow in the node.

For stationary thermal analysis, when temperature is independent on time, equation of heat transfer is simplified to the following form:

$$
[K]\{T\}=\{Q\} .
$$

It should be noted that solution of thermal conductivity equation was performed sequentially in different moments of time. At the initial stage of heating

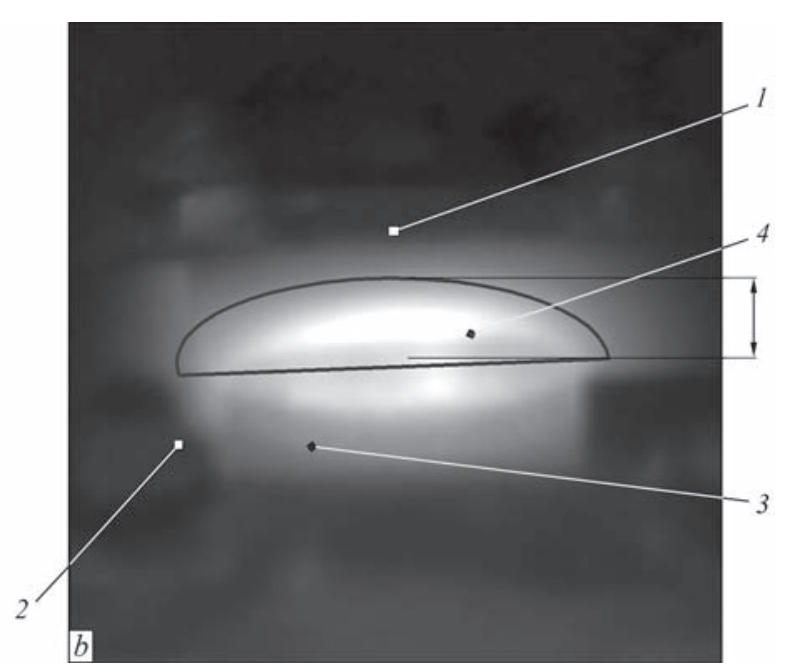

Figure 7. Successive illustrations of the process of welding with embedded element: $a-12 \mathrm{~s}\left(T_{\max }=160{ }^{\circ} \mathrm{C}\right) ; b-100 \mathrm{~s}\left(T_{\max }>\right.$ $>400^{\circ} \mathrm{C}$ ); 1 - sample 2; 2 - sample $1 ; 3$ - flash; 4 - embedded element 


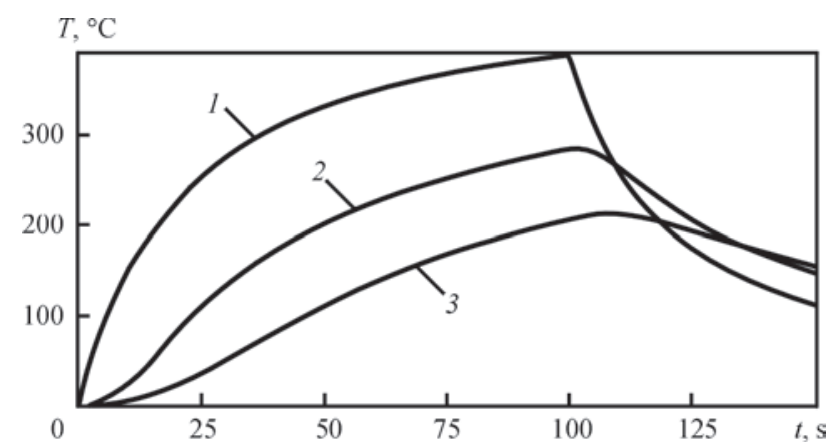

Figure 8. Results of modeling temperature variation in characteristic points of the welded joints: 1 - temperature on embedded element surface; 2 - temperature at $0.5 \mathrm{~mm}$ distance from embedded element surface; 3 - temperature in polymer layers removed from embedded element plane

the temperature is rather uniformly distributed by the width of the heating element (Figure 6, $a, c$ ). Non-uniformity of temperature distribution is increased by the end of the process of welded joint heating (Figure 6, $b, c)$, the central regions being heated more. This is associated with more intensive heat removal along the embedded element edges. After completion of the process of weld cooling, the overall temperature level in the welding zone is reduced. However, the temperature field takes a spherical shape with a maximum in the center.

To check the adequacy of the results obtained at modeling of thermal processes, successive recording of the change of the temperature field of welded joint side surface during welding was performed in infrared range using a thermal imager. One can see in infrared photos that with the start of the welding process (Figure 7, $a$ ) the free zone of the embedded element is predominantly heated with gradual surface melting of the polymer material at the joint edge. Futheron, with heating of the embedded element, the temperature maximum is concentrated in the welded joint central part that corresponds to the data obtained in mathematical modeling. Under the impact of pressing force, flash forms in this part of the welded joint. At the final stage of heating and after cooling (Fig-

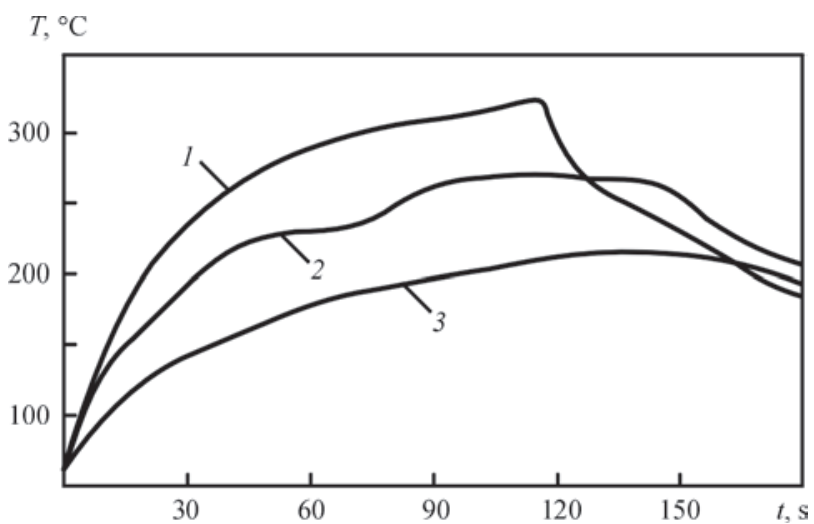

Figure 9. Results of experimental variation of temperature in characteristic points of the welded joint (for description of 1-3 see Figure 8)

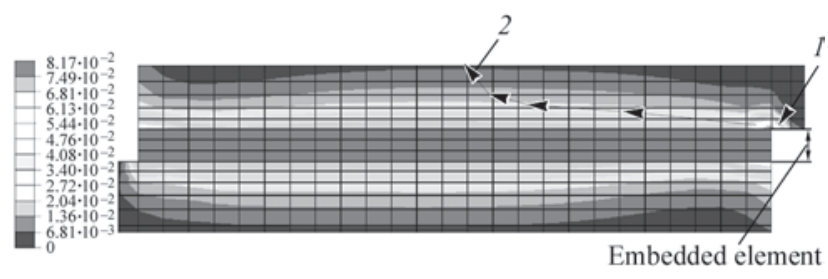

Figure 10. Field of equivalent plastic deformations in overlap welded joint: 1 - zone with maximum value of residual plastic deformation; 2 - fracture path

ure $7, b$ ) the thermal field takes an ellipsoidal shape with a maximum in the center. Obtained experimental data demonstrate the thermal field on the side surface of the welded joint that is why they differ somewhat from the data of the proposed calculation model, which considers the thermal field inside the welded joint.

Modeling results were used to plot the graphs of temperature variation (Figure 8) during welding with embedded element - mesh in characteristic points of the welded joint, shown in Figure 4.

Graphs derived experimentally at direct measurement of temperature with thermocouples during welding with embedded element at heating duration of 120 s, are given in Figure 9. It should be also noted that despite the difference in the duration of the heating process, the graphs are analogous and are of a similar shape that confirms the effectiveness of modeling and similarity of thermal processes running in the welded joint under different welding conditions.

Both in the calculation and experimental graphs, polymer material temperature in the mesh plane (point 2) rises gradually as heat propagates from heated longitudinal wires of the mesh from both sides towards the center. As during modeling a simplified representation of the heater in the form of a homogeneous and isotropic metal strip was used instead of the mesh, model graph of point 2 corresponds to $0.5 \mathrm{~mm}$ distance from the heater surface. Therefore, experimental temperature in this point is somewhat higher, compared to the data obtained during modeling.

Temperature in polymer layers removed from embedded element plane (point 3) rises slowly, compared to polymer matrix adjacent to the embedded element that is attributable to low thermal conductiv-

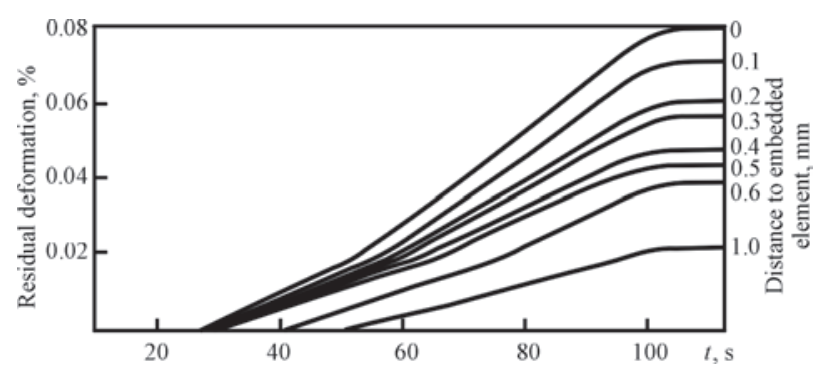

Figure 11. Change of the magnitude of plastic deformation of the polymer in time at different distances from embedded element surface 


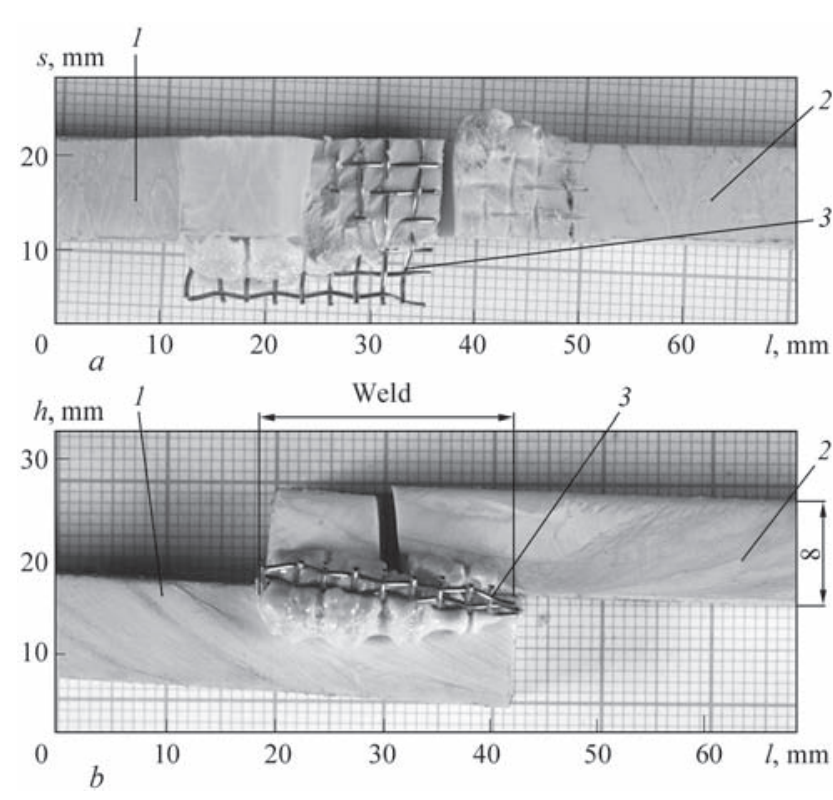

Figure 12. Nature of fracture of a sample ( $l$ - length, $h$ - height; $s$ - width), cut out of equivalent overlap joint of ZX-410 polymer material: $a$ - top view; $b$ - side view $(1-$ sample 2 ; 2 - sample $1 ; 3$ - embedded element)

ity of the material. Material melting point is achieved here practically at the moment of switching the power source off. However, because of the inertia of heat propagation process, material heating in this zone goes on for some more time. This promotes more uniform molten state of the base material and further normal formation of the welded joint. The curve of temperature change in point 3 derived as a result of modeling, confirms the obtained experimental results.

Modeling of residual plastic deformations, due to heat evolution during welding, was also performed in this work. Modeling results are shown in Figure 10.

At the initial heating stage plastic deformation is practically absent, its development is recorded only on welded joint edges, where the embedded element contacts the base polymer material. Further on plastic deformations uniformly propagate along the embedded element plane. The nature of variation of the magnitude of plastic deformation in time at different distances from the embedded element is given in Figure 11. One can see that the largest values of plastic deformation are achieved at the welded joint edge (Figure 10, pos. 1).

Mechanical testing of overlap welded joints, produced in optimum modes, shows that their strength is equivalent to that of the base material (Figure 12,a), where fracture ran not through the welded joint but through the base material. Fracture of overlap joint at shear testing (Figure 12) occurs along a trajectory, similar to the line of largest values of plastic deformation, derived at modeling (Figure 10, $d$ ).

\section{Conclusions}

The work presents a two-dimensional model of development of temperature fields in welding with embedded element of sheet polymer material ZX-410, allowing for its temperature-dependent thermophysical parameters, which also allows for development of residual plastic deformations at heating in the welding zone. Modeling correctness is confirmed by experimental temperature measurements during welding using thermocouples and thermal imager. It is shown that sample fracture at shearing load starts in the region of the greatest plastic deformations and propagates in the direction towards the weld central region.

Thus, proceeding from the results of modeling it allows to prediction of possible regions with higher risk of lack-of-penetration formation along the embedded element edges that is associated with non-uniform temperature distribution in the welding zone. Such lacks-of-penetration should be compensated by the respective increase of overlap weld area.

The developed models can be later used for prediction of optimum heating modes in welding with embedded element, in our case - metal mesh.

1. Jakobsen, T.B., Don, R.C., Gillespie, Jr. J.W. (1989) Two-dimensional thermal analysis of resistance welded thermoplastic composites. Polymer Eng. and Sci., 29(23), 1722-1729.

2. Ageorges, C., Ye, L., Mai, Y.-W. et al. (1998) Characteristics of resistance welding of lap shear coupons. Pt 1. Heat transfer. Composites Part A, 29, 899-909.

3. Colac, Z.S., Sonmez, F.O., Kalenderoglu, V. (2002) Process modeling and optimization of resistance welding for thermoplastic composites. J. of Composite Materials, 36(6), 721-744.

4. Yousefpour, A., Simard, M., Octeau, M.-A. et al. (2005) Process optimization of resistance-welded thermoplastic composites using metal mesh heating elements. In: Proc. of SAMPE (USA, Long Beach).

5. Stavrov, D., Nino, G.F., Bersee, H.E.N. et al. (2007) Optimization tool for welding of thermoplastic composites. In: Proc. of $16^{\text {th }}$ Int. Conf. on Composite Materials (Japan, Kyoto, Fellow Doshisha University).

6. Ibeh, C.C. (2011) Thermoplastic materials: Properties, manufacturing methods and applications. CRC Press, Boca Raton, Fl.

7. Menczel, J.D., Prime, R.B. (2009) Thermal analysis of polymers: Fundamentals and applications. John Wiley \& Sons, Inc., Hoboken, New Jersey, USA.

8. Simon, S.L. (1997) Enthalpy recovery of poly(ether imide): Experiment and model calculations incorporating thermal gradients. Macromolecules, 30(14), 4056-4063.

9. (2007) Principles and applications of thermal analysis. Ed. by P. Gabbott. Wiley, Blackwell Publishing Ltd.

Received 24.07.2017 


\title{
EFFICIENCY OF APPLICATION OF SUBSTRUCTURE STRENGTHENED TUBES ON HEATING SURFACES OF SUPERCRITICAL BOILER BLOCKS
}

\author{
A.V. GRUZEVICH \\ Institute of Magnetism under NAS and MES of Ukraine \\ 36-b Acad. Vernadskoho Blvd., 03142, Kiev, Ukraine. E-mail: trip.imag@gmail.com
}

\begin{abstract}
The results are presented on investigation of mechanical-thermal treatment of the tubes as an effective method to increase life and operation reliability of power equipment. General experience of commercial application of the tubes of mechanical-thermal strengthened steel 12Kh1MF on the heating surfaces of supercritical boilers is presented. Possibility and efficiency of application of this method is shown by the example of Trypolie HPP capacities. 11 Ref., 7 Tables, 7 Figures.
\end{abstract}

Keywords: mechanical-thermal treatment, steel strengthening, equipment life, substructure, high-temperature strength, heat resistance

Increase of operation reliability of the heating surfaces is one of the main conditions for reliable operation of the whole boiler unit.

Operation conditions of the heating surfaces in boilers of high capacity power generating units differ by corrosion activity of the medium at operating temperatures, effect of combustion products and other harmful factors on tube surface that results in rapid wear out. All this determines increased requirements to reliability and life of equipment operation.

One of the main reasons of emergency shutdown of power generating units of large unit capacity is damage of the tubes of boiler heating surfaces. Thus, breakdown of the tubes of superheaters, related with overheating of metal and accelerated development of creep or typical damage of waterwall system due to corrosion-thermal fatigue and gas corrosion, takes place already after 10-15 thou h of operation.

A relevant problem of reliable operation of the heating surfaces of boilers, supercritical pressure (SCP) blocks is studied in the work from point of view of application of tubes from 12Kh1MF steel, strengthened using mechanical-thermal treatment (MTT) method.

MTT method is one of the most effective modern methods of substructure strengthening of pearlite class steels. Idea of the method lies in deformation of metal after standard [1] heat treatment (normalizing (N) and tempering (T)) for small reduction above a yield plane and further polygonizational annealing in precrystallization temperature interval.

Metallurgical industry of Ukraine has produced MTT strengthened tubes of 32-42×4-6 mm diameter from steel $12 \mathrm{Kh} 1 \mathrm{MF}$ on TU 14-3-1072 specification [2]. This work considers the results of investigation of MTT tubes as a method to increase life and operation reliability of power generating units. Possibility and efficiency of application of this method for increase of operation life of power generating units is shown by the example of Trypolie HPP capacities.

In accordance with accepted technology the tubes of preformed size on [1] in a condition after $\mathrm{N}$ and $\mathrm{T}$ are subjected to deformation by $10-15 \%$ and further annealing at $700-720{ }^{\circ} \mathrm{C}$ temperature with $1.5 \mathrm{~h}$ holding.

Additional treatment does not make changes in the relationship of main structural constituents (bainite, ferrite, carbide phase), but results in change of fine dislocation structure of steel. Deformation provides introduction of additional amount of dislocations in a steel lattice and further annealing promotes their redistribution, partial annihilation and development of heat-resistant substructure. At the same time, there is grain fragmentation, ordering of submicrodefects with formation of dislocation walls and formation of polygonal substructure that generates strengthening effect $[3,4]$.

Data of metallographic investigations of $12 \mathrm{Kh} 1 \mathrm{MF}$ steel tubes, carried out on micro- and substructural levels, verify these concepts [4]. 


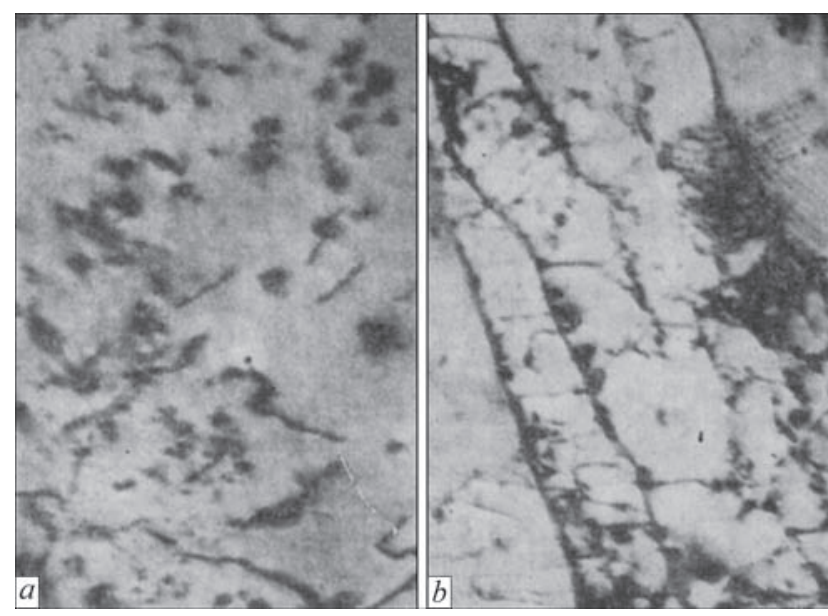

Figure 1. Fine structure $(\times 30000)$ of metal of $12 \mathrm{Kh} 1 \mathrm{MF}$ steel tubes: $a$ - after normalizing with tempering; $b$ - after MTT

A steel microstructure after MTT virtually does not change. At the same time, electron-microscopy analysis has detected significant changes in a material substructure. Thus, an unsystematic distribution of dislocations in the volume of inherent grains is typical for the initial state of steel after $\mathrm{N}$ and $\mathrm{T}$. Clearly expressed polygonization of the structure with formation of subboundaries and dislocation walls (Figure 1) [4] is observed in steel after MTT.

Comparison of short-term mechanical characteristics of steel after standard heat treatment $(\mathrm{N}$ and T) and MTT, at normal and elevated temperatures in $300-570^{\circ} \mathrm{C}$ interval, showed stable strengthening of tube metal after MTT at sufficient level of ductility (Table 1) [3, 4]. Thus, strengthening by ultimate strength makes $19 \%$ and that by yield strength at normal temperature is $27.5 \%$. At elevated temperatures strengthening by ultimate strength, on average, makes $8.4 \%$ and that by yield strength is $25.5 \%$. A value of relative elongation in the researched temperature interval is $17-23 \%$.

It is important to note a higher level of strengthening of MTT steel by yield strength that is provided
Table 2. High-temperature strength properties of metal of $12 \mathrm{Kh} 1 \mathrm{MF}$ steel tubes at $540{ }^{\circ} \mathrm{C}$ after standard heat treatment ( $\mathrm{N}$ and T) and MTT [5]

\begin{tabular}{|c|c|c|c|c|c|}
\hline \multirow{2}{*}{$\begin{array}{c}\text { Loading } \\
\text { in testing, } \\
\text { MPa }\end{array}$} & \multicolumn{2}{|c|}{$\mathrm{N}$ and $\mathrm{T}$} & \multicolumn{3}{c|}{ MTT } \\
\cline { 2 - 6 } & $\tau_{\text {fail, }}, \mathrm{h}$ & $\delta, \%$ & $\tau_{\text {fail, }}, \mathrm{h}$ & $\begin{array}{c}\text { Increase } \\
\tau_{\text {fail }}, \mathrm{h} \\
\text { (times) }\end{array}$ & $\delta, \%$ \\
\hline 160 & 2003 & 12.0 & 8352 & 4.2 & 13.7 \\
\hline 180 & 950 & 25.0 & 2727 & 2.9 & 9.0 \\
\hline 200 & 425 & 38.0 & 1643 & 3.9 & 13.0 \\
\hline 220 & 109 & 22.5 & 913 & 8.4 & 10.0 \\
\hline 240 & 51 & 23.5 & 270 & 5.3 & 13.0 \\
\hline
\end{tabular}

by stability of developed strengthened state in process of long-term operation of the tubes under the stresses below the yield plane, i.e. at normal working stresses.

High-temperature strength properties of metal of tubes from strengthened steel $12 \mathrm{Kh} 1 \mathrm{MF}$ were determined by the results of creep-rupture tests and long-term rupture resistance at $540{ }^{\circ} \mathrm{C}$ and stresses in 160-240 MPa range. Samples of standard [3] and after MTT [2] tubes (Table 2) [5] were tested under the same conditions. The results of tests were used to evaluate the increase of creep-rupture life of MTT samples in relation to standard ones.

Data given in Table 2 indicate the increase (on average 5 times) of long-term rupture resistance of MTT strengthened steel even at static stresses, which 2-3 times exceeds the nominal service operating stresses of power generating units.

Thus, complex examination of structure, substructure, short-term and long-term mechanical properties of the MTT strengthened heat-resistant tube steel 12Kh1MF showed a perspective of application of this method to increase the reliability of tubes of the heating surfaces of high- and superhigh-pressure boilers.

The work provides the results of long-term commercial operation of the substructure strengthened tubes of steel 12Kh1MF on low pressure convection

Table 1. Mechanical properties of metal of 12Kh1MF steel tubes after standard heat treatment (N and T) and MTT

\begin{tabular}{|c|c|c|c|c|c|c|c|c|}
\hline \multirow{2}{*}{$T,{ }^{\circ} \mathrm{C}$} & \multicolumn{3}{|c|}{$\mathrm{N}$ and $\mathrm{T}$} & \multicolumn{5}{|c|}{ MTT } \\
\hline & $\sigma_{\mathrm{t}}, \mathrm{MPa}$ & $\sigma_{y}, \mathrm{MPa}$ & $\delta, \%$ & $\sigma_{\mathrm{t}}, \mathrm{MPa}$ & $\%_{\text {str }}$ & $\sigma_{y}, \mathrm{MPa}$ & $\%_{\text {str }}$ & $\delta, \%$ \\
\hline \multirow{3}{*}{20} & 500 & 400 & 27.8 & 595 & 19.0 & 510 & 27.5 & 23.0 \\
\hline & \multicolumn{3}{|c|}{ Requirements of TU 14-3-460 [3], not less } & \multicolumn{5}{|c|}{ Requirements of TU 14-3-1072 [4], not less } \\
\hline & $450-650$ & 280 & 21 & \multicolumn{2}{|c|}{$490-637$} & \multicolumn{2}{|c|}{372} & 21 \\
\hline 300 & 510 & 410 & 19.0 & 570 & 12.0 & 500 & 22.0 & 17.0 \\
\hline 400 & 545 & 440 & 21.0 & 590 & 8.3 & 520 & 18.2 & 17.0 \\
\hline 450 & 490 & 360 & 26.0 & 530 & 8.2 & 450 & 29.0 & 20.0 \\
\hline 540 & 420 & 310 & 28.0 & 455 & 8.3 & 424 & 36.8 & 19.0 \\
\hline 550 & 407 & 345 & 26.3 & 444 & 9.1 & 404 & 17.1 & 22.3 \\
\hline 570 & 374 & 285 & 25.0 & 390 & 4.3 & 370 & 29.8 & 20.0 \\
\hline
\end{tabular}


superheater (l/p CSH) of TPP-210 A boiler and panels of lower radiant section (LRS) of TGMP-314A boilers of 300 MW blocks.

Long-term commercial operation of MTT tubes on 1/p CSH of TPP-201A PC-fired boilers of 300 MW block. An experience of application of substructure strengthened tubes of steel $12 \mathrm{Kh} 1 \mathrm{MF}$ on the heating surfaces of power boilers has own prehistory.

For the first time MTT strengthened tubes in form of the straight test inserts were installed in an exhaust stage of high-pressure superheater h/p CSH of BKZ 210-140 PT boiler with operating steam parameters, namely temperature $550{ }^{\circ} \mathrm{C}$ and pressure $14.0 \mathrm{MPa}$ [3]. In accordance with the design the boiler's $\mathrm{h} / \mathrm{p} \mathrm{CSH}$ was manufactured of austenite steel 12Kh18N12T with tube dimension-type $32 \times 5.0 \mathrm{~mm}$.

The experiment conditions were knowingly toughened. The inserts with thinned tube wall of $32 \times 4.0 \mathrm{~mm}$ dimension-type were installed in $\mathrm{h} / \mathrm{p}$ $\mathrm{CSH}$ together with the test inserts of nominal dimension-type.

MTT strengthened inserts of steel 12Kh1MF run on the superheater for $51382 \mathrm{~h}$ without damages and were disassembled during repair and reconstruction of the equipment.

Systematic inspections of MTT tube state were carried out in course of test inserts operation. Periodic examinations, measurement control and results of investigation of the reference cutoffs showed metal in a good state.

Investigation of stability of created strengthened state in process of long-term operation of the test inserts showed that dislocation subboundaries, dislocation walls and fragmentation of structure are preserved (Figure 2). At that, some widening of metal subboundaries takes due to inflow of the dislocations and precipitations along the boundaries of carbide phase disperse particles. It should be noted that decrease of wall thickness up to $4 \mathrm{~mm}$ does not activate these processes that can be explained by lower temperature gradients on the thinned tube section.

At the same time, there is a natural process of differentiation of bainite and ferrite-pearlite microstructure of steel due to aging with formation of areas of ferrite-carbide mixture, precipitations of detached carbides and their coagulation. However, preservation of the fragmented substructure provides stability of properties and inhibition of steel creep rate.

The maximum registered residual deformation of MTT tube inserts after 51 thou h of operation did not exceed $0.63 \%$.

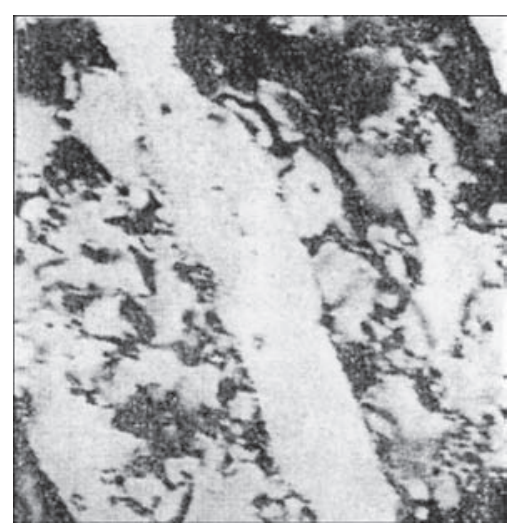

Figure 2. Fine structure $(\times 30000)$ of MTT strengthened tube metal after $51382 \mathrm{~h}$ of operation on h/p CSH

To prove the stability of strength characteristics and ductility of MTT tubes of steel 12Kh1MF there are the results of short-term mechanical tests of the cutoffs from the $32 \times 4.0 \mathrm{~mm}$ diameter test inserts of PK-41 boiler h/p CSH after different periods of operation (Table 3).

As can be seen from provided data, during the first operation period up to $5000 \mathrm{~h}$ there is a partial 5-4 \% recovery of strengthened state of steel by yield strength and then decrease of strength is delayed and makes 3.6-2.7 \%.

Steel softening by yield strength is insignificant and during the whole investigated operation time virtually does not exceed $1 \%$.

At that, steel ductility for all investigated time range remains at acceptance level.

The positive results of operation testing of MTT strengthened steel $12 \mathrm{Kh} 1 \mathrm{MF}$ on the test inserts made the basis for commercial implementation of MTT tubes instead of standard materials on HP and SCP boilers' superheaters.

3840 loops (100 \%) of four legs of secondary l/p CSH superheater were mounted on two TPP-201A boilers of 300 MW block from 12Kh1MF steel tubes of $42 \times 4.0 \mathrm{~mm}$ diameter after MTT [4]. Operating parameters of the assembly were steam temperature $545^{\circ} \mathrm{C}$ and pressure 3.7 MPa.

Table 3. Mechanical properties of metal of test inserts of MTT strengthened steel $12 \mathrm{Kh} 1 \mathrm{MF}$ after different periods of operation on $\mathrm{h} / \mathrm{p} \mathrm{CSH}$

\begin{tabular}{|c|c|c|c|c|c|c|}
\hline \multirow{2}{*}{$\begin{array}{c}\text { Time } \\
\text { of operation, h }\end{array}$} & \multicolumn{3}{|c|}{$\begin{array}{c}\text { Testing } \\
\text { temperature } 2{ }^{\circ} \mathrm{C}\end{array}$} & \multicolumn{3}{c|}{$\begin{array}{c}\text { Testing } \\
\text { temperature } 570{ }^{\circ} \mathrm{C}\end{array}$} \\
\cline { 2 - 7 } & $\sigma_{\mathrm{t}}, \mathrm{MPa}$ & $\sigma_{\mathrm{y}}, \mathrm{MPa}$ & $\delta, \%$ & $\sigma_{\mathrm{t}}, \mathrm{MPa}$ & $\sigma_{\mathrm{y}}, \mathrm{MPa}$ & $\delta, \%$ \\
\hline Initial state & 630 & 542 & 22.1 & 396 & 364 & 30.2 \\
\hline 4000 & 600 & 476 & 29.5 & 379 & 347 & 31.0 \\
\hline 7000 & 585 & 455 & 28.5 & 355 & 314 & 29.5 \\
\hline 15000 & 582 & 451 & 29.5 & 344 & 303 & 29.0 \\
\hline 23000 & 565 & 459 & 31.0 & 294 & 286 & 29.4 \\
\hline
\end{tabular}




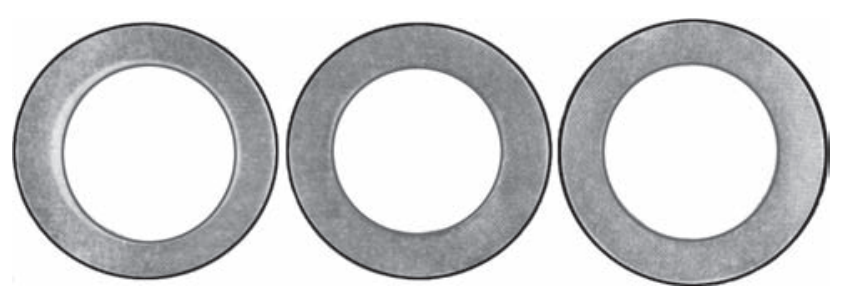

Figure 3. Cross-section of MTT strengthened LRS tubes after 21 thou h of operation

Earlier the boiler superheater, following the design, had the tubes of steel 12Kh2MFSR [1] that did not provide reliable operation of the assembly.

The total number of straight and bended elements of tubes after MTT, installed in the superheater, makes 3840 .

There were no difficulties with bending and welding of the tubes in manufacture of the superheater loops at the plant.

Up to the moment the tubes after MTT have worked 65374 and $68095 \mathrm{~h}$ in secondary l/p CSH of the boiler (block B and A of the boiler, respectively).

Tubes operation is virtually troublefree. During operation of the secondary l/p CSH it was one case of damage due to a wormhole in the welded joint that makes $0.03 \%$ of number of welded joints of tubes after MTT. Hydraulic pressure tests of the boiler after the scheduled repairs resulted in reject of 9 tubes on different loops of the superheater also because of the wormholes in welded joints that makes $2.8 \%$ of total number of welded joints.

Data on damages of standard 12Kh2MFSR steel tubes of boiler secondary l/p CSH for the same operation period can be provided for comparison. In course of this time 38 tubes were rejected by emergency or based on the results of inspection that makes $10 \%$.

There is a systematic monitoring of state of the metal of the strengthened tubes in process of operation during standard shutdown for routine and major shutdowns of the boiler, including inspections, measure-
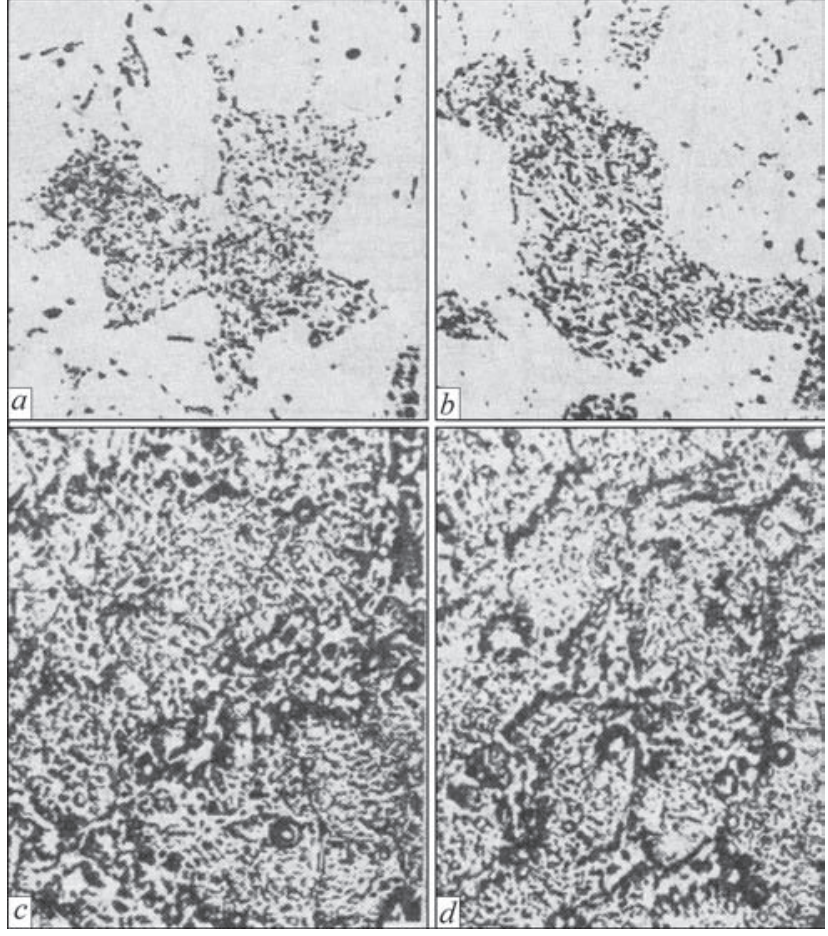

Figure 5. Microstructure $(a, b)$ and dislocation structure $(c, d)$ of strengthened LRS tube after 1 thou h of operation: $a, b$ - fireside; $c, d$ - backside of tube $(\times 1000)$

ments of residual creep deformation, determination of wall thickness and corrosion wear of tube metal.

It is planned in the future to do the reference cutoffs for investigation of structural changes and level of mechanical properties, high-temperature strength and heat resistance of metal in process of long-term operation.

Long-term commercial operation of tubes after MTT in lower radiation section (LRS) of TGMP-314A gas-and-oil-fired boilers of 300 MW blocks. The positive results of testing and long-term commercial operation of MTT tubes in superheaters of HP and SCP boilers made a basis for expansion of the experiment on application of substructure strengthened tubes in power generating units.

Investigation of the possibility of application of the strengthened tubes in zones of the largest man-

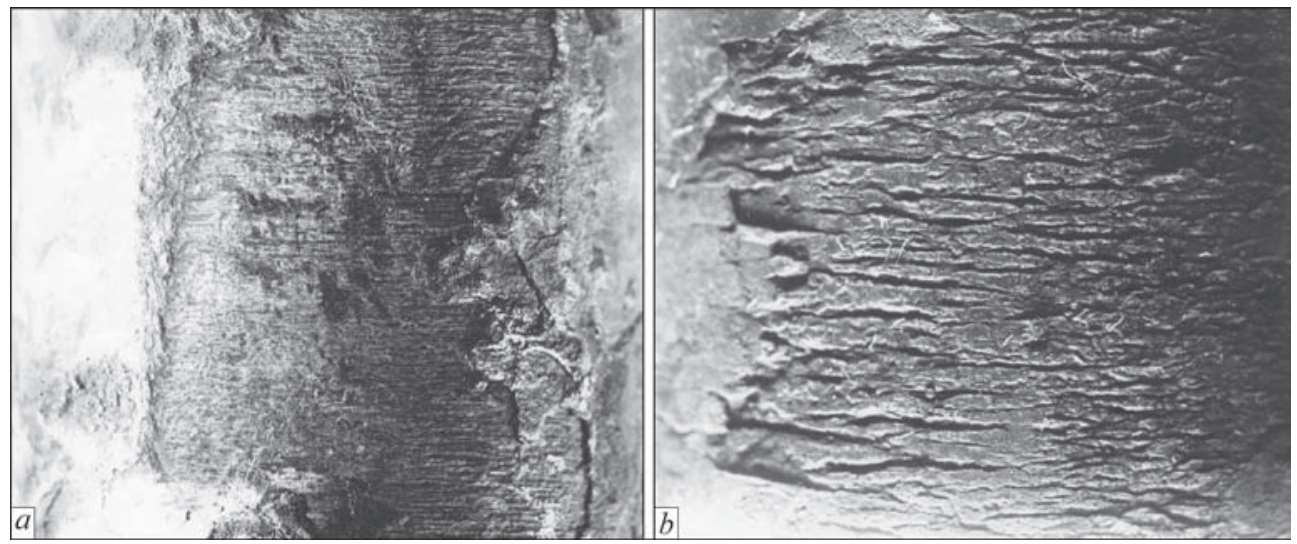

Figure 4. External surface of fireside of standard $(a)$ and strengthened $(b)$ LRS tubes after 21 thou h of operation 
Table 4. Mechanical properties of metal of MTT strengthened test inserts of side waterwalls of TPP-210 A boiler LRS after 21 thou h of operation

\begin{tabular}{|c|c|c|c|c|c|c|c|}
\hline \multirow{2}{*}{$\begin{array}{c}\text { Insert } \\
\text { number }\end{array}$} & \multirow{2}{*}{$\begin{array}{c}\text { Place of sample cutoff } \\
\text { (tube side) }\end{array}$} & \multicolumn{3}{|c|}{ Testing temperature $2{ }^{\circ} \mathrm{C}$} & \multicolumn{3}{c|}{ Testing temperature $550^{\circ} \mathrm{C}$} \\
\cline { 3 - 8 } & & $\sigma_{\mathrm{t}}, \mathrm{MPa}$ & $\sigma_{\mathrm{y}}, \mathrm{MPa}$ & $\delta, \%$ & $\sigma_{\mathrm{t}}, \mathrm{MPa}$ & $\sigma_{\mathrm{y}}, \mathrm{MPa}$ & \multicolumn{2}{c|}{$\delta, \%$} \\
\hline \multirow{2}{*}{1} & Backside & 632 & 488 & 24.6 & 401 & 379 & 22.4 \\
\cline { 2 - 9 } & Fireside & 633 & 506 & 22.5 & 401 & 368 & 22.3 \\
\hline \multirow{2}{*}{2} & Backside & 645 & 507 & 22.5 & 419 & 400 & 20.0 \\
\cline { 2 - 9 } & Fireside & 645 & 508 & 22.5 & 409 & 378 & 21.0 \\
\hline \multirow{2}{*}{3} & Backside & 608 & 460 & 24.4 & 404 & 374 & 21.6 \\
\cline { 2 - 8 } & Fireside & 606 & 450 & 24.2 & 390 & 360 & 21.4 \\
\hline
\end{tabular}

caused risk on SCP boilers, which are the waterwalls of furnace lower radiation section, is of undoubted interest. The experience of application of standard [1] tubes of steel $12 \mathrm{Kh} 1 \mathrm{MF}$ showed a mass damage of the waterwalls being observed already in the first operation period. There is virtually single-type damage nature for PC-fired and gas-and-oil-fired blocks. In the beginning there is thinning of wall of the tube front part due to thermal fatigue corrosion wear or external gas corrosion. Then thinned tubes failure due to development of accelerated creep under conditions of increased operating stresses.

During the first stage of the experiment the straight inserts of strengthened tubes were installed in the panels of side waterwalls of lower radiation section (LRS) of TPP-210A boiler and panels of backside and front LRS waterwalls of TGMP-314A boiler of 300 MW block using coal-dust mixture and oil-and-gas fuel. The straight sections of $12 \mathrm{Kh} 1 \mathrm{MF}$ steel tubes after MTT of $38 \times 6.0$ and $32 \times 6.0 \mathrm{~mm}$ diameters were used for operation testing. Assembly operating parameters are medium temperature $400-389{ }^{\circ} \mathrm{C}$, pressure $30 \mathrm{MPa}$, tube wall temperature $460^{\circ} \mathrm{C}$.

It should be noted that TPP-210A boilers had the experimental strengthened inserts without studding and, thus, they were operated under more rough conditions than standard stud LRS tubes [3].

The results of investigations [6] of cutoff metal of three test inserts in side wall of TPP-201A boiler LRS after 21 thou h of operation showed that deformation and thinning of the tubes due to corrosion are not observed (Figure 3).

Initial stage of development of corrosion-thermal metal fatigue from tube external surface (Figure 4) was detected.

Tube operation did not influence the structure and fine dislocation structure of steel even in the most stresses area of the section, i.e. tube fireside. State of the microstructure of strengthened tube is homogeneous along the whole section with the light features of differentiation (Figure 5, $a, b$ ). Examination of the dislocation structures [7] indicates absence of fine structural changes on tube section (Figure 5, c, d). Dislocation density, which is uniformly distributed in ferrite grains, makes $(0.6-0.8) \cdot 10^{-8} \mathrm{~cm}^{-2}$ that corresponds to the initial state.

Homogeneity of structural state on tube section after MTT agrees with the level of strength and ductile properties of steel, which are, virtually, the same on fireside and backside part of the tube. Determination of mechanical characteristics of metal under normal and high temperatures after 21 thou h of operation showed stability of the strengthened state and retention of steel ductility (Table 4).

The experience of troublefree operation of MTT inserts in boilers' LRS allowed proceeding from operation tests of the separate tubes to testing the block-panel at LRS back waterwall of TGMP-314A boiler. It was completely produced under plant conditions of 41 strengthened tubes (1/2 of LRS standard panel).

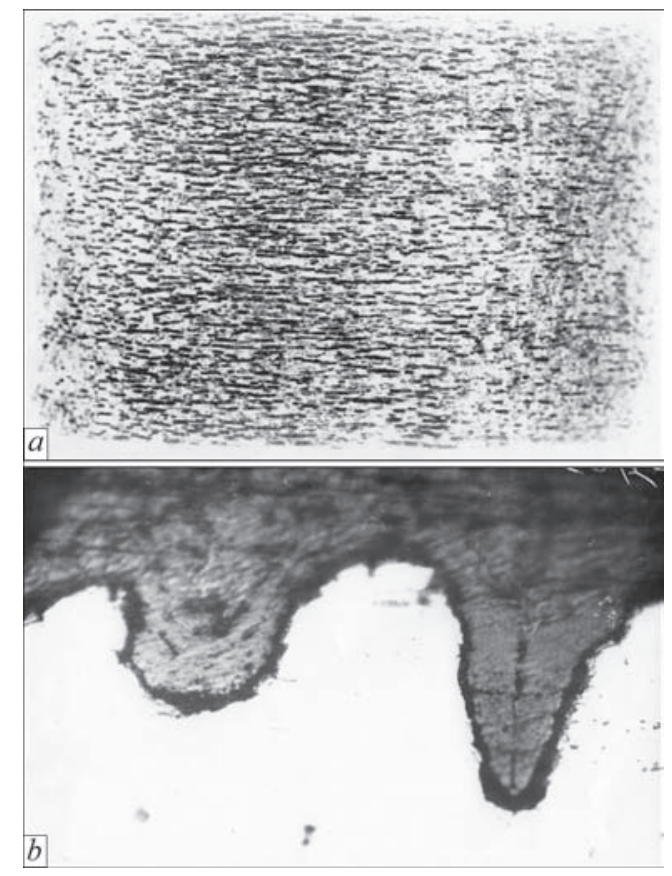

Figure 6. Corrosion-fatigue cracks on external surface $(a)$ and in section $(b)$ of MTT strengthened tube in LRS after 89 thou h of operation $(\times 100)$ 
Table 5. Heat resistance of MTT tubes in panels of front waterwall of TGMP-314A boiler LRS after long-term operation (operation time 89 thou h)

\begin{tabular}{|c|c|c|c|c|c|c|}
\hline \multirow{3}{*}{ Sample } & \multicolumn{6}{|c|}{ Corrosion depth, mm } \\
\hline & \multicolumn{2}{|c|}{ Tube external surface } & \multicolumn{2}{|c|}{ Tube internal surface } & \multirow{2}{*}{$\begin{array}{l}\text { Corrosion depth } \\
\text { (total wall thin- } \\
\text { ning) }\end{array}$} & \multirow{2}{*}{$\begin{array}{l}\text { Sum corrosion } \\
\text { depth }\end{array}$} \\
\hline & Thinning & Suboxide layer & Thinning & Suboxide layer & & \\
\hline Tube after MTT & - & 0.22 & - & 0.10 & 0.40 & 0.72 \\
\hline Tube after $\mathrm{N}$ and $\mathrm{T}$ (calculation data) & 0.71 & - & 0.13 & - & 0.84 & 0.84 \\
\hline
\end{tabular}

Performance of technological operations on bending of the strengthened tubes, resistance and manual electric arc welding of tubes after MTT as well as composite butt joints of tubes after MTT with standard tubes did not provoke any difficulties.

Operation of the test block-panel takes place troublefree. Periodic technical diagnostics of the panel in process of operation showed good state of metal. There are no traces of intensive external corrosion and tube thinning, unallowable residual tube deformation is absent. Bended parts of the tubes and butt joints are also in satisfactory state, that indicates inheritance of the strengthened state on tube bends and in welded joints.

Life of the test parts of LRS waterwalls of TPP201A and TGMP-314A boilers made 28-31 thou h.

Analysis of the results of carried operation testing proved stability of strengthened state of the tubes after MTT and made a sufficient basis for their commercial implementation in the LRS of boilers of SCP blocks instead of standard materials.

$46 \%$ of panels from MTT strengthened tubes (13.5 panels) were installed on two TGMP-314A boilers of 300 MW blocks at front, back and bottom LRS waterwalls. Installed panels are of plant production in accordance with the requirements of [2]. Total number of installed in the panels bended and straight MTT strengthened tube elements made 3500 units.

A period of commercial operation of tubes after MTT in the panels of TGMP-314A boiler LRS up to

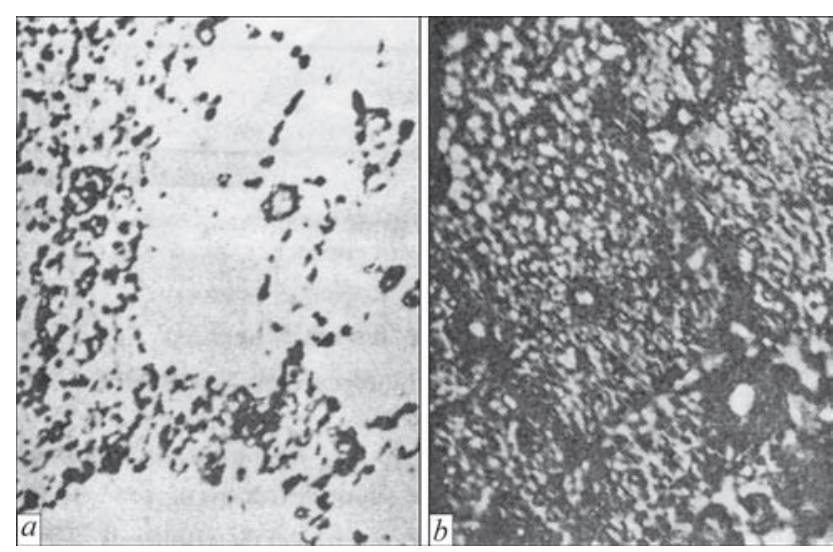

Figure 7. Microstructure $(a)$ and dislocation structure $(b)$ of strengthened LRS tubes after 89 thou h of operation $(\times 1000)$ the moment has made 96-104 thou. h including 137.6 thou h of test inserts being in operation.

Tube operation is virtually troublefree.

One of TGMP-314A boilers had a damage of MTT strengthened tube in burners' zone during the analyzed period of unit operation. It happened due to overheating (less that $0.03 \%$ of quantity of tubes installed after MTT) that was related with unsatisfactory operation of burner assembly of the boiler and required replacement and assembly reconstruction. 54 tubes were rejected during scheduled inspections due to surface appearance (external corrosion, tube deformation etc.). It made 1.5 $\%$ of quantity of installed tubes.

The systematic periodic inspections of state of tube metal in situ and on reference cutoffs were carried out in process of operation.

The data given below refer to investigation of cutoff of one of MTT strengthened tubes of $32 \times 6.0 \mathrm{~mm}$ diameter taken from the font panel of TGMP-314A boiler LRS after 89 thou. h of operation.

No tube deformation on diameter was found in cutoff investigation.

State of external and internal surfaces of the tube were investigated after cleaning from deposits and special heat etching.

The external surface of tube front part has a mesh of transverse (circumferential) corrosion-fatigue cracks (Figure 6, a). Single corrosion pits of up to $0.5 \mathrm{~mm}$ diameter were found on tube internal surface.

Metallographic examinations of a tube cross-section were carried out to determine a nature and level of corrosion damages. It is shown that the transcrystalline blunt cracks filled with oxides propagate to

Table 6. Mechanical properties of tube metal after MTT of front waterwall of TGMP-314A boiler LRS after operation (testing temperature $20^{\circ} \mathrm{C}$ )

\begin{tabular}{|c|c|c|c|}
\hline $\begin{array}{c}\text { Operation time, } \\
\text { thou h }\end{array}$ & $\sigma_{\mathrm{t}}, \mathrm{MPa}$ & $\sigma_{\mathrm{y}^{\prime}}, \mathrm{MPa}$ & $\delta, \%$ \\
\hline 21 (test inserts) & $606-645$ & $450-508$ & $22.5-24.6$ \\
\hline 89 & $\frac{623-692}{490-637}$ & $\frac{511-557}{\geq 372}$ & $\frac{21.1-20.7}{\geq \underline{21}}$ \\
\hline \multicolumn{4}{|l}{} \\
\hline
\end{tabular}


Table 7. Calculation of residual life by microdamage in metal of MTT strengthened tube of front waterwall of TGMP-314A boiler LRS after 89 thou h of operation

\begin{tabular}{|c|c|c|c|c|}
\hline Object being investigated & Operation time, thou h & Density, g/cm ${ }^{3}$ & Damage $\omega$ & Residual life, thou h \\
\hline Tube after MTT of LRS front waterwall & 89 & 7.831 & $<0.1$ & $\geq 100$ \\
\hline Steel 12Kh1MF after N and T [11, 12] & Initial state & 7.835 & 0 & $\geq 100$ \\
\hline
\end{tabular}

$0.22 \mathrm{~mm}$ depth (Figure $6, b$ ) in the section from the external surface. Corrosion damages of internal surface look like round-shape pits of up to $0.1 \mathrm{~mm}$ depth also filled with oxides.

Thus, sum depth of corrosion-damaged layer of tube section makes $0.32 \mathrm{~mm}$.

Depth of tube corrosion after MTT was evaluated on total wear of external and internal surfaces, expressed by the maximum value of wall thinning, which made $6.7 \%$ or $0.4 \mathrm{~mm}$.

A calculation [8] of allowable corrosion depth for the same period of service of standard tube was carried out for comparison as a sum value of wear of internal surface in SCP medium and external surface in a medium of combustion products of sulfur black oil.

As can be seen from the data given in Table 5, development of corrosion of strengthened tubes is delayed and corrosion depth after 89 thou. $\mathrm{h}$ is two times lower than the maximum allowable one [8]. The total volume of corrosion losses of tube metal after MTT can be considered as a sum of corrosion depth and depth of corrosion-damaged layers. Even in this case, taking into account corrosion-damaged suboxide layers of the section the sum depth of corrosion of MTT tube is below the allowable one for standard tube of steel 12Kh1MF.

Provided data indicate increased heat resistance of steel 12Kh1MF after MTT under conditions of longterm commercial operation.

There were no significant changes in the microstructure of metal of MTT tube cutoff after 89 thou h of operation. The structure consists of sufficiently dense bainite areas, ferrite and isolated carbides located along the grain boundaries.

Single dispersed carbides (Figure 7, a) are found in a ferrite grain volume. Such a structure can be referred to «acceptance» on scale [1] for steel 12Kh1MF after $\mathrm{N}$ and $\mathrm{T}$.

Comparison of state of investigated tube with microstructure of LRS tube test inserts shows their complete identity.

Investigation of dislocation structure of steel showed uniform distribution of the etch figures in a ferrite field with $(0.8-0.9) \cdot 10^{-8} \mathrm{~cm}^{-2}$ density (Figure 7 , $b)$, that is insignificantly higher than a density level after 21 thou. h of operation. The areas of regular construction of the etch figures with fragmented structure of separate grains (Figure 7, b) were detected that indicates stability of polygonal structure of MTT tubes in process of long-term operation.

Therefore, there are no fundamental changes in short-term mechanical properties of the tube metal (Table 6) in comparison with state of the strengthened tubes after 21 thou h of operation. It is only noted $3.9 \%$ decrease of a value of relative elongation, however, mechanical characteristics of tube metal after 89 thou $h$ of operation are at the level of requirements [2].

A residual life of MTT tube metal after 89 thou $h$ of operation was evaluated by a level of accumulated microdamage of steel, which is related with the processes of nucleation and propagation of pores and microcracks $[9,10]$. An integral estimation of changes being the result of these processes is a value of accumulated damage $\omega$ [11]. The samples for determination of volumetric density of material were taken from tube front part.

The value of integral damage $\omega$ was determined as a relationship of specific volume of pores in steel at the moment of 89 thou $\mathrm{h}$ investigation to volume of pores at the moment of failure. Calculation of residual life was carried out using empirical dependence of relative time before failure on damage. The latter was received in experimental way by measurement of material density (Table 7).

As can be seen from the Table, metal density of MTT strengthened tube after 89 thou h of operation turned out close to the reference density of standard steel in initial state.

Thus, process of damage accumulation in MTT strengthened steel during operation is delayed that indicates stability of fragmented substructure of strengthened state, in which polygonal boundaries prevent dislocation movement and formation of new microdefects in a crystalline lattice volume. Actual accumulated microdamage of tube metal after MTT is minimum and residual life after 89 thou. h of operation is at the level of calculation one, i.e. not less than 100 thou $h$.

Received results of commercial operation of MTT tubes of 12Kh1MF steel in SCP boiler LRS prove the 
stability of MTT strengthened state and retention of operation reliability of steel in course of long-term service.

\section{Conclusions}

1. Systematic periodic inspections of state of tube metal showed that dislocation polygonal steel substructure, providing strengthening effect, remains stable in process of operation. Therefore, no significant changes of mechanical, high-temperature strength and heat resistance properties of steel were found. Unallowable wall thinning of tube due to external corrosion was not determined. Welded joints of MTT tubes made by resistance and manual welding are in satisfactory state. Accumulation of microdamage of steel after MTT is delayed and residual life of tube metal after long-term operation is kept at the level of calculation, namely not less than 100 thou $\mathrm{h}$.

2. The experience of commercial operation of tubes of MTT strengthened 12Kh1MF steel on the heating surfaces of SCP boilers was generalized. Stability of MTT strengthened state in process of operation of up to 104 thou h duration was shown. Damages of the tubes after MTT for the indicated operation period do not exceed $0.1 \%$ of total determined amount.

3. Positive experience of long-term commercial operation of MTT strengthened tubes of 12Kh1MF steel on the heating surfaces of SCP boilers indicates technical and economical relevance of application of such tubes in power engineering that provides increase of life duration of critical assemblies in power generating units for more than $5-6$ times and solves the relevant problem of rise of operation reliability of critical assemblies of the units.
1. GP NITI (2009) TU 14-3-460:2009/TU U 27.2-05757883207:2009: Steel seamless tubes for steam boilers and pipelines [in Russian].

2. Minchermet SSSR 91982) TU 14-3-1072-82: 12Kh1MF steel seamless cold-deformed mechanical-thermal-treated tubes for steam boilers and pipelines [in Russian].

3. Gordienko, L.K., Versler, E.Ya., Chajkovsky, V.M. et al. (1981) Experience of operation of strengthened tubes on heating surface of high-pressure boilers. Energetika i Elektrifikatsiya, 3, 21-24 [in Russian].

4. Veksler, E.Ya., Mozharenko, I.P., Fridman, Z.G. et al. (1986) Substructural strengthening of boiler tubes from 12Kh1MF steel. Ibid., 2, 9-11 [in Russian].

5. Mozharenko, I.P., Dolinskaya, L.A., Veksler, E.Ya. et al. (1976) Structure and properties of boiler tubes from 12Kh1MF steels after mechanical-thermal treatment. Metallovedenie $i$ Termich. Obrabotka, 1, 2-4 [in Russian].

6. Veksler, E.Ya., Mozharenko, I.P., Chajkovsky, V.M. et al. (1980) Operation of strengthened by mechanical-thermal treatment of lower radiant section tubes from $12 \mathrm{Kh} 1 \mathrm{MF}$ steel. Energetik, 5, 22-23 [in Russian].

7. Veksler, E.Ya. (1972) Examination of dislocation structure changes of $12 \mathrm{Kh} 1 \mathrm{MF}$ steel during operation. Teploenergetika, 10, 61-65 [in Russian].

8. Minenergomash SSSR (1977) RTM 108.030.122-77: Steam stationary supercritical boilers. Procedure for calculation of corrosion losses and temperature mode of water-wall tubes [in Russian].

9. Veksler, E.Ya., Zamekula, I.V., Tolstov, V.Yu. et al. (2009) Assessment of residual life of high-pressure steam pipelines of thermal power plants by the level of metal microdamage. Energetika i Elektrifikatsiya, 5, 31-40 [in Russian].

10. Veksler, E.Ya., Zamekula, I.V., Tolstov, V.Yu. et al. (2010) Technology of diagnostics and assessment of residual life of high-pressure steam pipelines of thermal power plants by the level of metal microdamage. Tekhn. Diagnost. i Nerazrush. Kontrol, 1, 23-31 [in Russian].

11. Zheldubovsky, A.V., Serditov, A.T., Klyuchnikov, Yu.V. et al. (2013) Method of assessment of material residual life under conditions of long-term static loading. Vostochno-Evrop. Zh. Peredovykh Tekhnologij, 3/7(63), 24 [in Russian]. 


\title{
INFLUENCE OF WELDING WIRE COMPOSITION ON WELD QUALITY IN WELDED JOINTS OF DISSIMILAR STEELS IN GAS-SHIELDED MECHANIZED WELDING
}

\author{
V.P. ELAGIN \\ E.O. Paton Electric Welding Institute of the NAS of Ukraine \\ 11 Kazimir Malevich Str., 03150, Kiev, Ukraine. E-mail: office@paton.kiev.ua
}

\begin{abstract}
For welding of dissimilar joints, the high-alloy welding materials are widely used. It is shown that the use of shielded arc mechanized welding method of dissimilar austenitic and pearlitic steels is limited due to formation of defects in the austenitic multilayer weld, such as lacks of fusion and lacks of penetration caused by appearance of a refractory oxide crust on the deposited metal surface. It is possible to increase the weld quality by providing its self-separation from the metal surface in the process of cooling. This is achieved by presence of a high content of such elements as silicon, titanium, zirconium, etc. in the welding wire, which reduce the amount of spinels based on chromium, nickel, molybdenum and others in the composition of oxide crust and increase the amount of brittle glassy phase. 15 Ref., 3 Tables, 1 Figure.
\end{abstract}

Keywords: welding wire composition, mechanized arc welding, shielding gas, dissimilar steels, oxide crust, self-separation of crust

A characteristic feature of modern technologies for welding dissimilar steels is the application of predominantly manual arc welding using high-nickel materials even for joining pipe elements such as branch pipes, bends, T-bends, etc., which are usually produced by mechanized welding. The high content of nickel in the composition of welding materials is predetermined by the need in reducing the thickness of a martensitic interlayer and diffusion of carbon in the fusion zone of austenitic weld with pearlitic steel $[1,2]$. However, the instability of weld formation, characteristic for manual arc welding, leads to increase in chemical heterogeneity and decrease in the influence of nickel on structural heterogeneity in the fusion zone of dissimilar steels and promotes the formation of cracks in this zone. One of the main causes for limiting the application of mechanized welding of dissimilar steels in shielding gas is the formation of defects in the austenitic multilayer weld such as lacks of fusion and lacks of penetration due to the presence of refractory oxide crust on the deposited metal surface $[3,4]$. At the same time, it was established that during application of $\mathrm{CO}_{2}$ in its mixture with oxygen or with nitrogen as a shielding gas, the chemical and structural heterogeneity decreases [5, 6], and also the resistance to pore formation in this zone increases [7, 8]. This is facilitated both by increase in the level of austenite content in metal as well as improvement in the fluidity of metal in the weld pool and, in particular, in the near-wall area [9].

(c) V.P. ELAGIN, 2017
The successful use of mechanized welding of dissimilar steels is known in using carbon dioxide or its mixture with nitrogen or air as a shielding gas [10]. The absence of defects in the weld was obtained due to application of welding high-alloy wire of the composition $08 \mathrm{Kh} 20 \mathrm{~N} 9 \mathrm{G} 7 \mathrm{~T}$, during welding of which the formed oxide crust is independently separated from the surface of the deposited metal in the process of cooling. Consequently, during welding in an oxygen-containing shielding gas, it is possible to produce a defect-free austenitic weld and here the selection of the composition of welding wire is very important.

The aim of this work is determination of basic principles of selecting the composition of welding austenitic wire to prevent the formation of defects in the austenitic weld during mechanized welding of dissimilar steels in shielding gas.

The work was carried out by analyzing the chemical composition of the known high-alloy welding wires with different nickel content relative to the probability of self-separation of oxide crust from the surface of deposited metal. The results were checked by producing welds using mechanized welding in the mixture of $\mathrm{CO}_{2}$ with $2 \%$ nitrogen with evaluation of their quality. At the same time, the separation, chemical composition and glass transition temperature of oxide crust as well as crystallization temperature of the weld metal were determined by high-temperature thermal analysis using the installation VDTA-8M.

The fundamental principles for selecting chemical composition of welding wires for welding of dissim- 
Table 1. Grade composition of welding wires recommended for welding of dissimilar steels, mass.\%

\begin{tabular}{|c|c|c|c|c|c|c|c|c|c|}
\hline \multirow{2}{*}{$\begin{array}{l}\text { Grade (alloying type) of wire, } \\
\text { standard document }\end{array}$} & \multirow{2}{*}{$\begin{array}{l}\text { C, not } \\
\text { more }\end{array}$} & \multirow{2}{*}{$\mathrm{Si}$} & \multirow{2}{*}{ Mn } & \multirow{2}{*}{$\mathrm{Cr}$} & \multirow{2}{*}{$\mathrm{Ni}$} & \multirow{2}{*}{ Mo } & \multirow{2}{*}{$\mathrm{Ti}$} & $\mathrm{S}$ & $\mathrm{P}$ \\
\hline & & & & & & & & \multicolumn{2}{|c|}{ Not more } \\
\hline Sv- 08Kh20N9G7T, GOST 2246-70 & 0.10 & $0.5-1.0$ & $5.0-8.0$ & $18.5-22.0$ & $8.0-10.0$ & - & $0.6-0.9$ & 0.018 & 0.035 \\
\hline EP 622 (Kh25N25M3G2), TU 14-1-4968-91 & 0.08 & $\leq 0.40$ & $1.2-2.0$ & 23.5-26.5 & $23.5-26.5$ & $2.5-4.0$ & - & 0.015 & 0.020 \\
\hline EP 673 (Kh25N40M7G2), TU 14-1-4968-91 & 0.08 & $\leq 0.40$ & $1.2-2.0$ & $23.5-26.5$ & $38.5-41.5$ & $6.6-8.0$ & - & 0.015 & 0.020 \\
\hline EP 606 (Kh25N60M10G2), TU 14-1-4968-91 & 0.10 & $\leq 0.40$ & $1.0-2.0$ & $23.5-26.5$ & $58.5-61.5$ & $9.0-11.0$ & - & 0.01 & 0.015 \\
\hline
\end{tabular}

Table 2. Chemical composition of oxide crust on the weld surface in the mixture of $\mathrm{CO}_{2}$ with nitrogen, mass.\%

\begin{tabular}{|c|c|c|c|c|c|c|}
\hline Type of wire alloying & $\mathrm{SiO}_{2}$ & $\mathrm{MnO}$ & $\mathrm{Cr}_{2}$ & $\mathrm{MoO}_{3}$ & $\mathrm{Fe}_{2} \mathrm{O}_{3}$ & $\mathrm{TiO}_{2}$ \\
\hline Kh25N25M3G2 & 5.35 & 15.49 & 41.93 & 2.3 & 34.37 & - \\
\hline Kh20N9G7T & 12.5 & 29.69 & 12.35 & - & 13.63 & 23.52 \\
\hline
\end{tabular}

ilar steels are formulated in the work [1]. According to them, in order to reduce the structural heterogeneity in the fusion zone with pearlitic steel, the welding wire should provide producing of weld metal with an austenitic structure, increased nickel content and minimum content of carbide-forming elements. It is recommended to determine the amount of nickel in welding wire depending on the maximum service temperature of welded joints. The recommended conformity of the composition of welding wire to the service temperature of welded joints of dissimilar steels [1] is as follows: for alloyed wire Kh20N9G7T the permissible service temperature is 350 ; for Kh25N25M3G2 - 450; for Kh25N40M6G2 - 550; for $\mathrm{Kh} 25 \mathrm{~N} 60 \mathrm{M} 10 \mathrm{G} 2-650{ }^{\circ} \mathrm{C}$. In this case the amount of carbide-forming elements is determined from the condition of providing a sufficient resistance of austenitic weld to formation of hot cracks. At the same time, the carbide-forming elements should have a relatively low activity with respect to carbon and their quantity should be minimal to reduce the diffusion of carbon and the formation of carbides in the fusion zone. As to activity, such elements are chromium, molybdenum, tungsten, the presence and quantity of which is determined by the content of nickel in the wire: the higher it is, the more these elements are in the composition of the wire.

The amount of chromium in the composition of high-nickel wires is limited to $25 \%$, and that of molybdenum — to $10 \%$ (Table 1 ) due to their high tendency to $\sigma$-phase formation, embrittling the metal. The lower chromium content and the absence of molybdenum in the wire of type Kh20N9G7T are caused by the austenitic-ferritic structure of weld met-

Table 3. Temperature of aggregation state of weld metal and oxide film

\begin{tabular}{|c|c|c|c|c|}
\hline \multirow{2}{*}{ Type of wire alloying } & \multicolumn{2}{|c|}{ Weld metal } & \multicolumn{2}{c|}{ Oxide film } \\
\cline { 2 - 5 } & $T_{\mathrm{m}},{ }^{\circ} \mathrm{C}$ & $T_{\mathrm{s}},{ }^{\circ} \mathrm{C}$ & $T_{\mathrm{m}},{ }^{\circ} \mathrm{C}$ & $T_{\mathrm{gl}},{ }^{\circ} \mathrm{C}$ \\
\hline Kh25N25M3G2 & 1470 & 1330 & 1811 & 1680 \\
\hline Kh20H9G7T & 1460 & 1390 & 1300 & 960 \\
\hline
\end{tabular}

al, which provides it with a sufficient technological strength.

During welding using high-nickel wires in the mixture of $\mathrm{CO}_{2}$ with nitrogen the weld surface has a high roughness, in the depressions of which there is a larger amount of oxide crust. It practically does not break off and can be removed only applying abrasive disc. The weld surface, produced using the wire of type Kh20N9G7T, is smoother, and the oxide crust itself is separated from it in the process of cooling. At the same time, its thickness is in the range of 0.5$1.5 \mathrm{~mm}$ and has a shiny surface of fracture, characteristic for glass [11]. The chemical composition of oxide crust and its melting temperature depend on the composition of welding wire (Table 2, 3).

The analysis of state diagrams of binary systems formed by oxides, given in Table 2, shows that in the oxide crust of a high-nickel weld, the phases (FeMn) $\mathrm{OCr}_{2} \mathrm{O}_{3}$ and $\mathrm{FeCr}_{2} \mathrm{O}_{4} \mathrm{MoO}$ can form, which have a spinel lattice, isomorphic with the metal lattice [12].

The presence of titanium, increased content of silicon and also manganese in the wire of type Kh20N9G7T provides a more active interaction with oxygen than chromium and molybdenum. This reduces the amount of oxides of $\mathrm{Cr}_{2} \mathrm{O}_{3}$ and $\mathrm{MoO}_{3}$, which, in its turn, reduces the temperature of melting $\left(T_{\mathrm{m}}\right)$ and glassing $\left(T_{\mathrm{gl}}\right)$ of the crust (Table 3 ) to a temperature which is lower than melting and solidification temperature $\left(T_{s}\right)$ of weld metal. A good separation of oxide crust from the weld surface is explained by formation of a brittle glassy silicate phase in its composition [13, 14], which is cracked when the weld is cooled. The improvement of its separation is also facilitated by the presence of zirconium in the welding wire composition, which forms the zirconium oxides in the oxide crust, which have a higher coefficient of thermal expansion than the silicate phase, which contributes to its fracture when the weld is cooled [15].

A later solidification of oxide crust than that of the weld metal makes its surface smooth and the earlier solidification makes it rough. In the latter case, apparently, the capture of a solidified crust by liquid metal 
is possible, which leads to deterioration of its separation.

The results of the analysis were checked by evaluation of separation of oxide crust from the surface of deposited metal produced by standard welding wires (GOST 2240-70), which were designed for welding of high-alloy steels.

\section{Evaluation of separability of oxide crust from weld surface}

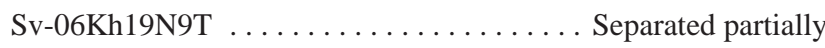
Sv-08Kh20N9G7T . . . . . . . . . . Complete self-separation Sv-07Kh18N9TYu ................ Separated partially Sv-05Kh20N9FBS . . . . . . . . . . . . Separated partially

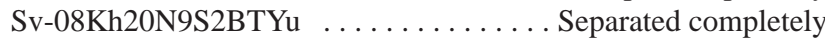
Sv-08Kh19N10G2B ................. Separated partially

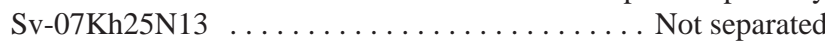
Sv-01Kh19N18G9AM4 .............. Separated partially Sv-10Kh16N25AM6 . ................ Not separated Sv-01Kh23N28M3D3T . ............... Not separated

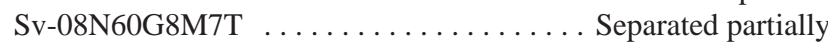
Sv-KhN75MBTYu . . . . . . . . . . . Separated partially

As is seen, only one welding wire Sv08Kh20N9G7T has a chemical composition which provides a complete self-separation of the oxide crust during cooling (Figure, $a$ ). However, it should be noted that its separation can be deteriorated by reducing the amount of silicon, manganese and titanium in the composition of the wire within the limits of grade composition (Table 1). At the content of Si $0.62 \%$, Mn $5.8 \%$, Ti $0.7 \%$ in wire composition the weld surface is completely covered with a black crust (Figure, $b$ ), which partially breaks off. A good separability of the oxide crust is observed in the presence of silicon and titanium in the wire Sv-08Kh20N9G7T, which is higher than $0.7 \%$ and the ratio of its quantity to the amount of manganese is higher than 0.125 . A significant deterioration in its separation, even when this ratio is satisfied, is observed with a decrease in the oxidizing capacity of shielding gas, for example, when using the mixture of argon with $0.5-4.0 \%$ oxygen or with less than $40 \% \mathrm{CO}_{2}$ as a shielding gas. The cause for this is a decrease in the composition of oxide crust of a brittle glassy phase and an increase in the oxides of the spinel-forming element - chromium, and also a decrease in its thickness to less than $0.5 \mathrm{~mm}$. The role of the latter factor in this, obviously, is due to a decrease in the level of thermal stresses, which contribute to its cracking.

The separability of oxide crust is deteriorated also at the increase in nickel content in the wire composition, and also at the presence of aluminum, niobium, vanadium, which are the strong spinel-forming elements.

Thus, when selecting the chemical composition of austenitic high-nickel wires for mechanized welding of dissimilar steels in the mixture of shielding gas

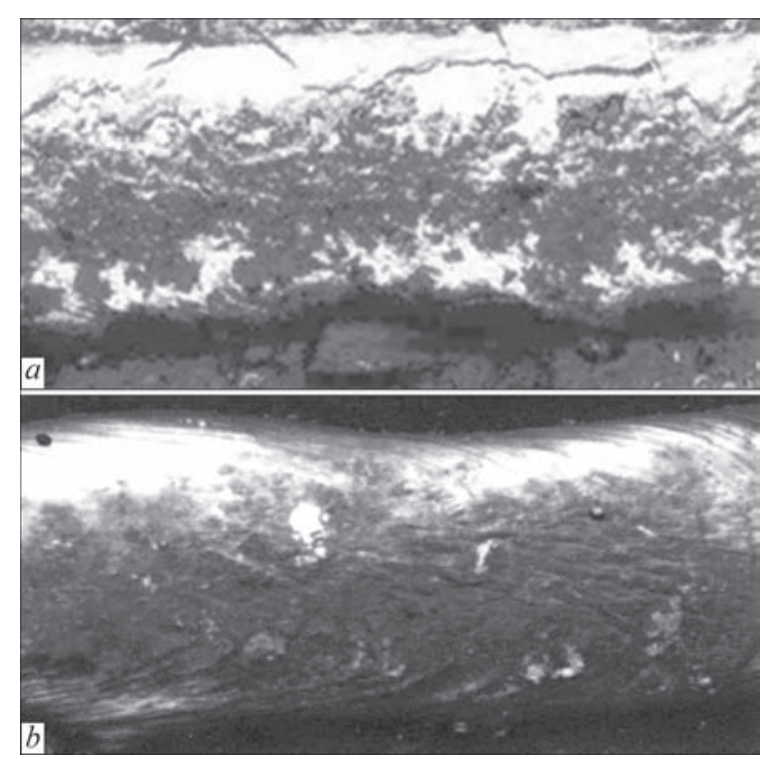

Surface of beads, deposited in $\mathrm{CO}_{2}$ using wire Sv-08Kh20N9G7T having a ratio $\mathrm{Si} / \mathrm{Mn}: a-0.142 ; b-0.11$

based on $\mathrm{CO}_{2}$, the following factors should be taken into account:

- correspondence of nickel amount in the composition of welding wire to the service temperature of welded joint;

- in the welding wire a minimum amount of carbide-forming elements, such as manganese, chromium, molybdenum and other should be present, sufficient to provide a high resistance of weld metal to hot cracks formation;

- to improve the separation of the oxide crust from the weld surface, the following elements of chemical composition of the wire should be in an increased amount: silicon, titanium, zirconium, manganese, etc., which form the brittle phases of glassy morphology in the composition of the oxide crust, as well as have a higher activity of interaction with oxygen than chromium, molybdenum and other elements, which are spinel-forming.

\section{Conclusions}

1. The application of mechanized arc welding of dissimilar steels in shielding gas based on $\mathrm{CO}_{2}$ is limited in connection with formation of a refractory oxide crust on the surface of deposited high-nickel metal and appearance of defects in the multilayer weld such as lacks of fusion and slagging.

2. The composition of welding wire for mechanized arc welding of dissimilar steels in shielding gas based on $\mathrm{CO}_{2}$ should have, except of a high content of nickel and the minimum amount of carbide-forming elements, such as chromium, molybdenum, tungsten, etc., an increased content of such elements as silicon, titanium, manganese, etc., forming a phase of glass- 
like morphology in the composition of oxide crust and lowering the temperature of its solidification.

3. The quality of multilayer weld of welded joints of dissimilar steels during mechanized welding in shielding gas based on $\mathrm{CO}_{2}$ is provided by applying the electrode welding wire of grade $\mathrm{Sv}-08 \mathrm{Kh} 20 \mathrm{~N} 9 \mathrm{G} 7 \mathrm{~T}$, in the composition of which a quantity of silicon and titanium is higher than $0.7 \%$, and the ratio $\mathrm{Si} / \mathrm{Mn}$ is higher than 0.125 .

1. Gotalsky, Yu.N. (1992) Welding of pearlitic steels by austenitic materials. Ed. by K.A. Yushchenko. Kiev, Naukova Dumka [in Russian].

2. Sudha, C., Thomac Paul, V., Terrance, A.L. et al. (2006) Microstructure and microchemistry of hard zone in dissimilar weldments of Cr-Mo steels. Welding J., 4, 71-74.

3. Snisar, V.V., Lipodaev, V.N., Elagin, V.P. et al. (1990) Influence of parameters of gas shielding in argon arc welding with austenitic wire of dissimilar steels on formation of oxide film on surface of layers of multilayer weld. Avtomatich. Svarka, 12, 44-48 [in Russian].

4. Gotalsky, Yu.N., Stretovich, A.D. (1971) About slag inclusions in multilayer weld during shielded-gas welding with austenitic wire. Ibid., 12, 39-43 [in Russian].

5. Elagin, V.P., Snisar, V.V., Savitsky, M.M. et al. (2001) Chemical and structural inhomogeneity in the zone of fusion of low-carbon steel with austenitic weld during shielded-gas welding. The Paton Welding J., 4, 7-12 [in Russian].

6. Snisar, V.V., Lipodaev, V.N., Elagin, V.P. et al. (1991) Influence of nitrogen alloying of austenitic weld on development of structural inhomogeneity in the zone of fusion with pearlitic steel. Avtomatich. Svarka, 2, 10-14 [in Russian].

7. Elagin, V.P., Snisar, V.V., Lipodaev, V.N. (1993) Peculiarities of nitrogen-containing shielded gases arc welding with austenitic wires of dissimilar and pearlitic steels. Ibid., 7, 12-16 [in Russian].

8. Pisarev, V.A., Zhiznyakov, S.N. (2016) Oxygen influence on the process of nitrogen-induced pore formation in consumable electrode arc welding. The Paton Welding J., 7, 47-50 [in Russian].

9. Potapievsky, A.G., Saraev, Yu.A., Chinakhov, D.A. (2012) Consumable electrode shielded-gas welding of steels. In: Engineering and technology of future: Monography. Tomsk, TPU [in Russian].

10. Elagin, V.P., Snisar, V.V., Lipodaev, V.N. et al. (1995) Mechanized welding of $15 \mathrm{Kh} 5 \mathrm{M}$ steel without preheating and heat treatment. Avtomatich. Svarka, 8, 19-23 [in Russian].

11. Elagin, V.P. (2014) Selection of shielding gas for mechanized arc welding of dissimilar steels. The Paton Welding J., 6-7, 110-114 [in Russian].

12. Petrishchev, A.S., Grigoriev, S.M. (2012) Some physical-chemical principles of carbon-thermal reduction of refractory elements in system (Mo, W, Cr, V, Nb)-O-C. Protsessy Litiya, 5, 3-9 [in Russian].

13. Vornovitsky, I.N., Saveliev, V.G., Sidlin, Z.A. (1997) Realization of silicate decomposition in welding slags. Svarochn. Proizvodstvo, 5, 11-12 [in Russian].

14. (2015) Essential factors in gas shielded metal arc welding. Kita-Shinagawa, Shinagawa-Ku, Kobe Steel, Ltd.

15. Gotalsky, Yu.N., Stretovich, A.D. (1975) Method of improvement of slag crust separation in gas electric welding with austenitic wire. Svarochn. Proizvodstvo, 9, 22-23 [in Russian].

Received 18.09.2017 


\title{
SANITARY-HYGIENIC CHARACTERISTIC OF THE PROCESS OF NONCONSUMABLE ELECTRODE ARGON-ARC WELDING OF 1201 AND 1460 ALUMINIUM ALLOYS
}

\author{
A.O. LUKYANENKO ${ }^{1}$, T.M. LABUR ${ }^{1}$, A.G. POKLYATSKY ${ }^{1}$, V.A. KULESHOV ${ }^{1}$ and DARKO R. BABICH ${ }^{2}$ \\ ${ }^{1}$ E.O. Paton Electric Welding Institute of the NAS of Ukraine \\ 11 Kazimir Malevich Str., 03150, Kiev, Ukraine. E-mail: office@paton.kiev.ua \\ ${ }^{2}$ University of Montenegro, Faculty of Mechanical Engineering, Podgorica
}

\begin{abstract}
The work presents the results of studying harmful substances in the air, released during nonconsumable electrode argon-arc welding of 1201 (Al-Cu-Mn) and 1460 (Al-Cu-Li) aluminium alloys. The objective of this work is performance of sanitary-hygienic assessment of the nature of aerosol and gas evolution from these alloys, in order to ensure favourable sanitary-hygienic working conditions for welders. It is shown that for 1460 alloy with lithium the intensity of welding aerosol formation is 1.5 times higher, and ozone concentration exceeds the maximum admissible concentration 3-4 times in the same welding modes. 13 Ref., 4 Tables, 5 Figures.
\end{abstract}

Keywords: aluminium-lithium alloys, nonconsumable electrode arc welding, labour safety, harmful substances, welding aerosols

Advance of technology promotes improvement of welded structures in different sectors of mechanical engineering. The most recent achievements of science and technology are introduced into manufacturing diverse products of modern engineering. This leads to introduction of new modifications of flying vehicles with more efficient tactico-technical and cost parameters, which are capable of preserving the required service functions for a long time in preset modes and application conditions. This is achieved by rational selection of materials and technologies of joining them, in particular, high-strength aluminium alloys. That is why higher requirements are made to the properties of the alloys and their welded joints. When selecting the alloy grade for application in specific structures, correspondence to sanitary and medical requirements is usually taken into account, alongside the main characteristics (specific weight, strength, corrosion properties, etc.) [1].

Among well-known aluminium alloys, a special place is occupied by aluminium-lithium alloys (ALA) Al-Li-Mg (1420, 1421, 1423, 1424) and Al-LiCu (1450, 1451, 1460, 1461, 1463, 1464) [1]. They are characterized by low density, higher modulus of elasticity and quite high strength that make them promising for manufacturing light-weight products, particularly, in aerospace industry. Their practical application in flying vehicles allowed reducing the structure weight by $8-15 \%$, owing to high specific strength and increased modulus of elasticity.
At present the conditions of formation of welding aerosols (WA) and gases, evolving in welding of different grades of steels and iron-based alloys have been comprehensively studied from the viewpoint of sanitary-hygienic requirements [2-4]. A little studied area is WA, forming in welding non-ferrous alloys, in particular, aluminium. Sanitary-hygienic assessment of ALA was performed only at the stage of metallurgical production [5]. As regards welding production, it is practically absent. Therefore, lithium toxicity [6] and mechanism of its compound formation under the conditions of its release in various welding processes, applied in manufacture of aerospace equipment, attract increased interest. It is known that lithium belongs to light-weight materials of higher toxicity [2].

The objective of the work is performance of sanitary-hygienic assessment of the nature of aerosol and gas evolution from 1201 (Al-Cu-Mn) and 1460 (Al$\mathrm{Cu}-\mathrm{Li}$ ) alloys during nonconsumable tungsten electrode argon-arc welding (TIG-argon).

Investigations were conducted on sheet semi-finished products of high-strength complex aluminium alloys $3.0 \mathrm{~mm}$ thick. Automated TIG-argon welding was performed with welding head ASTV-2M from TPS-450 power source of Fronius, Austria. These investigations were conducted in different current modes. For both the alloys, welding current was equal to: $I_{w}=140,200$ and 260 A. Condition of welding section air was assessed in keeping with the requirements of GOST 12.1.005-88. 
Table 1. Chemical composition of aluminium alloys in keeping with GOST 4784-97, wt.\%

\begin{tabular}{|c|c|c|c|c|c|c|c|c|c|c|c|c|}
\hline Alloy grade & $\mathrm{Si}$ & $\mathrm{Fe}$ & $\mathrm{Cu}$ & $\mathrm{Mn}$ & $\mathrm{Mg}$ & $\mathrm{Cr}$ & $\mathrm{Zn}$ & $\mathrm{Ti}$ & $\mathrm{Zr}$ & $\mathrm{Li}$ & Sc & Other \\
\hline 1201 & 0.20 & 0.30 & $5.8-6.8$ & $0.2-0.4$ & 0.2 & - & 0.1 & $0.02-0.10$ & $0.10-0.25$ & - & - & $(0.05-0.15) \mathrm{V}$ \\
\hline 1460 & 0.10 & 0.15 & $2.6-3.3$ & 0.1 & 0.1 & 0.05 & 0.25 & $0.01-0.06$ & $0.06-0.15$ & $2.0-2.5$ & $0.05-0.14$ & $(0.008-0.1) \mathrm{Be}$ \\
\hline
\end{tabular}

Chemical composition of welded metal is given in Table 1.

Selection of WA samples was performed by air intake by the method of its full capture. Not less than six samples were taken in each welding mode to ensure the validity of the obtained results. WA concentration in working zone air was assessed by gravimetric method [7], and the content of harmful components in WA, such as aluminium, manganese, copper and lithium compounds was determined by the procedure of [8]. Ozone concentration was determined using colorimetric method by selection of respective samples with «Taifun» sampler and absorber with potassium iodide solution. Presence of carbon oxide and nitrogen dioxide was determined using Aquilon 1-1 and Aquilon 1-4 instruments.

Investigation of welding aerosols released into the working zone air at TIG-argon welding of aluminium-lithium alloys.

Results of studying the sanitary-hygienic characteristics in mechanized TIG-argon welding of 1460 and 1201 alloys showed that the composition of main harmful substances of WA, which are released into the working zone air during welding include aluminium, manganese, copper, lithium and other elements.

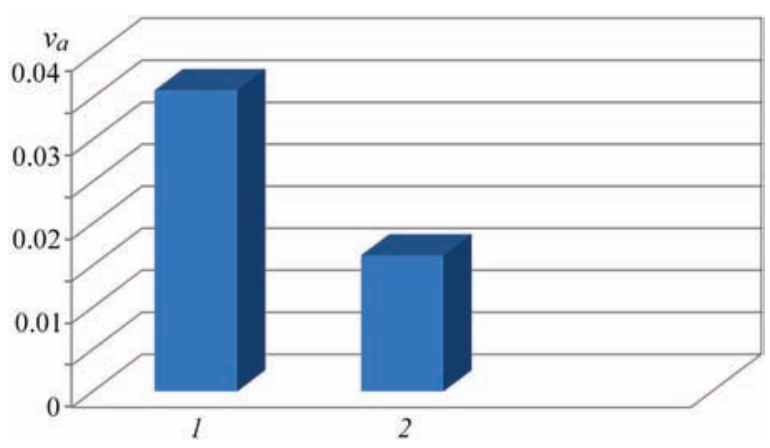

Figure 1. Intensity of WA generation in TIG-argon welding $\left(I_{w}=\right.$ $=140 \mathrm{~A}$ ): $1-1460$ alloy with $\mathrm{Li} ; 2-1201$ alloy without $\mathrm{Li}$

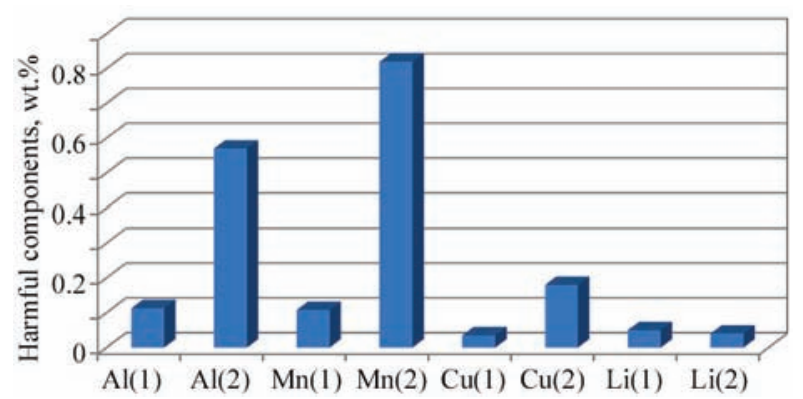

Figure 2. Mass fraction of the main harmful components of 1460 alloy in WA: $1-I_{\mathrm{w}}=140 ; 2-200$ A
For lithium-containing 1460 alloy at welding current $I_{\mathrm{w}}=140$ A the intensity of aerosol formation $\left(V_{\mathrm{a}}\right)$ is equal to 0.03586 . In welding of alloy 1201 without lithium at current $I_{\mathrm{w}}=140 \mathrm{~A} V_{\mathrm{a}}$ is equal to 0.0162 . Analysis of the results showed that in welding of the studied alloy grades 1460 and 1201 at the same current values (Figure 1) $V_{\mathrm{a}}$ is 3.5 times higher than that of 1460 alloy.

When studying the working zone air (Figure 2), it was found that weight fraction of the main harmful components evolving in WA in welding 1460 alloy in the following modes: $I_{\mathrm{w}}=140 \mathrm{~A}$ and $I_{\mathrm{w}}=200 \mathrm{~A}$, is increased at current rise.

Comparison of the results of studying 1460 and 1201 alloys in TIG-argon welding at the same current $I_{\mathrm{w}}=140$ A shows that under the conditions of welding the weight fraction of harmful components in WA differs essentially. Weight fraction of the substance of aluminium, manganese and copper in WA composition is much higher in 1201 than that in 1460 alloy (Figure 3).

As refractory tungsten used in TIG welding does not participate in WA formation, and the volume of molten filler wire is quite small, the quantity of metal evaporating in this process is also small.

Studying gases released into the working zone air in TIG-argon welding of aluminium-lithium alloys.

During ALA welding, release of WA into the working zone air is accompanied by generation of harmful welding gases, which also belong to the group of chemically hazardous and harmful production factors [9]. The cause for their formation in electric arc welding is presence of a high temperature welding arc, consisting of an electric discharge and ionized mixture of gases, and metal vapours, as well as their influence on the materials being welded, surrounded by argon and air. Part of the gases forms as a result of running of the process of thermal dissociation of the

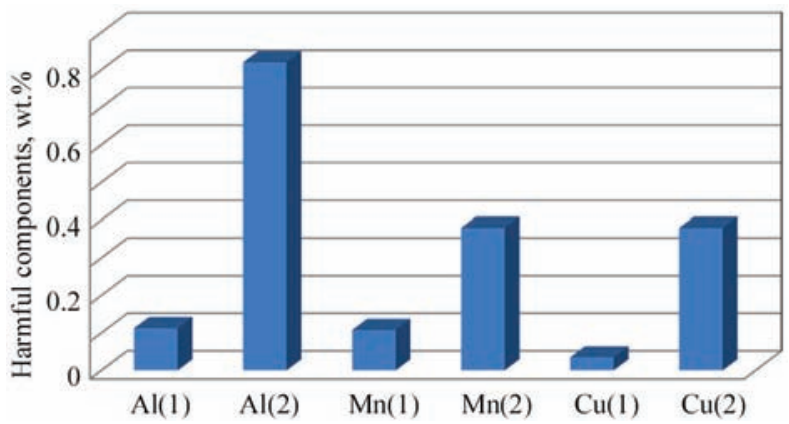

Figure 3. Mass fraction of harmful components in WA at $I_{\mathrm{w}}=$ = $140 \mathrm{~A} ; 1-1460$ alloy; $2-1201$ alloy 
Table 2. Maximum admissible concentrations (MAC) of the main gases in working zone air

\begin{tabular}{|c|c|c|}
\hline Substance & MAC, $\mathrm{mg} / \mathrm{m}^{3}$ & Class of hazard \\
\hline Nitrogen dioxide & 2 & 3 \\
\hline Ozone & 0.1 & 1 \\
\hline Carbon oxide & 20 & 4 \\
\hline
\end{tabular}

components of materials being welded which evaporate in the welding zone, others form from the molecules of ambient gas medium as a result of the impact of ultraviolet radiation (UVR) of the welding arc [10]. Composition of the forming mixture of harmful gases depends on chemical composition of welding materials, shielding gases and air. Carbon oxide, nitrogen oxides and ozone are the most common in the composition of welding gases. Their characteristics are given in GOST 12.1.005-88 [11]. Toxic gases tend to affect the respiratory tract, lungs and human mucous tissues. In terms of the degree of the effect on the body, ozone is considered to be extremely hazardous ( $1^{\text {st }}$ class of hazard). Nitrogen dioxide belongs to the $3^{\text {rd }}$ class of moderately hazardous substances, carbon oxide - to the $4^{\text {th }}$ class of low-hazard substances (Table 2).

Chemical kinetics of the studied substances points to the decisive role of UVR in the process of formation of such toxic gases as ozone and nitrogen oxides. Another factor, determining the volume of gases formed in welding, are overall dimensions of the weld pool under the high-temperature welding zone, as it is exactly carbon oxide that forms in the welding zone volume, and nitrogen oxide forms on the boundary of its contact with ambient air. UVR intensity is determined by temperature and welding current values. Therefore, it is anticipated that generation of ozone and nitrogen dioxide will largely depend on welding mode level [12]. Thus, the most noticeable impact of welding current will determine the process of formation of the respective ozone and nitrogen dioxide. It is anticipated that variation of carbon monoxide concentration will be not so significant, and its volume, either, due to the welding zone dimensions.

Results of investigations of the level of $\mathrm{CO}$ and $\mathrm{NO}_{2}$ concentration in the welder's workplace in argon-arc welding of 1460 ALA, depending on the welding mode, are given in Table 3, allowing for the error. As shown by their analysis, welding current value has a significant influence on the process of forma-

Table 3. $\mathrm{CO}$ and $\mathrm{NO}_{2}$ concentration in the workplace at argon-arc welding of 1460 ALA in different welding modes

\begin{tabular}{|c|c|c|}
\hline \multirow{2}{*}{ Welding current $I$, A } & \multicolumn{2}{|c|}{ Mass concentration, $\mathrm{mg} / \mathrm{m}^{3}$} \\
\cline { 2 - 3 } & $\mathrm{CO}$ & $\mathrm{NO}_{2}$ \\
\hline 140 & $0.4 \pm 0.7$ & $1.1 \pm 0.5$ \\
\hline 200 & $0.5 \pm 0.8$ & $1.3 \pm 0.5$ \\
\hline 260 & $0.5 \pm 0.8$ & $2.5 \pm 0.6$ \\
\hline
\end{tabular}

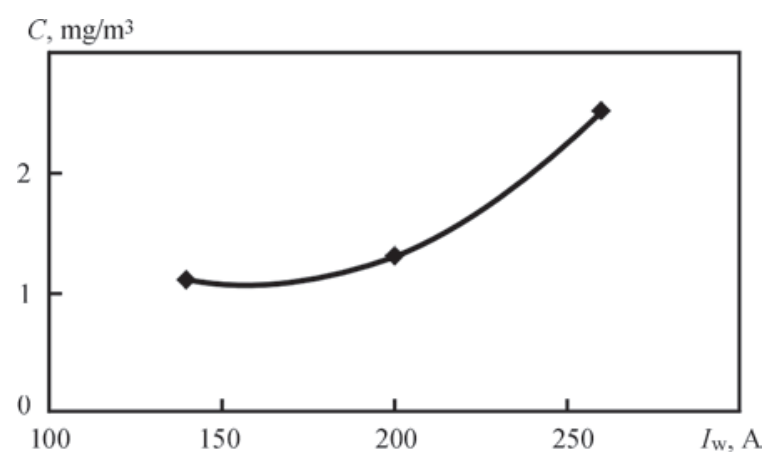

Figure 4. Dependence of mass concentration of nitrogen dioxide in the workplace in argon-arc of 1460 ALA

tion of nitrogen dioxide, raising its concentration to the level, exceeding MAC. Carbon monoxide concentration practically does not change. According to the data in Figure 4, dependence of nitrogen dioxide concentration on welding current is approximated with a high degree of accuracy by a parabola, and, therefore, the volume of the forming toxic gas increases considerably at increase of current, accompanying the welding process. At intensive welding modes, with more than 200 A currents, $\mathrm{NO}_{2}$ concentration in the working zone is higher than MAC.

Analysis of sanitary-hygienic characteristics obtained under the conditions of mechanized TIG-argon welding, showed that the main cause for ozone generation during welding operations is photodissociation of air oxygen molecules, running under the impact of welding arc UVR (Table 4).

This is exactly the process that causes release of atomic oxygen with its subsequent attachment to oxygen molecule. Influence of arc UVR on $\mathrm{O}_{2}$ molecules also leads to increase of ozone generation intensity, depending on the wave length of radiation, generated by the welding arc [13].

Results of studying the quantity of ozone in the working zone air showed that its concentration depends on electric current value in welding. The larger it is, the higher the gas concentration (Figure 5). For 1460 alloy at $I_{\mathrm{w}}=140$ A the concentration is just $0.13 \mathrm{mg} / \mathrm{m}^{3}$, and at $I_{\mathrm{w}}=260 \mathrm{~A}-49 \mathrm{mg} / \mathrm{m}^{3}$, and in all the studied welding current modes it exceeds MAC.

Table 4. Ozone content in working zone air in TIG-argon welding of 1460 and 1201 alloys

\begin{tabular}{|c|c|c|c|}
\hline \multirow{2}{*}{ Number } & \multicolumn{2}{|c|}{ Welding mode } & \multirow{2}{*}{ Ozone, $\mathrm{mg} / \mathrm{m}^{3}$} \\
\cline { 2 - 3 } & $I_{\mathrm{w}}, \mathrm{A}$ & $U_{\mathrm{a}}, \mathrm{V}$ & \\
\hline \multicolumn{3}{|c|}{1460 alloy } \\
\hline 1 & 140 & $12-15$ & 0.13 \\
\hline 2 & 260 & $12-15$ & 0.49 \\
\hline \multicolumn{4}{|c|}{1201 alloy } \\
\hline 3 & 140 & $12-15$ & 0.04 \\
\hline 4 & 260 & $12-15$ & 0.08 \\
\hline
\end{tabular}




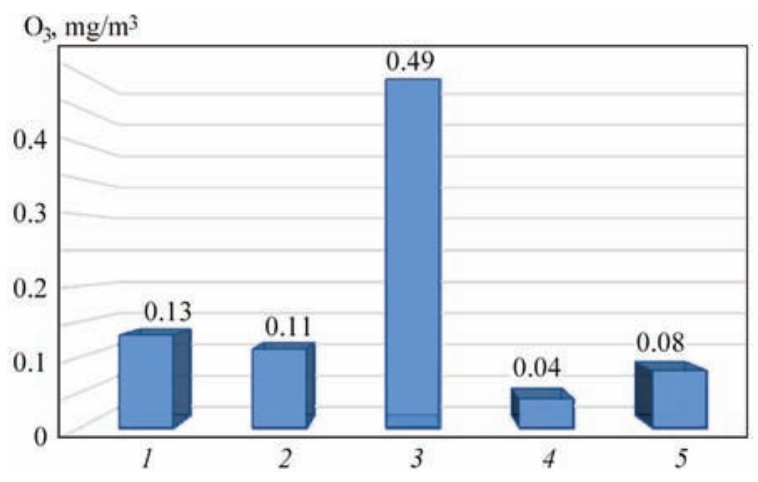

Figure 5. Dependence of ozone concentration on the mode of TIG-argon welding of 1460 alloy $\left(1-I_{\mathrm{w}}=140 ; 2-200 ; 3-\right.$ $260 \mathrm{~A})$ and $1201\left(4-I_{\mathrm{w}}=140 ; 5-260 \mathrm{~A}\right)$

The level of ozone concentration in welding 1201 alloy is much lower, being within MAC range, but it also rises with current increase in welding.

Thus, when studying the sanitary-hygienic conditions of performance of TIG-argon welding of 1460 ALA, it was found that the process is accompanied by formation of toxic gases in the workplace, namely nitrogen dioxide and carbon monoxide. Mass concentration of carbon monoxide of approximately $1 \mathrm{mg} / \mathrm{m}^{3}$ in the range of welding currents of 140-260 A is much lower than its MAC, and mass concentration of nitrogen dioxide strongly depends on current and exceeds its MAC at high values. Welding current increase leads to increase of ozone concentration for 1460 and 1201 alloys. Here, for 1460 alloy ozone concentration is much ( 3 to 4 times) higher than MAC. It is found that UVR is the main factor of toxic gas generation in the working zone in TIG welding of the studied aluminium alloys.

Generalization of the derived results of sanitary-hygienic assessment of the processes running in the working zone in TIG-argon welding of 1201 and 1460 alloys showed that the working zone air contains WA with complex chemical composition of elements, as well as toxic gases. The air mixture composition includes the following aerosols and gases: aluminium, lithium, manganese, copper, ozone, carbon oxide, nitrogen dioxide, and other compounds. In other words, welder's labour conditions are still unsatisfactory. In order to provide more favourable labour conditions, it is necessary to additionally take a number of known preventive measures for protection of welder's breathing organs from deleterious impact of WA elements and toxic gases.

In order to provide favourable sanitary-hygienic conditions of welder's labour during work performance and ensure a considerable service life of a welded structure from aluminium-lithium alloys, it is necessary to further study the toxicity of individual WA components and to develop a system of technological recommendations, which will reduce the risk of toxic aerosol formation.

1. Ishchenko, A.Ya., Labur, T.M. (2013) Welding of modern structures from aluminium alloys. Kiev, Naukova Dumka [in Russian].

2. Levchenko, O.G. (2015) Welding aerosols and gases: Processes of formation, methods of neutralization and protection facilities. Kiev, Naukova Dumka [in Russian].

3. Levchenko, O.G., Lukyanenko, A.O., Polukarov, Yu.O. (2011) Concentration of carbon oxide and nitrogen dioxide in air of a working zone in covered-electrode welding. The Paton Welding J., 1, 32-35 [in Russian].

4. Levchenko, O.G., Maksimov, S.Yu., Lukyanenko, A.O. et al. (2015) Comparative hygienic evaluation of arc welding process at constant and pulsed electrode wire feed. Ibid., 12, 39-44 [in Russian].

5. (1999) GOST 4784-97: Aluminium and aluminium wrought alloys. Grades. In: Interstate council on standardization, metrology and certification. Minsk [in Russian].

6. Nekrasov, B.V. (1970) Fundamentals of general chemistry. Vol. 3. Moscow, Khimiya [in Russian].

7. Minzdrav SSSR (1978) MU 1924-78: Hygienic evaluation of welding materials and methods of welding, surfacing and cutting of metals. Procedural guidelines [in Russian].

8. Minzdrav SSSR (1988) MU 4945-88: Procedural guidelines on determination of harmful substances in welding aerosol (solid phase and gases). Moscow [in Russian].

9. GOST 12.0.003-74: SSBT. Dangerous and harmful production factors. Classification. Moscow, Standart [in Russian].

10. Levchenko, O.G. (2010) Labour protection in welding production: Manual. Kyiv, Osnova [in Ukrainian].

11. (1988) GOST 12.1.005-88: SSBT. General sanitary-hygienic requirements to air of working zone. Moscow, Gosstandart SSSR [in Russian].

12. Erokhin, A.A. (1973) Fundamentals of fusion welding: Physical-chemical principles. Moscow, Mashinostroenie [in Russian].

13. Pattee, H.E., Mayers. L.B., Evans, R.M. et al. (1973) Effects of arc radiation and heat on welders. Welding J., 52, 297-308. 


\title{
FLUX-CORED WIRES FOR WEAR- AND HEAT-RESISTANT SURFACING AND SPRAYING
}

\author{
Yu.S. KOROBOV ${ }^{1}$, V.I. SHUMYAKOV ${ }^{1}$, M.A. FILIPPOV ${ }^{1}$, \\ O.V. PIMENOVA ${ }^{1}$, A.N. BALIN ${ }^{2}$ and A.A. VISHNEVSKY ${ }^{2}$ \\ ${ }^{1}$ Ural Federal University \\ 19 Mir Str., 620002, Ekaterinburg, Russia. E-mail: yukorobov@gmail.com \\ ${ }^{2} \mathrm{JSC}$ «Plant of welding materials» \\ 18 Zapadnaya promzona, Berezovsky, Sverdlovsk region, Russia
}

\begin{abstract}
The results of development and industrial implementation of economically alloyed flux-cored wires are presented, differed by the fact, that the deposited metal and coatings produced with their use, are characterized by resistance to wear and gas corrosion. 4 Ref., 1 Figure.
\end{abstract}

Keywords : arc welding, surfacing, flux-cored wires, wear resistance, heat resistance

Wear-resistant flux-cored wires of the type 150Kh8T2Yu provide a metastable austenite (MSA) structure in the coating. They show a high resistance to wear (abrasive, shock-abrasive, hydro- and gas-abrasive, erosive, cavitation, adhesion, fatigue, etc.). At contact loading, the energy of external action is consumed in the first turn for the conversion of MSA into dispersed martensite [1]. As a result, both the hardness from HV0.1-500 to HV0.1-800 and the wear resistance of such materials are increased during operation. The rational fields of application of surfacing and spraying differ due to peculiarities of formation of coatings by these methods [2, 3]. In particular, they are used for surfacing hardening by arc surfacing or metallization (Figure).

Heat-resistant flux-cored wires of the base system $\mathrm{Fe}-\mathrm{Cr}-\mathrm{Al}$, additionally alloyed with Ti, B, Y during their tests for heat resistance at $700{ }^{\circ} \mathrm{C}$ for 24 hours showed that the specific loss of mass of metallization coating is by an order lower than the similar values for pearlitic and martensitic-ferritic steels $12 \mathrm{Kh} 1 \mathrm{MF}$ and $1 \mathrm{Kh} 12 \mathrm{~V} 2 \mathrm{MF}$ for boiler construction and are comparable with the values of austenitic steels $1 \mathrm{Kh} 18 \mathrm{~N} 12 \mathrm{~T}$ and Kh23N18 [4].

The selected combination of chromium and boron content provides the formation of strengthening phases of complex carboborides $(\mathrm{Fe}, \mathrm{Cr})_{2}(\mathrm{~B}, \mathrm{C})$ of hardness HV0.1-1400 and a high ability to resist fracture by abrasive particles.

The adding of aluminium and yttrium into the charge of flux-cored wire provides a decrease in the degree of oxidation of particles of the sprayed material and improves the interaction conditions in the «particle-substrate» contact, which predetermines an adhesion strength at the metallization of $50 \mathrm{MPa}$ and also the formation of complex oxides $(\mathrm{Fe}, \mathrm{Al}, \mathrm{Y})_{2} \mathrm{O}_{3}$ with high protective properties.

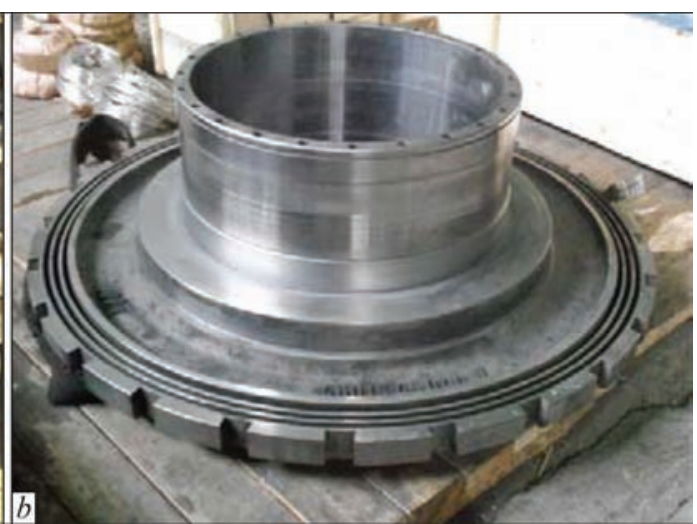

Examples of application of wear-resistant MSA-wires: $a$ - surfacing of spindels of caterpillar tracks; $b$ - deposition of coating of $5 \mathrm{~mm}$ thickness on $500 \mathrm{~mm}$ diameter support surface 
The presented wear- and heat-resistant wires with the diameter of 1.2-1.6 mm are produced serially using a roller mill for formation of a workpiece and can be delivered to the consumers.

1. Korobov, Yu.S., Filippov, M.A., Shumyakov, V.I. et al. (2013) Metastable chrome austenite as a structural factor for improvement of wear resistance of deposited metal and sprayed coatings. Ed. by S.S. Chernyak. In: Metal and metallurgy experts. Irkutsk, IGUPS, 40-46 [in Russian].

2. Kulishenko, B.A., Balin, A.N., Filippov, M.A. (2004) Electrodes for wear-resistant surfacing of parts subjected to abra- sive and shock-abrasive impact. Svarochn. Proizvodstvo, 11, 28-32 [in Russian].

3. Korobov, Yu.S., Shumyakov, V.I., Filippov, M.A. (2016) Development of iron-based flux-cored wires for producing of wear- and temperature-resistant thermal coatings. In: Current problems of welding production: Transact. Ed. by M.A. Ivanova, I.A. Iliina. Chelyabinsk, YuUrGU, 284-289 [in Russian].

4. Korobov, Yu., Nevezhin, S., Filippov, M. et al. (2016) Study of high velocity arc sprayed heat resistant coatings from $\mathrm{Fe}-$ CrAlBY cored wire. Thermal spray. Fostering a sustainable world for a better life. In: Proc. of the Int. Thermal Spray Conf. and Exposition ITSC 2016 (10-13 May, 2016, Shanghai, China), 852-856. 


\section{INTERNATIONAL CONFERENCE ON BEAM TECHNOLOGIES}

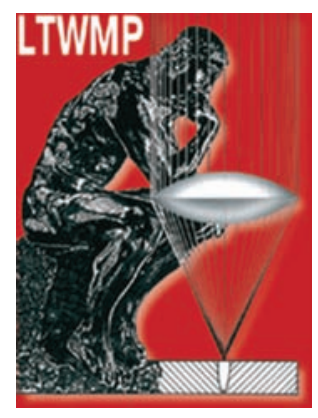

$8^{\text {th }} \quad$ International Conference «Beam Technologies in Welding and Materials Processing» (BTWMP-2017) was held on September 11-15, 2017 at «Kurortny» boarding house in Odessa (Ukraine). It was organized by the E.O. Paton Electric Welding Institute of the NAS of Ukraine, Research Institute on Laser Engineering and Technology of NTUU «Igor Sikorsky Kyiv Polytechnic Institute» and International Association «Welding».

50 scientists and specialists from Ukraine, Belarus, Poland, Iran, Canada participated in the Conference work as well as specialists from China with remote participation. The Conference was organized in a form of plenary and poster sessions. The working languages of the Conference were Russian, Ukrainian and English with simultaneous translation of the papers. 34 presentations were discussed in a course of plenary and poster sessions.

This year the format of the Conference was extended by initiative of Prof. I. Krivtsun, Conference Chairman, and presentations on electron beam technologies in welding and special electrometallurgy were included in the Conference program in addition to the traditional «laser» topics.

The Conference was opened by a review presentation of Prof. I. Krivtsun on «Hybrid laser-arc welding processes» (E.O. Paton Electric Welding Institute, Kyiv, Ukraine). The presentation indicated that application of hybrid technologies provides synergy effect, due to which usage of welding heat sources with relatively low power allows getting significantly higher penetration.

It is necessary to outline some presentations, which give an idea on the problems covered by the Conference:

- «Peculiarities of formation of magnesium alloy welded joints at pulse multilayer electron beam welding» Nesterenkov V.M., Kravchuk L.A., Arkhangelskiy Yu.A., Orsa Yu.V. (E.O. Paton Electric Welding Institute of the NAS of Ukraine, Kyiv, Ukraine);

- «Efficiency of application of laser quenching of gear wheels for strength increase» Devojno O.G., Kardapolova M.A., Avsievich A.M., Shvets I.V. (Belarusian National Technical University, Minsk, Belarus);

- «Modelling of temperature fields for different types of 3D samples at their layer-by-layer formation using electron beam welding equipment xBeam 3D Metal Printer» Makhnenko O.V., Milenin A.S., Velikoivanenko E.A., Rosynka G.F., Pivtorak N.I., Kozlitina S.S., Dzyubak L.I. (E.O. Paton Electric Welding Institute of the NAS of Ukraine, Kyiv, Ukraine);

- «Effect of electron beam welding and local heat treatment on properties of welded joints of highstrength pseudo $\beta$-titanium alloy VT19» Akhonin S.V., Belous V.Yu., Selin R.V., Vrzhyzhevsky E.L. (E.O. Paton Electric Welding Institute of the NAS of Ukraine, Kyiv, Ukraine);

- «The new generation device for laser-microplasma (laser-plasma) welding» Krivtsun I. ${ }^{1}$, Korzhyk $V^{1,2}$, Khaskin $V_{.}^{1,2}$, Sydorets $V_{.}^{1,2}$, Lou $Z^{3}{ }^{3}$, Han $S .{ }^{3}$, Bushma A. ${ }^{1}$, Dolyanovskaya O. ${ }^{1}$ ( ${ }^{1}$ E.O. Paton Electric Welding Institute of the NAS of Ukraine, Kyiv, Ukraine, ${ }^{2}$ China-Ukraine E.O. Paton Institute of Welding, Guangzhou, P.R. China, ${ }^{3}$ Guangdong Welding Institute, Guangzhou, P.R. China);

- «Structure and properties of welded joints produced by electron beam welding of boron-alloyed titanium» Grigorenko S.G., Belous V.Yu. (E.O. Paton Electric Welding Institute of the NAS of Ukraine, Kyiv, Ukraine);

- «Laser radiation welding in different spatial positions of circular joints of dissimilar steels» Shelyagin V.D., Bernatsky A.V., Siora A.V., Shuba I.V., Kurilo V.A., Suchek V.M., Dakal V.A., Bondareva V.I., Bistriker F.E. (E.O. Paton Electric Welding Institute of the NAS of Ukraine, Kyiv, Ukraine);

- «Increase of production efficiency of diamond coatings of abrasive tools using laser sintering» Golovko L.F., Fadi Jaber (NTUU «Igor Sikorsky Kyiv Polytechnic Institute», Kyiv, Ukraine);

- «Model of evaporation of multicomponent alloys in electron beam treatment» Krivtsun I.V., Akhonin S.V., Berezos V.A., Severin A.Yu. (E.O. Paton Electric Welding Institute of the NAS of Ukraine, Kyiv, Ukraine);

- «Possibilities of electron beam and laser welding over a layer of activating flux (A-EBW and A-LW processes)» Kovalenko D.V., Abdulakh V.M. (E.O. Paton Electric Welding Institute of the NAS of Ukraine, Kyiv, Ukraine);

- «New possibilities of additive manufacturing using xBeam 3D-Metal Printer technology» Kovalchuk D.V., Melnik V.I., Melnik I.V., Tugaj B.A. (SPE «Chervona Khvylya», Kyiv, Ukraine);

- "Restorative repairs of elements and assembly units of gas turbine engines» Nesterenkov V.M. ${ }^{1}$, 


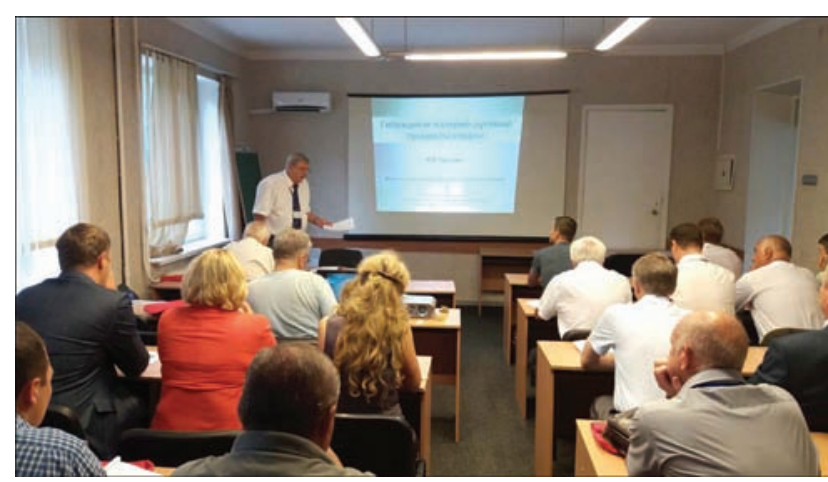

Presentation of Prof. I. Krivtsun

Orsa Yu.V. ${ }^{1}$, Khripko K.S. ${ }^{1}$, Gusev Yu.V. ${ }^{2}\left({ }^{1}\right.$ E.O. Paton Electric Welding Institute of the NAS of Ukraine, Kyiv, Ukraine, ${ }^{2} \mathrm{LRF}$ «Motor», Lutsk, Ukraine);

- «Development of gradient transition zones for protective EBPVD coatings» Yakovchuk K.Yu., Rudoj Yu.E., Mikitchik A.V., Tkach R.A. (SE «International Center of Electron Beam Technologies of E.O. Paton Electric Welding Institute of the NAS of Ukraine» Kyiv, Ukraine);

- «Innovative technologies and equipment for laser and hybrid welding processes of Guangdong Welding Institute» Dong C. ${ }^{1}$, Korzhyk $V^{2}$, Khaskin $V^{2}$, Sydorets V. ${ }^{2}$, Lou Z. ${ }^{1}{ }^{1}$ Guangdong Welding Institute, Guangzhou, P.R. China, ${ }^{2}$ China-Ukraine E.O. Paton Institute of Welding, Guangzhou, P.R. China);

- «Disperse and laminated volumetric nanocrystalline materials based on copper and molybdenum» Grechanyuk N.I., Grechanyuk V.G. (I. M. Frantsevich Institute of Problems of Materials Science of the NAS of Ukraine, Kyiv, Ukraine);

- «Production of ingots of intermetallic alloys in electron beam machines» Akhonin S.V. ${ }^{1}$, Severin A.Yu ${ }^{1}$, Berezos V.A. ${ }^{1}$, Pikulin A.N. ${ }^{1}$, Erokhin A.G. ${ }^{2}$ ( ${ }^{1}$ E.O. Paton Electric Welding Institute of the NAS of Ukraine, Kyiv, Ukraine; ${ }^{2} \mathrm{SE}$ «SPE «Titan» of E.O. Paton Electric Welding Institute of the NAS of Ukraine» Kyiv, Ukraine);

- «Distribution of alloying elements in welded joints of magnesium alloys, obtained by hybrid electron-beam technique» Nesterenkov V.M.,

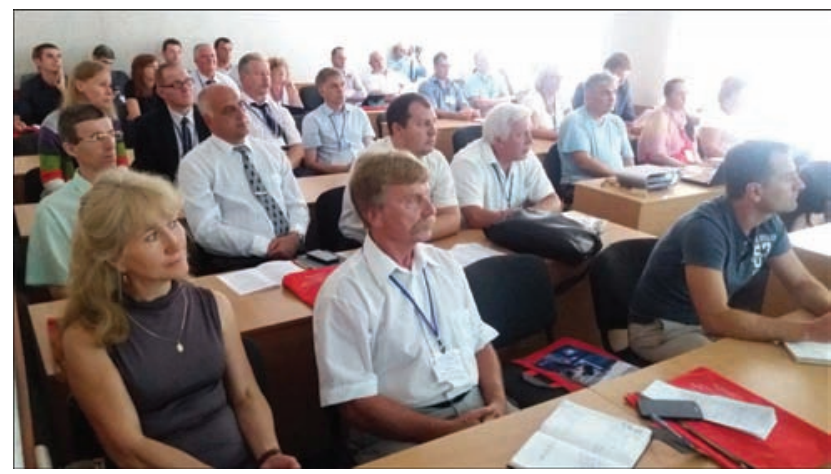

During plenary session
Kravchuk L.A., Arkhangelskiy Yu.A. (E.O. Paton Electric Welding Institute of the NAS of Ukraine, Kyiv, Ukraine);

- «Optimization of laser welding technology for multicomponent high-temperature alloys based on niobium» Brodnikovskii M.P., Shelyagin V.D., Siora O.V., Shuba I.V. (E.O. Paton Electric Welding Institute of the NAS of Ukraine, Kyiv, Ukraine);

- «Principles of obtaining aerospace industry and turbine construction products by rapid prototyping method with application of electron beam techniques» Matviichuk V., Rusynyk M. (E.O. Paton Electric Welding Institute of the NAS of Ukraine, Kyiv, Ukraine);

- «Electron beam fusion of ingots of high-strength $\alpha+\beta$ and pseudo $\beta$-titanium alloys» Akhonin S.V. ${ }^{1}$, Pikulin A.N. ${ }^{1}$, Berezos V.A. ${ }^{1}$, Severin A.Yu. ${ }^{1}$, Erokhin A.G. ${ }^{2}\left({ }^{1}\right.$ E.O. Paton Electric Welding Institute of the NAS of Ukraine, Kyiv, Ukraine; ${ }^{2} \mathrm{SE}$ «SPE «Titan» of E.O. Paton Electric Welding Institute of the NAS of Ukraine» Kyiv, Ukraine);

- «Production of high-strength titanium alloys using electron beam melting method» Akhonin S.V. ${ }^{1}$, Berezos V.A. ${ }^{1}$, Pikulin A.N. ${ }^{1}$, Severin A.Yu. ${ }^{1}$, Erokhin A.G. ${ }^{2}\left({ }^{1}\right.$ E.O. Paton Electric Welding Institute of the NAS of Ukraine, Kyiv, Ukraine; ${ }^{2} \mathrm{SE}$ «SPE «Titan» of E.O. Paton Electric Welding Institute of the NAS of Ukraine» Kyiv, Ukraine);

- «Role of structure in change of service properties of high-strength steel welded joints produced by laser and hybrid laser-arc welding» Markashova L.I., Poznyakov V.D., Shelyagin V.D., Berdnikova E.N., Bernatsky A.V., Siora A.V., Alekseenko T.A., Polovetsky E.V. (E.O. Paton Electric Welding Institute of the NAS of Ukraine, Kyiv, Ukraine);

- «Numerical prediction of deformations in spirally welded pipes using different welding techniques» Kubiak M., Piekarska W., Saternus Z., Domański T. (Institute of Mechanics and Machine Design Foun-

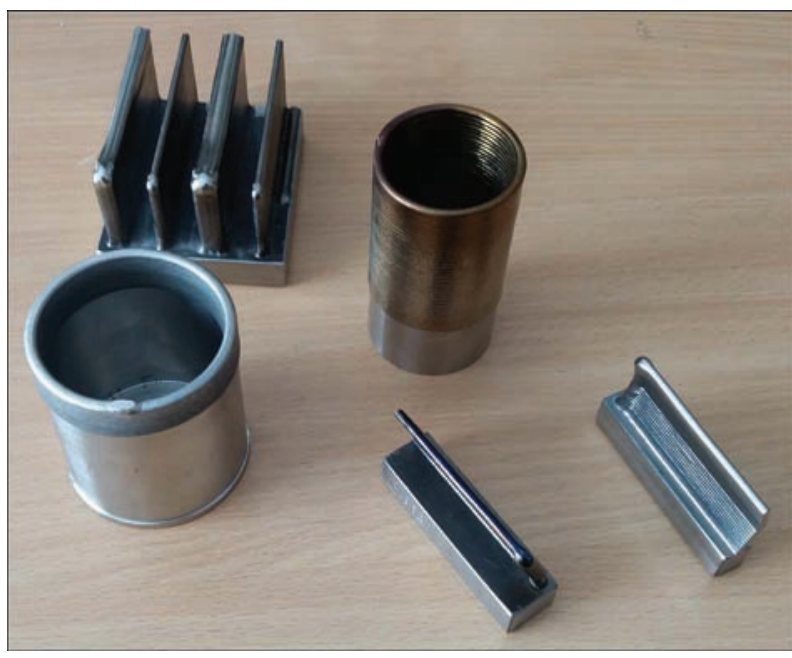

Samples of products of SPE «Chervona Khvylya» Company 


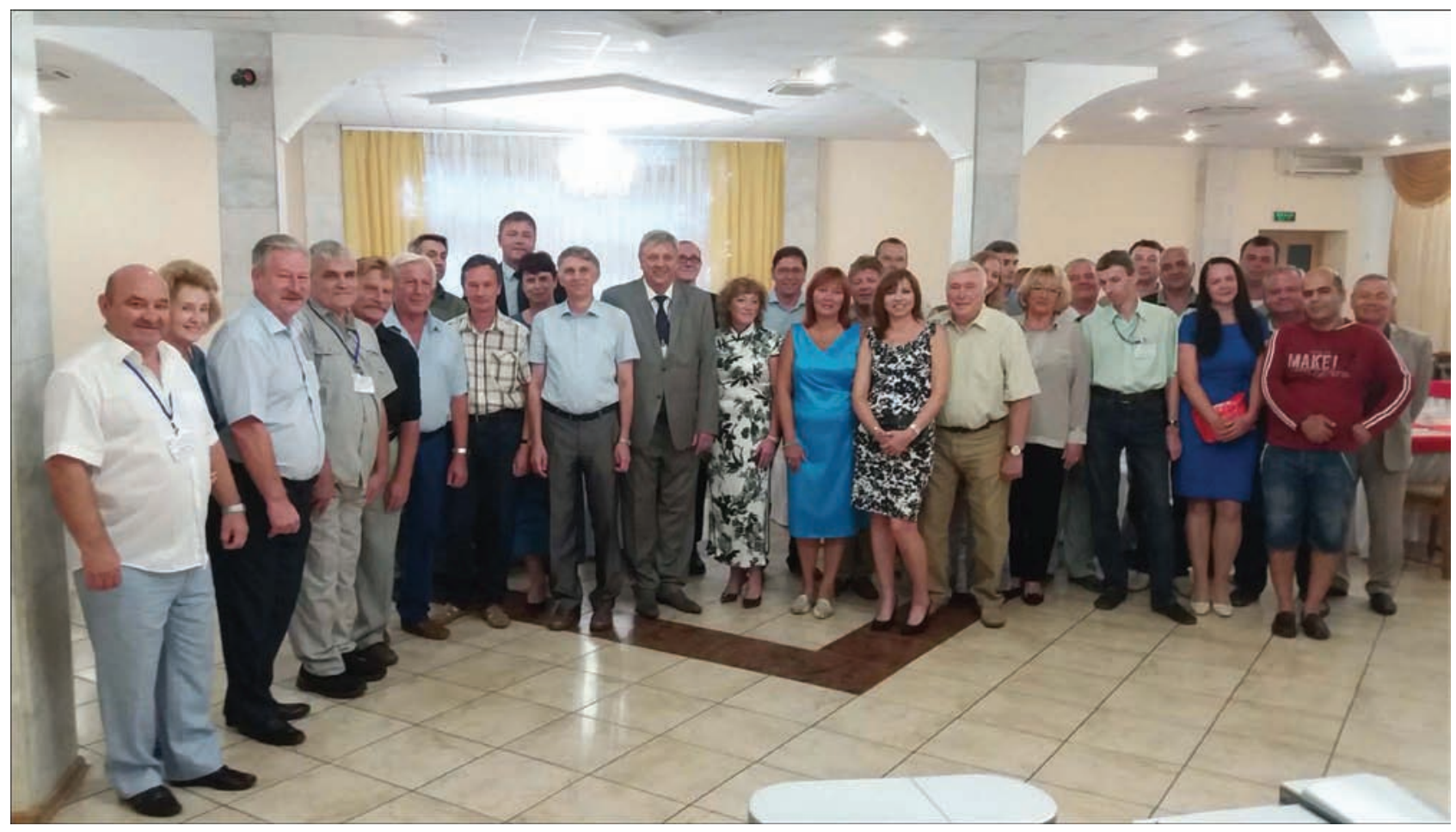

Participants of the Conference

dations, Czestochowa University of Technology, Częstochowa, Poland);

- «Study of properties of welded joint using DANTEC'S ISTRA 4D systems» Domański T., Piekarska W., Kubiak M. (Institute of Mechanics and Machine Design Foundations, Czestochowa University of Technology, Częstochowa, Poland).

There were also presentations on application of lasers in medicine. Out of the Conference program A.P. Mukhachev, Director of SSPE «Tsyrkonij» (1998-2003) provided the information on directions of enterprise activities in production of hafnium, zirconium, niobium and molybdenum using electron beam remelting machines. The representatives of a series of commercial Ukrainian enterprises also took part in the Conference without presentations.

A round-table discussion on «Perspectives of development and application of 3D beam technologies» was carried out at the end of the Conference. It was noted that up to the moment the largest amount of products is manufactured using classical technologies such as casting, welding, forging, stamping, mechanical treatment etc. At the same time, a new and completely original technology of 3D-printing and quick prototyping was proposed in the recent decades. Such technologies combine three main factors, i.e. material, energy (laser, electron beam, plasma flow etc.) and mathematical model of a future product. The round-table was also dedicated to discussion of the relevant problems of development of beam technologies applicable to production of 3D products of different metallic materials, and SPE «Chervona Khvylya» showed the samples of the products made with 3D electron beam surfacing.

Proceedings of BTWMP-2017 will be published till the end of 2017. Proceedings of the previous LTWMP conferences - 2003, 2005, 2007, 2009, 2011, 2013 and 2015 can be ordered in the editorial office of «Avtomaticheskaya Svarka» journal or get in open access from the site of the E.O. Paton Electric Welding Institute publishing house by reference http://patonpublishinghouse.com/eng/proceedings/ltwmp.

Friendly, hospitable and creative atmosphere promoted development of useful discussions and arrangement of business contacts. The Conference participants unanimously agreed on proposal of performance of the next, $9^{\text {th }}$ International Conference on Beam Technologies in Welding and Materials Processing (BTWMP-2019) in the middle of September 2019 in Odessa, Ukraine.

The Organizing Committee expresses thanks and gratitude to SPE «Titan» of E.O. Paton Electric Welding Institute and Center for Electron Beam Welding of E.O. Paton Electric Welding Institute for beneficent help provided in performance of the $8^{\text {th }}$ International Conference «Beam Technologies in Welding and Materials Processing». 


\title{
PATON PUBLISHING HOUSE
}

\author{
www.patonpublishinghouse.com
}

\section{SUBSCRIPTION}

\section{The ifitiolonal \\ Автоматическая B P}

"The Paton Welding Journal» is Published Monthly Since 2000 in English, ISSN 0957-798X.

"Avtomaticheskaya Svarka» Journal (Automatic Welding) is Published

Monthly Since 1948 in Russian, ISSN 005-111X.

«The Paton Welding Journal» is Cover-to-Cover Translation of

Avtomaticheskaya Svarka» Journal into English.

If You are interested in making subscription directly via Editorial Board, fill, please, the coupon and send application by Fax or E-mail.

The cost of annual subscription via Editorial Board is $\$ 348$ for «The Paton Welding Journal» and $\$ 180$ for «Avtomaticheskaya Svarka» Journal.

«The Paton Welding Journal» can be also subscribed worldwide from catalogues subscription agency EBSO.

\section{SUBSCRIPTION COUPON \\ Address for journal delivery \\ Term of subscription since \\ Name, initials \\ Affiliation \\ Position \\ Tel., Fax, E-mail}

20

till

20

We offer the subscription all issues of the Journal in pdf format, starting from 2009.

The archives for 2009-2014 are free of charge on www.patonpublishinghouse.com site.
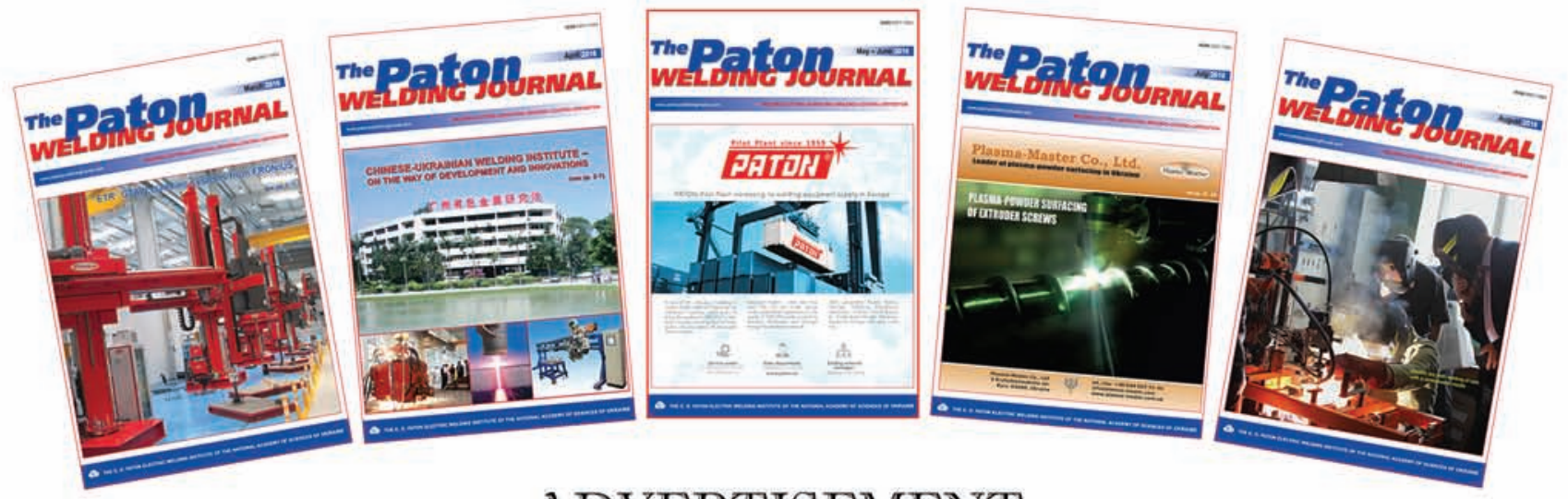

ADVERTISEMENT

in "Avtomaticheskaya Svarka" and "The Paton Welding Journal"

External cover, fully-colored:

First page of cover $(190 \times 190 \mathrm{~mm})-\$ 700$

Second page of cover $(200 \times 290 \mathrm{~mm})-\$ 550$

Third page of cover

$(200 \times 290 \mathrm{~mm})-\$ 500$

Fourth page of cover

$(200 \times 290 \mathrm{~mm})-\$ 600$
Internal cover, fully-colored: First/second/third/fourth page of cover $(200 \times 290 \mathrm{~mm})-\$ 400$

Internal insert: Fully-colored $(200 \times 290 \mathrm{~mm})$ $\$ 340$

Fully-colored (double page A3) $(400 \times 290 \mathrm{~mm})-\$ 500$
- Article in the form of advertising is $50 \%$ of the cost of advertising area

- When the sum of advertising contracts exceeds $\$ 1001$, a flexible system of discounts is envisaged

Size of journal after cutting is $200 \times 290 \mathrm{~mm}$

Editorial Board of Journal «Avtomaticheskaya Svarka» and \& The Paton Welding Journal» E.O. Paton Electric Welding Institute of the NAS of Ukraine International Association «Welding» 